Portland State University

PDXScholar

7-19-1983

\title{
Audiological Characteristics of the Monge Family of Costa Rica
}

Christine Moulton

Portland State University

Follow this and additional works at: https://pdxscholar.library.pdx.edu/open_access_etds

Part of the Genetics Commons, and the Speech Pathology and Audiology Commons Let us know how access to this document benefits you.

\section{Recommended Citation}

Moulton, Christine, "Audiological Characteristics of the Monge Family of Costa Rica" (1983). Dissertations and Theses. Paper 3343.

https://doi.org/10.15760/etd.5233

This Thesis is brought to you for free and open access. It has been accepted for inclusion in Dissertations and Theses by an authorized administrator of PDXScholar. Please contact us if we can make this document more accessible: pdxscholar@pdx.edu. 
AN ABSTRACT OF THE THESIS OF Christine Moulton for the Master of Science in speech Communication, with an emphasis in Audiology and Speech-Language Pathology, presented July 19, 1983.

Title: Audiological Characteristics of the Monge Family of Costa Rica.

APPROVED BY MEMBERS OF THE THESIS COMMITTEE :
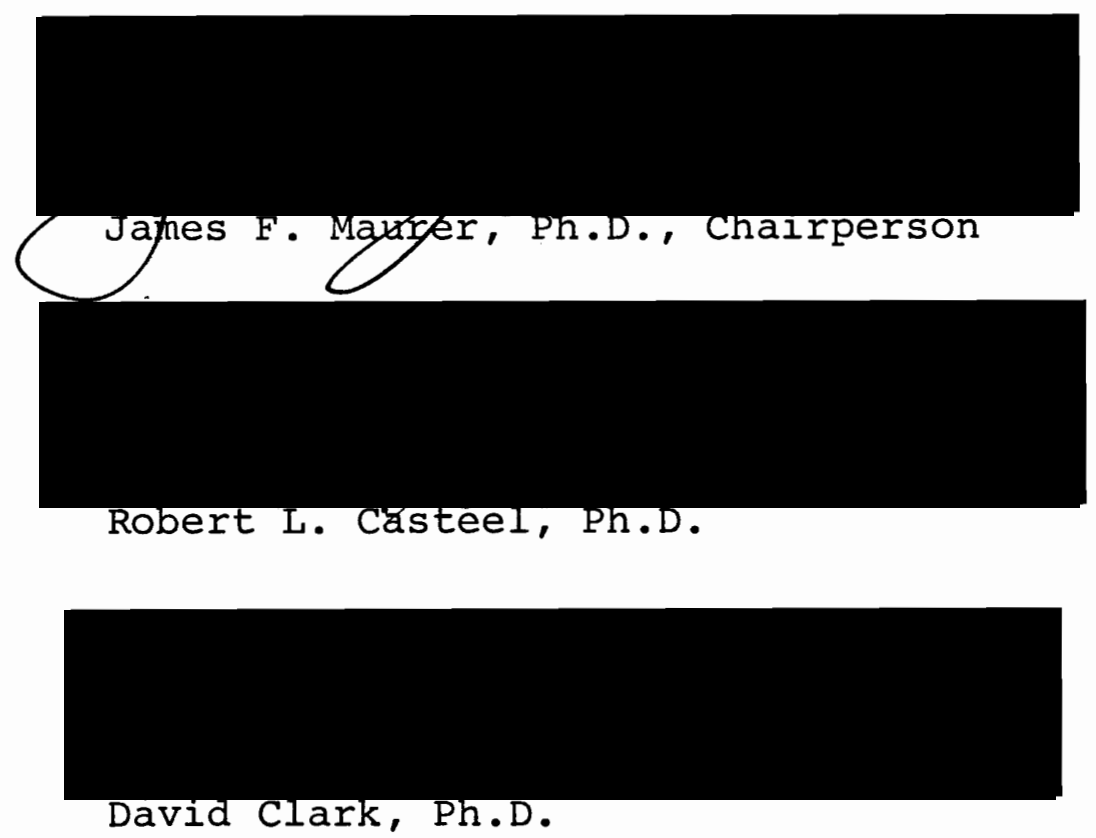

The audiological characteristics of the Monge family of Costa Rica were investigated in a sample of fifty-two affected members and twelve unaffected members. Through laboratory analysis by staff personnel from the University of Costa Rica and audiological test results obtained in the present investigation, it was concluded that affected Monge members 
demonstrate a slowly progressive low frequency sensorineural hearing loss of autosomal dominant transmission. The initial site of lesion appears to be the apical portion of the cochlea, with significant onset occurring during early childhood following normal speech and language acquisition. The rate at which the hearing loss progresses and the frequency regions affected are contingent upon chronological age, culminating in a flat profound hearing impairment by age thirty for all affected members. 


\author{
AUDIOLOGICAL CHARACTERISTICS \\ OF THE \\ MONGE FAMILY \\ OF \\ COSTA RICA
}

by

CHRISTINE MOULTON

A thesis submitted in partial fulfillment of the requirements for the degree of

MASTER OF SCIENCE IN SPEECH COMMUNICATION:

with an emphasis in

AUDIOLOGY/SPEECH-LANGUAGE PATHOLOGY

Portland State University

1983 
TO THE OFFICE OF GRADUATE STUDIES AND RESEARCH :

The members of the Committee approve the thesis of Christine Moulton presented July 19, 1983.
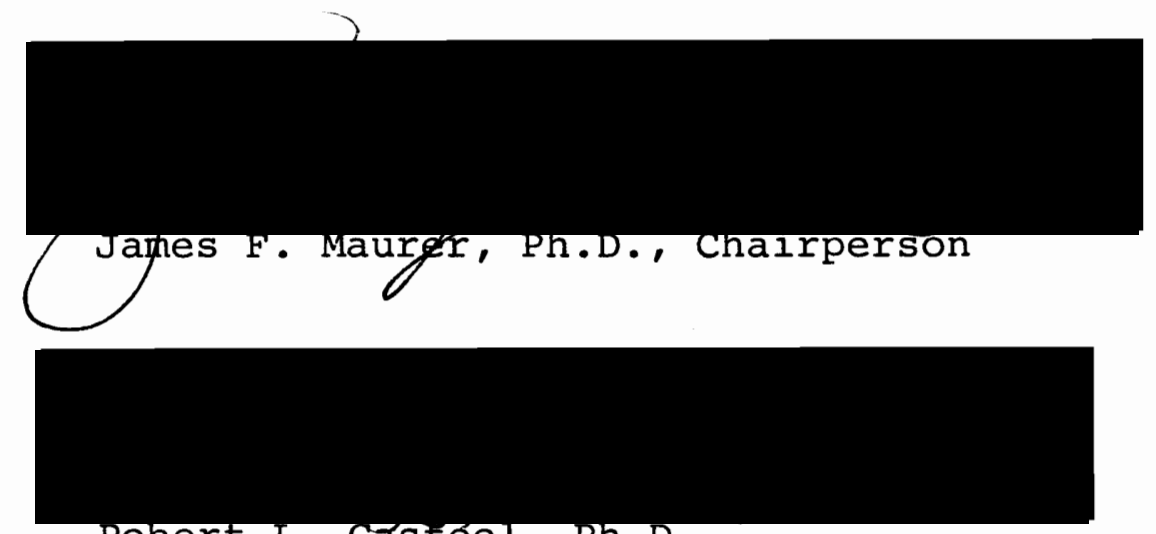

Robert L. Cástéel, Ph.D.

David Clark, Ph.D.

APPROVED :

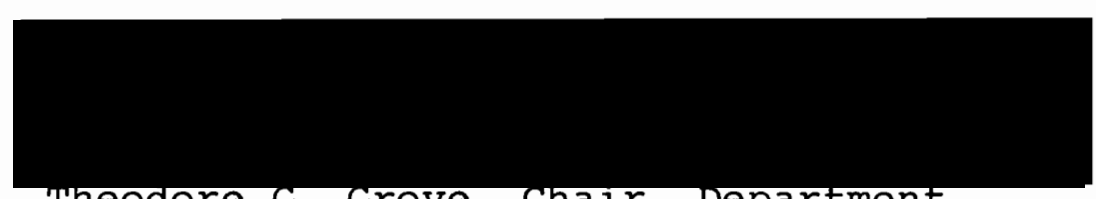

Theodore G. Grove, Chair, Department of Speech Communication

Stanley E. Rauch, Dean, Graduate

Studies and Research 
To Katya and David 


\section{ACKNOWLEDGEMEINTS}

I wish to express my deep appreciation to the Chairperson of my thesis committee, Dr. James F. Maurer who not only allowed me the opportunity to participate in this study, but who generously gave the assistance and encouragement necessary for me to complete this project. To each of the other members of my thesis committee, Dr. Robert L. Casteel and Dr. David Clark, sincere appreciation is expressed.

Further appreciation is extended to Dr. Pedro León for his genetic expertise and invaluable assistance. A special note of thanks goes to the staff personnel from the University of Costa Rica who served as interpreters and aided in data collection.

I am grateful to Dr. Al Knox, Kansas City Veterans Administration Medical Center, who contributed his technical expertise to the installation of necessary instrumentation. I wish to acknowledge the Portland Veterans Administration for permitting me access to their Medical Research Services.

Finally, I wish to extend a special thank you to my parents, Douglas and Shirley Matney and to my daughter, Sarah, for the continual support and understanding they so generously gave throughout this project. 
TABLE OF CONTENTS

Page

DEDICATION

iii

ACKNOWLEDGEMENTS

iv

LIST OF TABLES . . . . . . . . . . . . . . . . . vii

LIST OF FIGURES

CHAPTER

I INTRODUCTION

II REVIEW OF THE LITERATURE • • • • • • • • • 8

Identification of Hereditary

Hearing Loss . . . . . . . . . 8

Mode of Transmission

Associated Abnormalities

His topathology

Audiological Characteristics

Identification of Autosomal

Dominant Hearing Loss

Site of Lesion

Age of Onset

Progression Rate

Laterality/Symmetry

Monge Deafness . . . . . . . . 52

Statement of Purpose . . . . . . . 56

III METHODS . . . . . . . . . . . 58

IV RESULTS ............. . . 65

Genetic Laboratory Tests and Case

History Documentation . . . . . . 65

Audiological Characteristics . . . . 66

Discussion ............ . 88 
CHAPTER Page

V SUMMARY AND IMPLICATIONS $\quad$ • • • • • . . . • • 93 Recommendations for Future Research . . 95 REFERENCES 


\section{LIST OF TABLES}

TABLE

Page

I Population Comparisons Between Control

Group and Experimental Groups I and II . .

II Puretone Air Conduction Hearing Threshold Levels for Control Group . . . . . . .

III Puretone Air Conduction Hearing Threshold Levels for Experimental Group I

IV Puretone Air Conduction Hearing Threshold Levels for Experimental Group II . . . . .

$\mathrm{V} \quad t$-Test Values for Mean Hearing Threshold Level Difference Between Experimental

Groups I and II . . . . . . . . . . .

VI Comparison of Puretone Air Conduction Hearing Threshold Levels Between Right and Left Ears for Experimental Group . . . . .

VII t-Test Values for Mean Hearing Threshold Level Difference Between Right and Left Ears for Experimental Group . . . .

VIII Comparison of Puretone Air Conduction Hearing Threshold Levels Between Males and Females for Experimental Group . . . . .

IX $t$-Test Values for Mean Hearing Threshold Level Difference Between Males and Females for Experiemtnal Group . . . . .

$\mathrm{X}$ Puretone AirConduction Hearing Threshold Levels as a Function of Age for Experimental Group

XI Puretone Air Conduction Hearing Threshold Levels as a Function of Age for Control Group

XII Mean Average Puretone Thresholds as a Function of Age for Experimental Group . . . 
XIII Pearson $r$ and $r^{2}$ Values for the Degree of Association Between Age and Hearing Threshold Levels for Experimental Group . . . . . . . . . . . . .

XIV Comparison of Mean Speech Discrimination Score to the Average Puretone Threshold as a Function of Age for Experimental Group • • • • • • • • • • • • • •

XV Comparison of Averaged Percentage Correct on Ling's 5-Sound Test to the Mean Average Puretone Threshold as a Function of Age for Experimental Group . . . . .

XVI Comparison of Mean Acoustic Reflex Sensation Levels and Puretone Air Conduction Hearing Threshold Levels as a Function of Age for Control Group . . . . . . . .

XVII Comparison of Mean Acoustic Reflex Sensation Levels and Puretone Air Conduction Hearing Threshold Levels as a Function of Age for Experimental Group . . . . .

XVIII Comparison of Mean Acoustic Reflex Sensation Levels, Averaging all Frequencies, as a Function of Age for Control Group and Experimental Group 


\section{LIST OF FIGURES}

FIGURE

Page

1 Possible Combinations for Dominantly

Inherited Traits

2 Possible Combinations for Recessively

Inherited Traits

3 Possible Combinations for Sex-Linked Recessive Traits . . . . . . . . . 16

4 Possible Combinations for Sex-Linked Dominant Traits

5 Syndromes Characteristically Associated with Hearing Loss . . . . . . . . . .

6 Comparison of Audiometric Configurations for Different Etiologies . . . . . . . .

7 Comparison Between Hearing Threshold

Levels and Acoustic Reflex Sensation

Levels for a Normal Hearing Carrier

8 Comparison of Mean Puretone Audiograms in Patients with Low Frequency Hearing

Loss and Those with Normal Hearing

9 Acoustic Reflex Sensation Levels as a Function of Hearing Threshold Levels for 515 subjects with Sensorineural Impairment

10 Pedigree of the Monge Family $\quad . \quad$. . . . . 53

11 Representitive Puretone Audiograms as a Function of Age for the Monge Family

12 Reported Age of Onset for the Monge Family

13 Block Diagram of the Test Procedure

Utilized in this Study . . . . . . . .

14 Current Monge Family Pedigree 
15 Puretone Air Conduction Hearing Threshold Levels for Control Group and Experimental Groups I and II . . . • .

16 Comparison of Puretone Air Conduction Hearing Threshold Levels Between Right and Left Ears for Experimental Group

17 Comparison of Puretone Air Conduction Hearing Threshold Levels Between Males and Females for Experimental Group

18 Puretone Air Conduction Hearing Threshold Levels as a Function of Age for Control Group

19 Puretone Air Conduction Hearing Threshold Levels as a Function of Age for Experimental Group . . . • • . . • • . . .

20 The Amount of Decibel Loss for each Frequency as a Function of Age for Experimental Group . . . . . . . . . . .

21 Comparison of Average Puretone Thresholds as a Function of Age Between Males and Females for the Experimental Group . . .

22 Comparison of Puretone Air Conduction Hearing Threshold Levels for Different Family Branches . . . . . . . . . . .

23 Comparison of Puretone Air Conduction Hearing Threshold Levels in Older subjects from Different Family Branches . . . .

24 Comparison of Puretone Air Conduction Hearing Threshold Levels in Siblings from Different Family Branches . . . . . . . 
CHAPTER I

\section{INTRODUCTION}

When a child is suspected of a hearing loss, those concerned are often perplexed as to the etiology of the disorder. The cause may not be easily identifiable, especially if the parents have normal hearing, and no event known to cause deafness has occurred during the child's development. The cause of deafness among adults may be just as difficult to establish. Some individuals may develop a severe hearing loss by the age of sixty, while others living and working in the same milieu continue to have good hearing into their eighties.

The myriad of causes contributing to hearing loss is reflected in the number of individuals affected by this deficit. Approximately 10 to 15 percent of the adult population in this country is reported to have a significant hearing impairment (Paparella, Hanson, Rao, Ulvestad, 1975). Estimates on the incidence of profound hearing loss among prelingual children range from 1 in 800 (Bergstrom, 1981) to 1 in 1000 live births (Brown, 1967).

In spite of these figures, relatively little is understood about many of the causes of early onset deafness. Frequently no cause can be determined, which results in a large number of the hearing impaired, especially children, being placed in a category for unknown etiology. This group 
includes approximately 30 to 40 percent of all individuals who develop a significant hearing loss before the acquisition of normal speech (Bergstrom, 1981; Ruben and Rozycki, 1971; Taylor, Hine, Brasier, Chiveralls, Morris, 1975).

If the etiology of hearing loss is known, the prognosis for treatment and rehabilitation can be better predicted. However, for those individuals in which no cause can be determined, the risk of providing inadequate or inappropriate measures greatly increases. For example, the approach taken in family genetic counseling varies considerably with the causal factors involved. Decisions must be made as to the probability of recurrence in siblings and offspring of the affected person, or whether special precautions are necessary for future pregnancies. The family should be informed if the hearing loss will get worse or if other abnormalities will develop later. If the hearing impairment is thought to be familial, then other affected members must be quickly identified and treated appropriately.

Prompt identification is particularly important for prelingual hearing impaired children. Whetnall and Fry (1964) describe a critical period during a child's early life when the auditory system is especially sensitive to the acquisition of language skills. Even a very mild loss of hearing sensitivity during this period can cause difficulty in the development of normal speech and language. Unfortunate for many children, only when their communicative skills are obviously delayed or fail to develop, is the hearing loss 
finally suspected. If the causal factors for the disorder can be determined early, then appropriate measures for habilitation can begin before the child matures through the critical period of speech and language acquisition.

The necessity for identifying the causes of deafness in children has intensified efforts to establish a practical system for the classification of known etiologies. Several models have been proposed in recent years, but due to the difficulty in categorizing the many variables involved, each system has its own limitations. The approach utilized in the subsequent review of the literature is based on a genetic framework outlined by Fraser (1964), and modified by Jones (1976), Makishima and Snow (1975) and Ruben and Rosycki (1971). As described in these reports, the identifiable causes of deafness originate from either (1) acquired, (2) chromosomal, or (3) hereditary factors.

\section{Acquired Causes}

An acquired hearing loss results from injury to the auditory system by environmental influences which can occur at any point throughout an individual's lifetime. Among children, the time of onset may occur during the prenatal, perinatal, and postnatal periods of early childhood development. Acquired hearing loss accounts for approximately 36 percent (Bergstrom, 1976) to 46 percent (Fraser, 1964) of all causes of profound deafness among children, with most reported cases attributed to viral infections, ototoxic drugs, and prematurity 
(Bergstrom, 1976; Riccardi, 1979).

Chromosomal Causes

Hearing loss may also result from disruption in the normal development of chromosomes, the genetic material containing the coded messages of DNA (dioxyribonuleic acid). Estimates on the incidence of profound deafness attributed to chromosomal abnormalities range from 1 percent (Ruben and Rozycki, 1971) to 3 percent (Bergstrom, 1976). The hearing loss, seldom hereditary, is usually associated with a specific pattern of severe multiple malformations determined by the type of chromosomes involved. A defective sex chromosome, as described by Wright (1971), is responsible for such disorders as Klinefelter's and Turner's syndromes. Aberrations of a non-sex chromosome may lead to a group of disorders, collectively called trisomies. Down's syndrome is the most commonly recognized trisomy (Holmes, 1977; Lindsay, 1973; Riccardi, 1979; Wright, 1971).

\section{Hereditary Causes}

Hearing loss in children is associated with hereditary factors that account for approximately 40 percent (Bergstrom, 1976) to 53 percent (Hereditary Deafness Public Service Programs, 1975; Konigsmark, 1972) of all profound childhood deafness. The ability to hear, as with any trait, is dependent upon the normal development and transmission of genes from parent to offspring. Collectively, genes formulate chromosomes, and as described by Nance (1971), are primarily 
responsible for the specification and regulation of certain proteins and enzymes. If these proteins and enzymes are altered to the extent of causing a recognizable physiologic change within the organism, the gene responsible is considered abnormal or mutant. Thousands of genes may contribute to normal auditory function, but the presence of a single genetic mutation that alters the genetic code can have a profound effect on hearing.

The differentiation of acquired, chromosomal and hereditary factors is complicated by a number of variables. The necessity for early identification has lead to delineating childhood deafness by age of onset rather than by etiology. Frequently, a child's hearing loss is referred to as either congenital (present at birth) or adventitious (occurring after birth) (Report of the Conference Committee on Nomenclature, 1938). Many types of deafness overlap in their time of onset, some are present at birth, while others progress slowly through early childhood or even later. If the hearing loss is discovered only after speech and language fail to develop normally, it may be impossible to determine for many children whether the disorder was congenital or occurred rapidly in early life.

Similarly, it may be impossible to ascertain the relative contribution of acquired, chromosomal, and hereditary factors. Each category may have in common a number of characteristics. The age of onset is one of many traits for hearing loss that may be identical in several etiologies. 
The progression rate, the severity, and the site of lesion for the disorder can appear very similar clinically, but may be very different in origin. To further complicate attempts at accurate identification, various etiologies may interact with one another resulting in a unique manifestation of the hearing deficit. Finally, the cause of deafness, whether acquired, chromosomal, or hereditary, frequently occurs in unexplainable sporadic mutations.

In spite of the variables which may interfere with the early diagnosis of deafness, certain etiologies consistently demonstrate established patterns of characteristics. For example, many types of acquired hearing loss can be readily traced to well known ototoxic drug agents, bacteria, or viruses. Chromosomal abnormalities are generally associated with a specific cluster of congenital physical malformations. Among the three causes of early deafness, hereditary factors, in particular, may escape early detection and diagnosis. This oversight may be attributed to a number of conditions, for example, (I) the current decline in the extended family nucleus contra-indicates the establishment of an accurate pedigree in many cases, (2) the diagnostic sophistication necessary for genetic identification is often inadequate in some rural areas, and (3) the sheer complexity of anomalies manifested in certain types of hereditary deafness may prevent recognition even in sophisticated clinics. These factors cumulatively delay appropriate diagnostic and habilitative measures. 
Despite these limitations, the bank of knowledge representing signs and symptoms of inherited deafness is steadily increasing. A recent contribution to this data bank was the discovery of a potentially new form of hearing loss within a family constellation in Costa Rica. The subsequent review of the literature will explore hereditary deafness in general and focus on the early research surrounding the present investigation of this family. 


\title{
CHAPTER II
}

\author{
REVIEW OF THE LITERATURE
}

\section{Identification of Hereditary Hearing Loss}

The identification of hearing loss due to hereditary origin cannot be determined by simply establishing a positive family history for the disorder. Frequently, congenitally deaf individuals marry persons who are also deaf, subsequently creating a pedigree particularly difficult to interpret. In contrast, a negative family history for hearing loss does not preclude the possibility of a hereditary etiology when such factors as lack of information, forgetfulness, or deliberate concealment are considered. Many causes of deafness earlier classified as unknown are eventually identified as inherited. Fraser (1970) studied 920 congenitally deaf children whose hearing loss was of unknown etiology. Ultimately, 54 percent of these cases were discovered to have a hereditary basis.

Nevertheless, a careful study of the pedigree for an affected family is critical when attempting to establish the causal factors for hereditary deafness, but only when viewed as part of the total identification process. With approximately 60 (Konigsmark, 1972) to 70 different types of inherited hearing loss currently recognized (Northern and Downs, 
1978), the most effective method for delineating these various forms has been achieved through an interdisciplinary approach. Oftentimes, the identical characteristics manifested by the numerous types of hereditary deafness can only be separated from one another when comparisons are made among several independent techniques. Those aspects most commonly investigated in the identification of hereditary deafness include (1) mode of transmission, (2) associated abnormalities, (3) histopathology, and (4) audiological characteristics (Konigsmark, 1972; Lim, 1977; Schuknecht, 1967).

Mode of Transmission

Established by the family pedigree and specific laboratory analysis, the pattern by which genes are inherited from generation to generation is designated as the mode of transmission. As described by Nance (1971), genes operate in pairs, with one member of each gene pair transmitted by each parent. Every physical characteristic or trait results from this genetic pairing which may originate through either polygenic or Mendelian inheritance.

Polygenic (multifactorial) transmission, as described by Brown (1967) and Riccardi (1979), is attributed to the cumulative effect of several genetic mutations acting in unison with unidentified environmental factors. The incidence of all diseases due to polygenic inheritance ranges between 1 in 500 and 1 in 2000 (Holmes, 1977). Hearing loss originating from polygenic factors is relatively uncommon. Bergstrom 
(1976) attributed only .7 percent of 427 prelinguistic deaf individuals to polygenic origin. Identification of polygenic disorders is difficult to distinguish from Mendelian inheritance because both may be transmitted to the offspring from either affected or unaffected parents. However, unlike Mendelian inheritance, which has a much higher recurrence risk, Holmes (1977) and Riccardi (1979) estimate the recurrence rate for polygenic disorders among siblings as only 2 to 5 percent.

The most common manner for inherited traits to be transmitted is through Mendelian inheritance; whereby, as described by Riccardi (1979), single genetic mutations arise from specific gene sites. The total number of human mutations originating from Mendelian inheritance is 2336 , as reported by Holmes (1977). The incidence of single mutant genes causing deafness is not known, but Fraser (1964) discovered in a sample of 2355 severely deaf children that over 50 percent inherited their disorder in a simple Mendelian manner. The pattern of Mendelian inheritance, as reported by Riccardi (1979), is contingent upon two factors: (1) the dominance of one gene over its paired counterpart, and (2) whether the genetic mutation occurs on a sex chromosome or non-sex chromosome.

Dominant and recessive transmission. When a person carries two different genes with respect to a specific gene pair, e.g., hearing gene and deafness gene, the individual is considered heterozygotic for the trait in question. In 
contrast, someone who carries two identical genes, whether normal or mutated, is termed homozygotic for that particular trait (Nance, 1971). The mode of transmission for heterozygotic and homozygotic combinations is dependent upon the dominance of one member of a gene pair over the other, in which case the dominant trait is exhibited regardless of the presence of a normal but recessive gene.

Although dominant inheritance occurs much less frequent1y than recessive inheritance, a dominantly transmitted disorder may be easier to recognize due to a consistent pattern of affected individuals identified across several generations. A carrier of a dominant gene exhibits the mutation, at least to some degree, as well as having a similarly affected parent. As illustrated in Figure 1, when a dominant single genetic mutation is identified as originating from either a homozygotic or heterozygotic combination, the possibility of predicting the pattern of inheritance through the laws of probability greatly increases. In Figure la, when both parents carry a homozygotic dominant trait, all offspring will be affected and homozygotic. If one parent is homozygotic and the other parent is normal for the trait (Figure 1b), all offspring will again be affected, but all will be heterzygotic carriers since they received two different genes. When both parents are heterozygotes for the mutant gene (Figure 1c), their children will inherit the dominant trait in 75 percent of the cases. The most common dominantly transmitted combination is the case of a heterozygotic parent and normal 


$$
\underset{D D}{0}+\underset{D D}{O} \bigodot_{D D} \bigodot_{D D}
$$

a. $100 \%$ of offspring affected and homozygotic carriers

$$
\underset{D D}{O}+\underset{\text { hh }}{\mathrm{O}}=\mathrm{D}_{\mathrm{Dh}} \mathrm{O}_{\mathrm{Dh}} \mathrm{D}_{\mathrm{Dh}}
$$

b. $100 \%$ of offspring affected but heterozygotic carriers

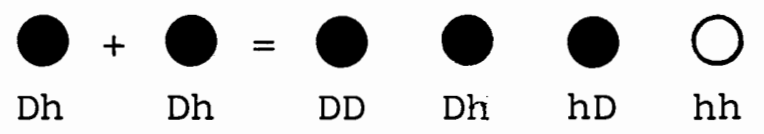

c. $75 \%$ of offspring affected with $50 \%$ heterozygotic and $50 \%$ homozygotic (25\% pure for the mutation, 25\% normal)

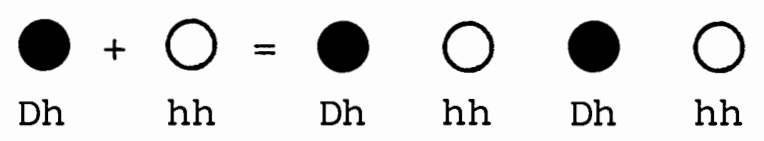

d. $50 \%$ of offspring affected with $50 \%$ heterozygotic and $50 \%$ normal

Figure 1. Possible combinations for dominantly inherited traits. $D=$ deafness, $h$ hehearing; $O=a f f e c t e d$, =unaffected (Hereditary Deafness Public Service Programs, 1975).

parent, who will demonstrate a 50 percent chance of producing an affected heterozygotic offspring (Figure 1d). Since nonaffected children do not carry the mutant gene in most cases, they have little risk of transmitting the trait to any of their offspring, as seen in Figures lc and ld (Hereditary Deafness Public Service Programs, 1975).

In contrast to dominantly transmitted disorders, which require only one mutant gene, the appearance of recessive traits necessitates two mutant genes, one contributed from each parent. Both genes must also be identical for the same 
trait. For example, two affected parents whose cause of deafness is due to two different recessive genes generally will not transmit the disorder to their children because the genetic mutations do not match (Jones, 1976). Brown (1967) estimates approximately 25 percent of the general population carries at least one recessive gene for deafness, but the probability of producing an affected offspring by two random1y selected individuals having the same mutation is less than 1 in 1000 .

Pedigrees for a recessively transmitted disorder are more difficult to interpret than for dominant inheritance. As described by Bergstrom (1976), a recessive trait may occur among siblings but rarely appears in the parents, other family members, or across generations, unless relatives of an affected kindred intermarry. With consanguinous marriages it is more likely for abnormal gene pair combinations to occur and be identified by a positive pedigree.

Possible combinations of recessive Mendelian inheritance are illustrated in Figure 2. When both parents carry a homozygotic recessive trait (Figure $2 \mathrm{a}$ ), all offspring are affected and are homozygotic carriers. If one parent is homozygotic with two abnormal genes and the other is normal for the trait (Figure 2b), all offspring are unaffected but all are heterozygotic carriers. When one parent is homozygotic for the disorder and the other parent is heterozygotic (Figure 2c), their children will inherit the recessive trait in 50 percent of the cases. As seen in Figure $2 \mathrm{~d}$, the most 


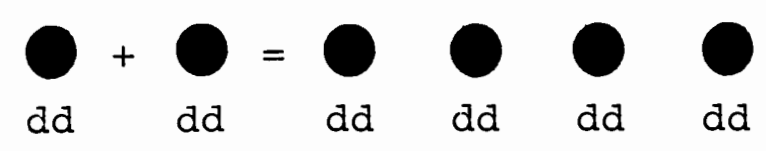

a. $100 \%$ of offspring affected and homozygotic carriers<smiles>OC(O)OC(O)O</smiles>

b. $0 \%$ of offspring affected but heterozygotic carriers

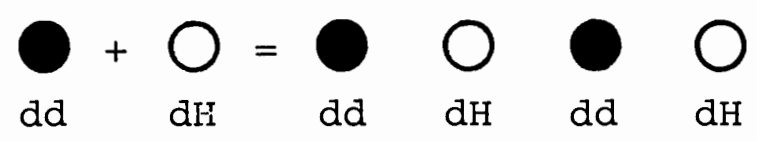

c. $50 \%$ of offspring affected with $50 \%$ heterozygotic and 50\% homozygotic (pure for the mutation)

$$
\underset{d H}{O}+\underset{d H}{O}=\underset{d d}{O} \underset{d H}{O} \underset{H d}{\bigcirc} \underset{H H}{O}
$$

d. $25 \%$ of offspring affected with $50 \%$ heterozygotic and 50\% homozygotic (25\% pure for the mutation, 25\% normal)

Figure 2. Possible combinations for recessively inherited traits. $d$ =deafness, $\mathrm{H}=$ hearing; $O$ affected, $O=$ unaffected (Hereditary Deafness Public Service Programs, 1975; Holmes, 1977; Konigsmark, 1972; Nance, 1971).

common recessively transmitted combination results from the pairing of two heterozygotic parents, who have 25 percent chance of producing an affected homozygotic offspring (Hereditary Deafness Public Service Programs, 1975; Holmes, 1977; Konigsmark, 1972; Nance, 1971).

Autosomal and gonosomal transmission. Every human cell possesses twenty-three pairs of chromosomes, twenty-two autosomal pairs and one gonosomal, i.e., sex-linked pair (Lindsay, 1973). Within a given family, the pattern of inheritance for 
the site of mutation can generally be identified by examining the ratio between affected males to affected females. For autosomal transmission, the sex of either the carrier parent or affected offspring will not influence the inherited pattern. Both sexes are affected equally, with the mode of transmission following patterns previously described in Figures 1 and 2, depending upon the dominant or recessive nature of the mutation.

In the case of gonosomal mutations, affected males far outnumber affected females. This disparity between sexes is due to the tendency for inherited sex-linked traits to be carried almost exclusively on the larger $\mathrm{X}$ chromosome, as opposed to the much smaller $\mathrm{Y}$ chromosome which contributes little to genetic transmission (Brown, 1967; Nance, 1971; Paparella et al., 1975).

Since females carry two $\mathrm{X}$ chromosomes, the presence of the additional $\mathrm{x}$ chromosome allows greater protection against inheriting an abnormal sex-linked mutation. Males carry one $\mathrm{X}$ and one $\mathrm{Y}$ chromosome; therefore, the probability of receiving a mutated $\mathrm{x}$ chromosome greatly increases. The transmission of the abnormality is almost always maternal in origin, since males only inherit their $\mathrm{X}$ chromosome from their mothers .

This female-to-male pattern of inheritance is characteristic for gonosomal recessive traits, affecting 100 males for every affected female (Brown, 1967). As illustrated in Figure 3, the mode of transmission for sex-linked recessive 


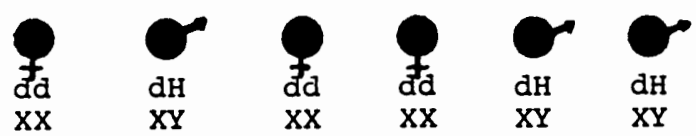

a. 1008 of females affected and homozygotic carriers 1008 of males affected transmitting the mutation to all daughters

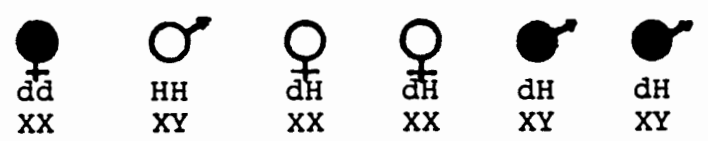

b. 08 of females affected by heterozygotic carriers 1008 of males affected transmitting the mutation to all daughters

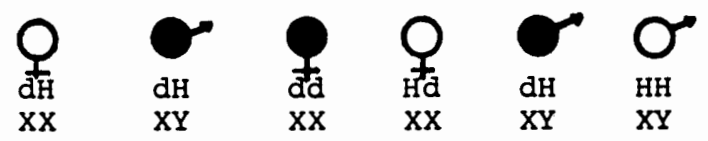

c. 508 of females affected and homozygotic (pure for the mutation); with 508 unaffected but heterozygotic carriers

508 of males affected and capable of transmitting the mutation to all daughters; with 508 homozygotic (normal)

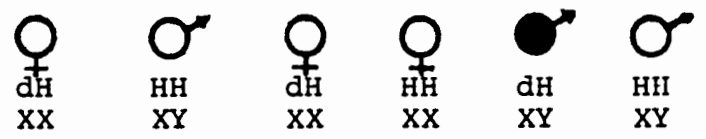

d. 08 of females affected with 508 heterozygotic and 508 homozygotic (normal)

508 of males affected and capable of transmitting the mutation to all daughters, with 508 homozygotic (normal)

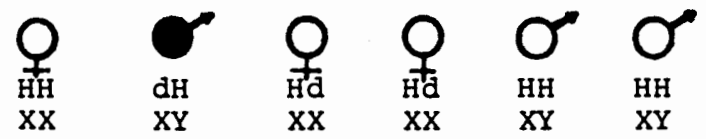

e. 0 of of females affected but heterozygotic carriers 08 of males affected and homozygotic (normal)

Figure 3. Possible combinations for sex-linked recessive traits. $d$ =deafness, $H=$ hearing; $O$ affected, =unaffected (Brown, 1967; Nance, 1971; Riccardi, 1979 ). 
disorders is not only dependent upon the sex of the offspring, but also upon the pairing of homozygotic or heterozygotic parents. When both parents carry an abnormal $X$ chromosome and the mother is homozygotic for the trait (Figure 3a), all offspring are affected. Daughters then become homozygotic carriers and sons become capable of transmitting the mutation to their female offspring but not to their male progeny. If the mother is homozygotic with 2 abnormal $\mathrm{X}$ chromosomes and the father is normal for the trait (Figure $3 b$ ), none of the female offspring are affected, but all are heterozygotic carriers. Hence, all male offspring will be affected, and therefore, capable of transmitting the abnormality to their daughters. As seen in Figure 3c, when both parents carry an abnormal $\mathrm{X}$ chromosome and the mother is heterozygotic for the disorder, 50 percent of their children will exhibit the trait. The affected daughters will be homozygotic carriers, and the unaffected daughters will be heterozygotic for the abnormality. The affected sons again become capable of transmitting the mutation to their female offspring, and the unaffected sons will be normal for the trait. The pairing of a heterozygotic mother and normal father (Figure $3 d$ ) will produce no affected females, but 50 percent will be heterozygotic carriers. Fifty percent of the male offspring will be affected and subsequently will transmit the mutation to their daughters. If the mother is normal, but the father carries the mutated $\mathrm{X}$ chromosome (Figure 3e), none of the offspring will be affected, but all females will be heterozygotic carriers 
(Brown, 1967; Nance, 1971; Riccardi, 1979).

Gonosomal dominant transmission, as illustrated in Figure 4 , is similar to autosomal dominant inheritance, in that all carriers of the mutation, regardless of sex, will manifest the trait. When the mother is heterozygotic for the disorder and the father has a normal $x$ chromosome (Figure 4a), 50 percent of all offspring will be affected. In contrast, if the father carries the mutated $\mathrm{X}$ chromosome and the mother is normal for the trait (Figure 4b), all female offspring will manifest the disorder but all male offspring will be unaffected (Brown, 1967; Riccardi, 1979).

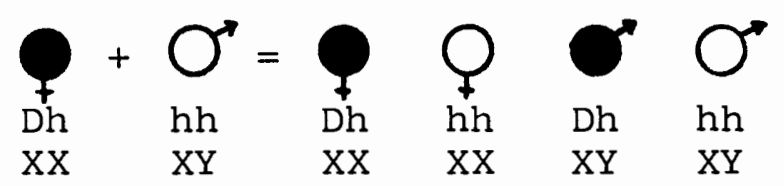

a. 50\% of females affected and heterozygotic carriers, with $50 \%$ homozygotic (normal)

$50 \%$ of males affected and capable of transmitting the mutation to all daughters, with 50\% homozygotic (normal)

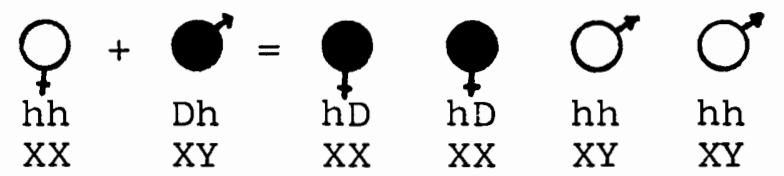

b. $100 \%$ of females affected and heterozygotic carriers

$0 \%$ of males affected and homozygotic (normal)

Figure 4. Possible combinations for sex-linked dominant traits. D=deafness, h=hearing; $=$ affected,
$O=$ unaffected (Brown, 1967; Riccardi, 1979).

Gonosomal Mendelian mutations, both dominant and recessive, account for only a small portion of all inherited 
disorders, with approximately 171 sex-linked mutant genes currently recognized (Holmes, 1977). Congenital deafness attributed to sex-linked origin is estimated between $I$ percent (Proctor and Proctor, 1967; Ruben and Rozycki, 1971) and 3 percent (Hereditary Deafness Public Service Programs, 1975; Konigsmark, 1972).

Most hereditary hearing losses are due to mutations on non-sex chromosomes, with approximately 70 percent (Anderson and Wedenberg, 1968; Fraser, 1964) to 90 percent (Paparella et al., 1975; Proctor and Proctor, 1967) caused by autosomal recessive transmission. Holmes (1977) reports a total of 947 identified genetic mutations of autosomal recessive origin with at least 30 (Brown, 1967) to 45 (Sank, 1969) of these abnormal genes known to cause hearing loss. It is estimated that autosomal recessive deafness accounts for 37 percent (Brown, 1967; Northern and Downs, 1978) to 40 percent (Hereditary Deafness Public Service Programs, 1975; Nance, 1971) of all congenital deafness.

The dominant form of autosomal transmission is much less common than the recessive type. Although there are 1218 autosomal dominant mutant genes currently recognized (Holmes, 1977), the exact number causing hearing loss is not known. However, at least 10 percent (Hereditary Deafness Public Service Programs, 1975; Konigsmark, 1972) to 15 percent (Fraser, 1970; Nance, 1971) of all congenital deafness is attributed to autosomal dominant transmission.

Accurate identification of the mode of transmission is 
an essential step in the delineation of the various types of hereditary deafness, but genetic patterns can be influenced by several factors which may significantly alter the probability of recurrence and the severity of abnormal development. When the pattern of genetic inheritance is unclear, accurate analysis may only be accomplished through further investigation of other distinguishing characteristics for the disorder.

\section{Associated Abnormalities}

The identification of hereditary hearing loss may be delineated by its association with abnormalities in other organs or systems. Frequently, deafness is only one of several disorders exhibited by an individual and is sometimes overshadowed by the severity of the related anomalies. However, certain abnormalities which consistently occur together, called syndromes, usually have a common origin (Jones, 1976). Therefore, if a disorder is identified as part of a well recognized syndrome, the affected individual is then considered at risk for other abnormalities associated with that syndrome. Further evaluation must then be made to establish the presence and/or severity of the related defects.

Various syndromes with hearing loss as a common feature have been described throughout the literature. Many are hereditary, but some, as reported by Lindeman (1967), are the result of acquired factors or chromosomal abnormalities. A disorder often associated with middle ear defects, usually 
due to sporadic genetic mutation rather than inherited origin, is the first and second branchial arch syndrome. This anomaly generally occurs during embryologic development of the branchial arch system, which is the foundation for the subsequent formation of the embryo. As described by Bergstrom (1976) and Lindsay (1973), the outer and middle ear and facial nerve are derived from branchial arches one and two. If either arch fails to develop normally, the resulting structural defects may cause a hearing loss. Branchial abnormalities may include microtia, atresia, ossicular malformations, mandibular anomalies, and facial nerve paralysis.

The first and second branchial arch syndrome can often be distinguished from inherited syndromes on either a clinical or genetical basis. Clinically, inherited deafness usually involves inner ear pathology, and genetically the hearing loss or its associated abnormalities follows a characteristic pattern of inheritance, most frequently recessive. Approximately nineteen inherited syndromes have been identified in association with severe congenital deafness (Konigsmark, 1971), accounting for approximately one-third of all cases of hereditary hearing loss (Brown, 1967; Paparella et al., 1975).

As illustrated in Figure 5, and explained by Bergstrom (1976), most inherited syndromes are due to genetic mutations of the three primary tissue layers of the developing embryo: (1) the ectoderm, (2) the mesoderm, and (3) the endoderm. Ectodermal tissue is the precursor to the skin, sense organs, and central nervous system. The middle layer, mesoderm, 

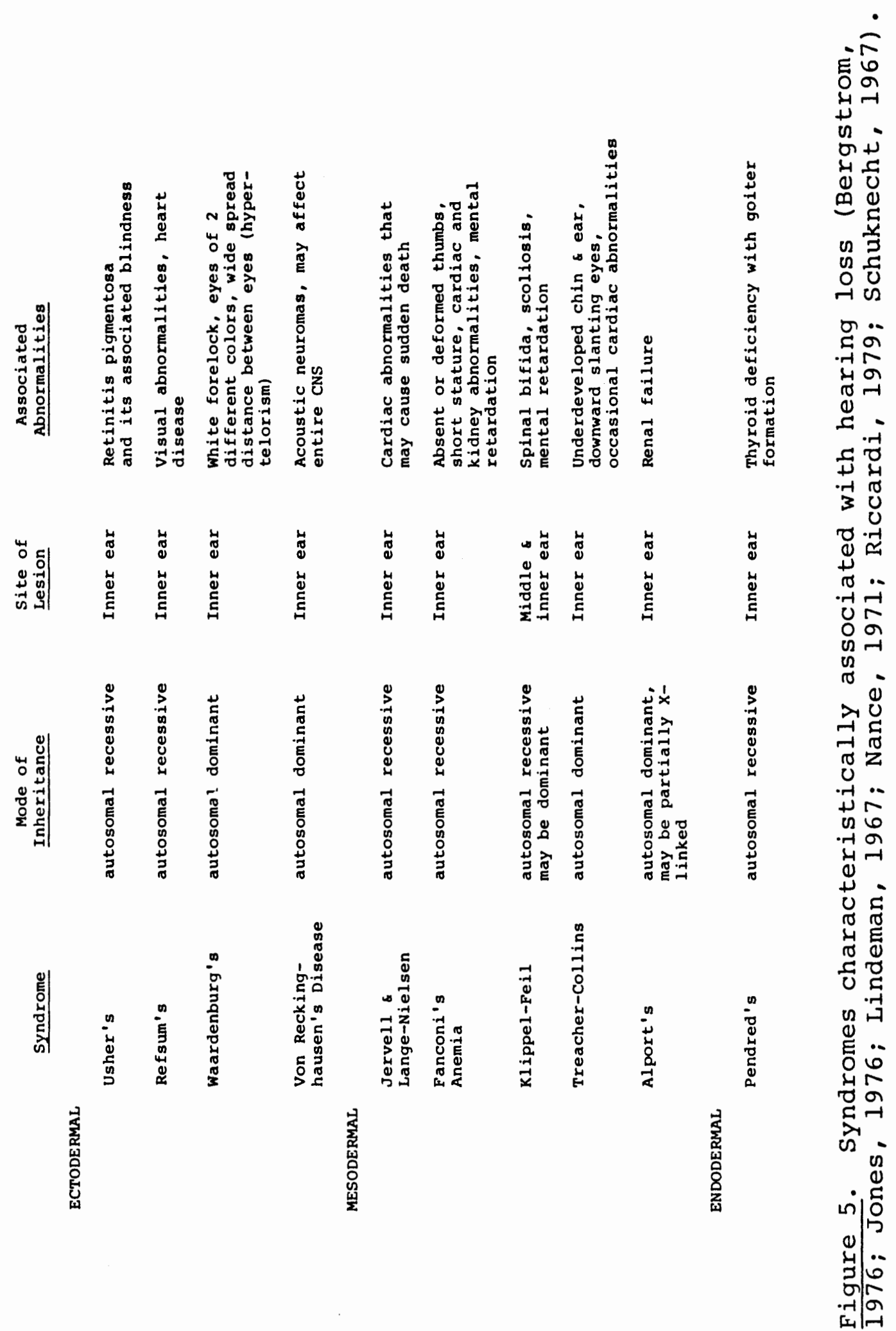
develops into the skeletal and muscular systems, while the innermost layer, endoderm, is responsible for the digestive and respiratory networks.

If a child exhibits a well recognized characteristic for a particular syndrome and the disorder is known to be associated with deafness, the likelihood of identifying the hearing loss greatly increases. However, not all inherited abnormalities are exhibited to the same degree of severity in all affected individuals. Members of the same family may possess an identical mutated gene, with some individuals showing full expression of the trait while others appear clinically normal. This variation in the degree of severity by which a gene is manifested in a particular individual is referred to as its "expressivity" (Paparella et al., 1975; Schuknecht, 1967). Although considered by Brown (1967) to be independent of the mode of inheritance itself, expressivity is most apparent in autosomal dominant disorders (Holmes, 1977) .

In addition to fluctuation in expressivity, the frequency with which a trait is exhibited among all those who are carriers also varies, regardless of its severity. Referred to as the penetrance of a trait, ranging from complete to nearly zero with any given type of abnormal gene, this statistical concept measures the proportion of individuals carrying a specific genetic mutation who actually manifest the expected trait (Brown, 1967; Schuknecht, 1967). For example, in Waardenberg's syndrome, an autosomal dominant 
disorder, the penetrance for deafness associated with this condition is only 20 percent of the total carrier population (Bergstrom, 1976; Proctor and Proctor, 1967). Therefore, 80 percent of those who display other characteristics of the syndrome, such as white forelock, will have normal hearing. The average penetrance for most autosomal dominant genes is much higher than for Waardenburg's syndrome, with approximateIy 80 to 100 percent exhibiting the expected trait (Brown, 1967).

Although the wide variability in the expressivity and penetrance of a genetic mutation may impede early detection of a hereditary hearing loss, those individuals who exhibit a well recognized syndrome commonly linked with deafness are more readily identified. However, most inherited hearing losses are not associated with other abnormalities. Konigsmark (1969) acknowledges at least fifteen types of hereditary deafness that occur as isolated disorders. Since there are no related anomalies to signal the possible presence of a hearing loss in this particular population, accurate identification must therefore depend upon other methods of detection.

Histopathology

The causal factors involved with certain types of hereditary hearing loss may be reflected by the malformation or complete destruction of specific anatomical sites along the auditory pathways. Utilization of temporal bone X-rays 
(polytomographs), in conjunction with microscopic studies of the structural and biochemical aspects of the auditory system, has enabled the establishment of a method of classification based on histopathology. This system of identification classifies auditory anomalies by the varying degrees of malformation resulting from either acquired, chromosomal, or inherited factors (Makishima and Snow, 1975). As reported by Lindeman (1967) and Lindsay (1973), there are four histopathological types of deafness: (1) Michel aplasia, (2) Mondini-Alexander dysplasia, (3) Bing-Siebenmann dysplasia, and (4) Scheibe dysplasia.

Michel aplasia. Always present at birth, Michel aplasia demonstrates a complete failure of development of the bony and membranous inner ear, with possible involvement of both the middle ear and auditory nerve (Bergstrom, 1976; Lindeman, 1967; Schuknecht, 1967). Estimated to occur in only 1 percent of the profoundly deaf population (Bergstrom, 1976), Michel aplasia may be acquired through thalidomide ingestion or inherited in association with Klippel-Feil's syndrome (Figure 5) (Lim, 1977).

Mondini-Alexander dysplasia. Incomplete development occurs with Mondini-Alexander dysplasia in both the bony and membranous labyrinth, often accompanied by middle and external ear anomalies (Makishima and Snow, 1975; Whetnall and Fry, 1964). The occurrence of a wide range in the degree of severity of malformation is reflected by an even greater variation in hearing loss, extending from normal to profound. 
Mondini-Alexander dysplasia may originate from acquired factors or from the chromosomal aberation Trisomy 13-15, or it may be inherited as part of another syndrome, including Penred's, Waardenburg, and Treacher-Collins syndromes (Figure 5) (Bergstrom 1976; Lim, 1977). Unfortunately, some inherited types of deafness occur without associated abnormalities (Parving, 1981), which can lead to difficulties in identification of the mode of transmission.

Bing-Siebenmann dysplasia. Although developmental abnormalities associated with Bing-Siebenmann dysplasia occur only in the membranous portion of the inner ear, this entire structure, including the vestibular area, is invariably malformed (Bergstrom 1976; Lindeman, 1967; Lindsay, 1973). It is commonly associated with Jervell and Lange-Nielsen and Usher's syndromes (Figure 5) (Lim, 1977).

Scheibe dysplasia. Bergstrom (1976) and Lindsay (1973) describe scheibe dysplasia as incomplete development of the membranous saccule and cochlear duct of the inner ear. It is the most common type of histopathological deafness, accounting for at least 70 percent of all profound childhood hearing losses (Bergstrom, 1976). Scheibe dysplasia is usually recessively inherited, associated at times with well-recognized syndromes, but it also arises from acquired factors such as congenital rubella (Lim, 1977; Whetnall and Fry, 1964).

In summary, the laboratory science of histopathology identifies the extent to which structural aberrations contribute to an individual's hearing loss although recognizing 
that the causal factors associated with deafness may be far more complex than the exposed site of lesion. Polytomography, on the other hand, which is limited to revealing bony structures alone, cannot accurately identify certain pathological entities, such as Bing-Siebenmann and Scheibe dysplasia, since they are both isolated membranous anomalies. Finally, biochemical findings are often limited by the availability and condition of temporal bone specimens.

The prompt identification of the extent of hereditary hearing loss in cases of uncertain genetic transmission and no associated abnormalities or recognized structural deformities often necessitates a fourth method of investigation, the auditory test battery.

Audiological Characteristics

The identification of hereditary hearing loss is simplified if the causal factors for the deafness are well recognized. In those cases where etiology is unknown, anomalies may be so subtle they go unnoticed. For example, as reported by Anderson and Wedenberg (1968), genetic mutations cause abnormalities in the metabolic activity necessary for normal development and function of the auditory system. There are no biochemical tests yet available to detect these subtle errors of metabolism, but the degree of severity these changes may cause can be measured by indirect methods sensitive to very minute deviations. One of the most common techniques utilized in the identification of hereditary deafness 
is the analysis of audiological characteristics reflected by the disorder.

There is evidence to suggest a direct correlation between an individual's audiometric profile and the etiology for the hearing loss. Despite intervening acquired factors, such as trauma, noise, infection, and aging, similar audiometric patterns frequently are exhibited among carriers of the same genetic abnormality. Taylor, Brasier, Hine, Morris, and Powell (1973) classified eighty-six deaf children by etiology and demonstrated significant differences in the audiometric configurations among the various groups. Their results are illustrated in Figure 6a. These investigators further compared the mean audiometric data between the recognized inherited group and the group of unknown etiology, (Figure 6b), suggesting very similar audiometric patterns for both.

In some cases, as suggested by Anderson and Wedenberg (1968), normal hearing carriers with deaf offspring may exhibit subclinical identifying characteristics of the disorder. These investigators reported evidence of a distinct audiometric pattern among sixty individuals with otherwise normal hearing, but who were the parents of deaf progeny. However, when Taylor et al. (1975) attempted to replicate the study, they were unable to find any corresponding pattern to that described by Anderson and Wedenberg.

Another characteristic observed in normal hearing carriers is the presence of elevated acoustic reflex thresholds. According to Barr (1973), within the frequency range of $250 \mathrm{~Hz}$ 

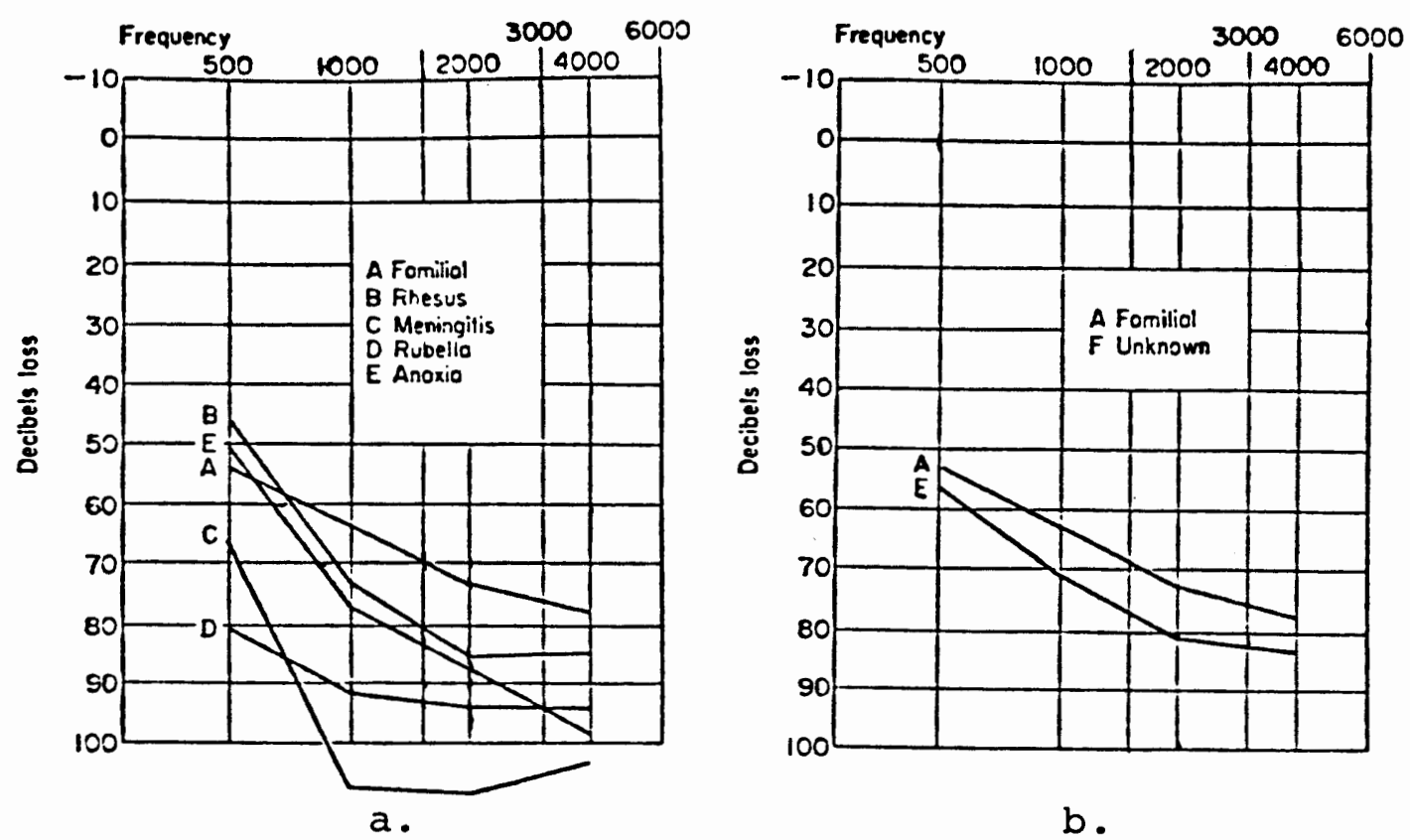

Figure 6 . Comparison of audiometric configurations for different etiologies (a) Mean audiograms for 82 deaf children classified by etiology, (b) Mean audiograms for the inherited group and the group of unknown etiology (Taylor et al., 1973).

to $4000 \mathrm{~Hz}$, a normal listener's stapedial reflex should occur between 80 and $90 \mathrm{dBHL}$, but in some types of inherited deafness, as seen in Figure 7, carriers who appear clinically normal, will exhibit higher than expected acoustic reflex thresholds. Anderson and Wedenberg (1968) demonstrated pathologically elevated reflex thresholds in 62 percent of their carrier parents, but found an incidence of only 3 percent in their control group. These investigators postulated the site of lesion was located in the sensory system of the stimulus ear, rather than in the motor branch of the reflex arch. obtaining similar results, Barr (1973) concluded the anomaly was of genetic origin. 


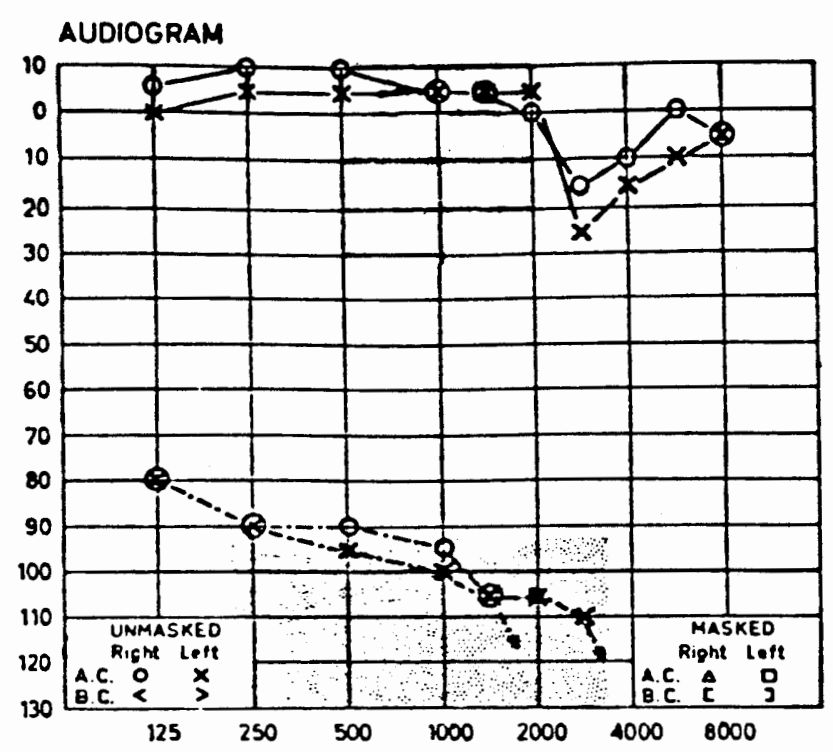

Figure 7. Comparison between Hearing Threshold Levels and acoustic reflex Sensation Levels for a normal hearing carrier (Barr, 1973). Hearing=solid line; Reflex Thresholds=dotted line. The values within the shaded area lie above the pathologic limit.

The audiological characteristics of hereditary deafness are measured by a battery of tests designed specifically for determining an individual's ability to hear. The most frequently used audiometric techniques include puretone audiometry for both air and bone conduction, speech reception and discrimination testing, and impedance measurements. The distinction between dominant and recessively transmitted deafness cannot be made by audiological evaluation alone. However, this method of identification can determine the type and extent of hearing loss reflected by the mutated gene and contribute evidence toward the specific site of lesion in the hearing mechanism. 
Conductive and sensorineural hearing loss. In general, peripheral deafness may be classified according to site of lesion, with clear distinctions between conductive and sensorineural origins. It is important to distinguish between the two, since a conductive hearing loss is oftentimes corrected by medical treatment. Arising from either acquired or genetic abnormalities, conductive deafness is due to the inability of the outer or midale ear to properly transmit sound to the inner ear. Disorders associated with a conductive hearing loss may include acute or chronic otitis media, ossicular discontinuity or fixation, and congenital malformation of the outer and middle ear. Genetic conductive deafness can originate from sporadic mutation, as exemplified by the first and second branchial arch syndrome, or through simple Mendelian inheritance, as demonstrated in cases of Klippel-Feil syndrome (Bergstrom, 1976).

When a hearing loss exhibits no conductive component, the site of lesion is assumed to be sensorineural with involvement of either the cochlea, the eighth nerve, or the more central auditory pathways. Although pathologies within these systems may overlap, areas primarily involved have been classified as either cochlear, in which the specific site is located within the inner ear, and retrocochlear, which encompasses all pathways central to the cochlea and includes the auditory cortex (Kirikae, Shitara and Sato, 1966). A sensorineural hearing loss may originate from a variety of inner ear disorders, including congenital malformations, viral 
infections, ototoxic drug ingestion, noise trauma, and aging. If the deafness is inherited, it is generally due to recessive transmission with no associated abnormalities.

If both conductive and sensorineural pathologies are involved, the disorder is referred to as a mixed loss. This condition occurs primarily in acquired cases (Whetnall and Fry, 1964), but may be inherited when abnormal development includes the outer or middle ear as well as the inner ear.

Frequencies affected. In addition to identifying the type of hearing loss, the disorder may also be characterized by the tonal frequencies involved. Classification is based on the distinction made for high, mid, and low frequencies from $250 \mathrm{~Hz}$ through $8000 \mathrm{~Hz}$. Involvement of only the high or low frequencies may be consistent with some conductive types, however, this condition usually affects the entire frequency range, particularly in congenital cases (Whetnall and Fry, 1964).

In contrast, the most common type of sensorineural hearing loss is characterized by greater impairment for $3000 \mathrm{~Hz}$ and above, the region most vulnerable to environmental and age-related factors. The effects of noise trauma, viral infections, or presbycusis may be exacerbated if the affected individual also has inherited a gene for high frequency deafness. Even if the defective gene does not manifest itself clinically as a hearing loss, genetic mutations may predispose the auditory system to a higher level of susceptability to exongenous injury (Vanderbilt Group, 1968). 
The frequency range between $250 \mathrm{~Hz}$ and $3000 \mathrm{~Hz}$ is much more resistent to acquired factors (Anderson and Wedenberg, 1968), resulting in fewer reported cases of sensorineural deafness occurring in this region than for higher frequencies. Konigsmark (1972) and Paparella et al. (1975) described a dominantly transmitted mid frequency hearing loss, revealed by a basin-shaped audiometric configuration primarily affecting the $1000 \mathrm{~Hz}$ and $2000 \mathrm{~Hz}$ area.

Hereditary hearing loss occurring in the low frequencies below $2000 \mathrm{~Hz}$ (Parving, 1981; Vanderbilt Group, 1968) is considerably more rare than those cases identified by higher frequency losses. Parving, Johnsen and Holm-Jensen (1978) reported two dominantly transmitted types, (1) a mixed impairment of incomplete penetrance with middle and inner ear anomalies, and (2) a sensorineural low frequency hearing loss of complete penetrance. This latter type of deafness usually demonstrates normal thresholds for frequencies above $3000 \mathrm{~Hz}$, while exhibiting at least a $20 \mathrm{~dB}$ loss at $250 \mathrm{~Hz}$ and $500 \mathrm{~Hz}$, with slightly improved sensitivity for $125 \mathrm{~Hz}$ (Gravendeel, 1960; Lundborg, 1955). Figure 8 exemplifies this upwardsloping audiometric configuration characteristic of low frequency hearing loss.

Low frequency conductive and sensorineural hearing losses. Low frequency hearing loss of a sensorineural nature is oftentimes confused with the more commonly found conductive lesion. Both types can demonstrate very similar audiometric configurations, characterized by a more pronounced 


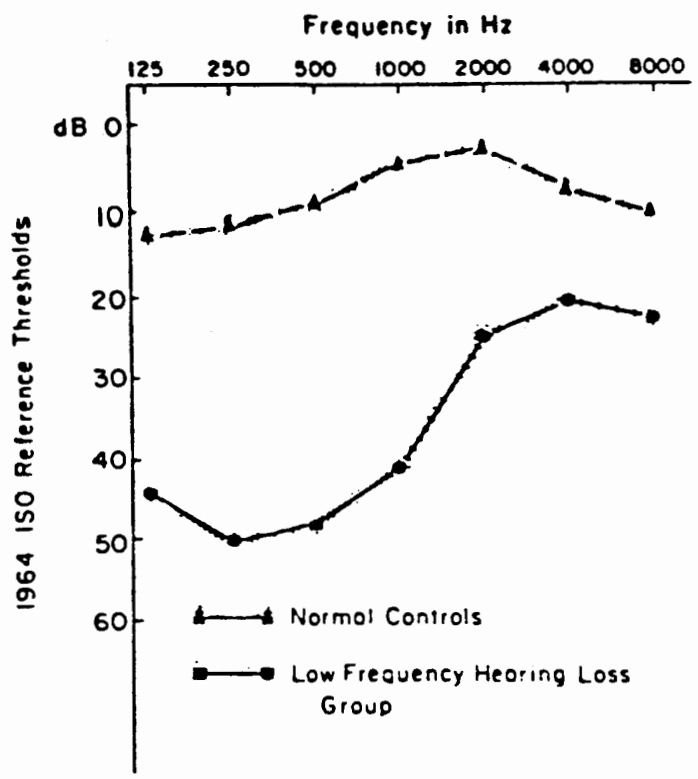

Figure 8 . Comparison of mean puretone audiograms in patients with low frequency hearing loss and those with normal hearing (Vanderbilt Group, 1968).

reduction in low frequency air conducted thresholds than those for higher frequencies. As described by Parving (1981), conductive pathology can be audiometrically recognized by its stiffness tilt, an almost linear improvement in sensitivity of approximately 4-5 dB per octave towards the high frequency area. In contrast, a sensorineural lesion is less likely to reflect such a uniform pattern, and is instead more consistent with a sharper upward slope, reaching an asymptote between $1000 \mathrm{~Hz}$ and $4000 \mathrm{~Hz}$.

An isolated conductive hearing loss is never total since the more peripheral auditory structures can be circumvented by increasing the intensity of sound to a level at which bone vibration can stimulate the cochlea directly. The presence of an air/bone gap, where bone conduction thresholds 
are better than air conduction thresholds is characteristic for conductive pathology.

A low frequency sensorineural hearing loss may demonstrate a similar pattern, leading erroneously to the assumption that the site of lesion is conductive. Parving (1981) examined two families with sensorineural low frequency deafness and discovered one group to have consistent air and bone conduction thresholds, while the other demonstrated a low frequency air/bone gap. Utilizing other audiological tests, Parving evaluated the latter group further and found approximately 75 percent to be of sensorineural origin. Presumably, these subjects were intitially responding to either tactile cues or harmonic frequencies associated with intense, low frequency stimulation.

Invalid bone conduction thresholds obtained at low frequencies among sensorineural losses may be due to harmonic distortion or tactile sensations associated with overdriving. the mastoid bone. In the case of the former, Thornton and Abbas (1980) reported that both puretone and speech formant energies below $1000 \mathrm{~Hz}$ stimulate higher frequency nerve fibers along the basilar membrane of the cochlea, permitting perception of the harmonic even though the hearing loss contra-indicates recognition of the lower frequency fundamental. Thus an individual with no hearing by bone conduction at $250 \mathrm{~Hz}$, but whose thresholds are within normal limits at higher frequencies, might respond to the $250 \mathrm{~Hz}$ signal at a sufficient intensity, because harmonic frequencies are generated at 
above threshold intensities (Gravendeel, Plomp and Eng, 1960). Similarly, Nober (1964) has observed pseudoauditory bone conduction thresholds at low frequencies among the deaf that he associated with tactile perception. He conjectured that the large displacement of the bone conduction oscillator associated with high intensity, low frequency stimulation creates a tactile vibration that can be perceived and responded to by individuals unable to hear tonality. It is interesting to note that both harmonic frequency and tactile stimulation are observed at approximately the same oscillator intensity levels, 40-60 dB, and are only observed at the applied frequencies of $250 \mathrm{~Hz}$ and $500 \mathrm{~Hz}$.

Further distinction between low frequency conductive and sensorineural hearing losses can be made on the basis of speech audiometry. Those affected with low frequency sensorineural deafness usually demonstrate good speech discrimination ability when stimuli are presented at a normal conversational speech level. Frequently, there is a marked difference between the speech reception threshold (SRT) and the average puretone threshold (APT) (Suga, Naunton, Maitland, Hedberg, 1976). Oftentimes those affected with a low frequency sensorineural impairment hear whispered speech better than voiced speech (Parving and Bak-Pedersen 1978; Vanderbilt Group, 1968).

These speech characteristics, consistent with low frequency sensorineural hearing loss, are attributed by Parving (1981) to the presence of normal sensitivity for higher 
frequencies. Near normal residual hearing in the higher frequency region of the speech spectrum allows high frequency nerve fibers to respond to low frequency speech stimuli (Thornton and Abbas, 1980). Thus vowel sounds may be discriminated among low frequency hearing loss cases by virtue of the spread of their energies into more sensitive, higher frequency units. As stated by Parving (1981), only after the hearing loss involves higher frequency regions, will speech discrimination ability deteriorate.

The speech characteristics of those individuals affected with low frequency deafness may be further explored by their responses to Ling's 5-sound test (Ling, 1978). The ability to detect the five phonemes $/ a /, / u /, / i /, / S /$, and /s/ demonstrates the capacity to recognize all aspects of speech, since these five sounds encompass the frequency range for all English phonemes. Depending upon the slope and severity of the hearing loss, certain phonemes may or may not be discriminated. For example, the ability to hear /a/ but not $/ \mathrm{u} /$ indicates involvement of the frequency range between $750 \mathrm{~Hz}$ and $1000 \mathrm{~Hz}$ because both the first formant of /a/ and the second formant of $/ u /$ occur within this same region. For a high frequency hearing loss, the three vowels should be easier to recognize than the two consonants, and as suggested by Berlin (1981), an individual with a low frequency impairment would be expected to detect the $/ S /$ and $/ s /$ sounds at thresholds equal to or better than those for the $/ a /, / u /$ and /i/ phonemes. 
Conductive and sensorineural deafness may be further differentiated by impedance audiometry. Tympanometry, an objective measure of middle ear function, is particularly useful in distinguishing conductive pathology from sensorineural losses and normals. In general, the combination of the absence of an air/bone gap during audiometry and a normal, Type A tympanogram reflects a sensorineural site of lesion among individuals demonstrating a loss of hearing sensitivity.

Further delineation of site of lesion may be accomplished by observing impedance changes associated with stapedial reflex testing. As demonstrated by Jerger, Jerger, and Mauldin (1972), 95 percent of the acoustic reflex thresholds of normal hearing listeners can be elicited by tonal stimuli at sensation levels ranging from 70 to $100 \mathrm{dBHL}$, with an average of 85 dBHL. As illustrated in Figure 9, sensation levels for the stapedius reflex in subjects with sensorineural impairment increase in proportion to the existing hearing loss. Although with cochlear lesions, the reflex is often elicited at sensation levels of less than $60 \mathrm{~dB}$ (Wilber, 1976).

Young children with apparently normal hearing may demonstrate absent or elevated reflex thresholds at any test frequency. Jerger, Jerger, Mauldin, and Segal (1974) reported, however, that only 4 percent of their sample of 200 children with normal or sensorineural hearing losses of less than $70 \mathrm{~dB}$ failed to elicit stapedial reflexes.

Reflex thresholds have been reported to decrease as age increases, up to the age of thirty years, with children from 


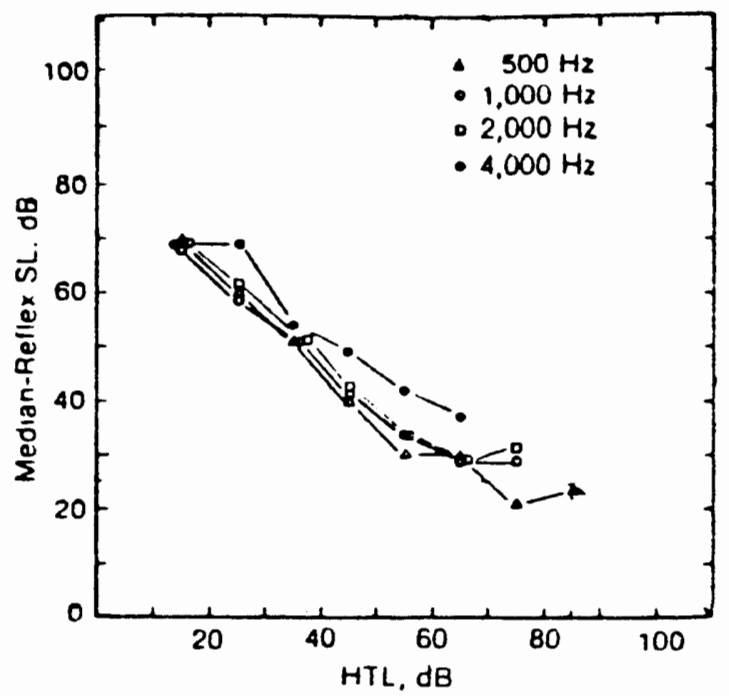

Figure 9. Acoustic reflex Sensation Levels as a function of Hearing Threshold Levels for 515 subjects with sensorineural impairment (Jerger, Jerger, and Mauldin, 1972).

infancy to six years accounting for the greatest rate in threshold decline (Jerger et al., 1974). These investigators found a median reflex level of $95.5 \mathrm{~dB}$ for children younger than 3 years, while 5 year olds demonstrated a median reflex level of $89.5 \mathrm{~dB}$, closer to the estimated average adult threshold of $85 \mathrm{~dB}$. Osterhammel and Osterhammel (1979) described a similar decrease in reflex thresholds as a function of age for older children. This phenomenon is thought to be caused by either incomplete development of the reflex arc or subclinical middle ear abnormalities (Jerger et al., 1974; Osterhammel and Osterhammel, 1979). 
Summary

The identification of hereditary hearing loss is best achieved through an interdisciplinary approach. By comparing test results obtained from several independent fields, a more definitive classification can be made for each type of deafness. The aspects most commonly investigated include (1) mode of transmission, (2) associated abnormalities, (3) histopathology, and (4) audiological characteristics. Each area has contributed valuable information towards the accurate identification of hereditary hearing loss.

\section{Identification of Autosomal Dominant}

\section{Hearing Loss}

By utilizing current identification measures made available through a number of investigative disciplines, a classification system for hereditary hearing loss occurring with no associated abnormalities has been established. Holmes (1977) recognized eleven types of inherited deafness: (1) dominant congenital severe deafness, (2) dominant progressive nerve deafness, (3) dominant unilateral deafness, (4) dominant low frequency hearing loss, (5) dominant mid frequency hearing loss, (6) recessive congenital severe deafness, (7) recessive early onset neural deafness, (8) recessive congenital moderate hearing loss, (9) sex-linked congenital deafness, (10) sex-linked early onset deafness, and (11) sex-linked moderate hearing loss. There is general agreement with this 
classification system, except for Konigsmark (1972) who included an additional category for the pathology of otosclerosis.

Among the twelve types, the dominant low frequency sensorineural hearing loss (4) is oftentimes the most difficult to accurately identify. As reflected by the scarcity of reported case studies, this disorder is considerably less common than other types of inherited deafness. However, the composite of data now available from a number of investigations reveals a very distinct and characteristic pattern for identification.

Besides identifying the type of hearing loss and the frequencies affected, audiological evaluation can contribute further to the delineation of dominant low frequency sensorineural deafness. Characteristic aspects that may be audiometrically measured include (1) site of lesion, (2) age of onset, (3) progression rate, and (4) severity (Konigsmark, 1972; Parving, Johnsen, and Holm-Jensen, 1978; Vanderbilt Group, 1968).

Site of Lesion

Although low frequency hearing loss may result from certain retrocochlear lesions, there has been little evidence to support such findings among various types of inherited deafness (Konigsmark, Mengel, and Berlin, 1971; Vanderbilt Group, 1968). Most audiometric studies of inherited low frequency deafness report a cochlear site of lesion, as indicated 
by the presence of recruitment, an abnormal growth in loudness for tonal stimuli; and the absence of abnormal auditory adaptation to puretones (Gravendeel, Plomp, and Eng, 1960; Konigsmark, Mengel, and Berlin, 1971; Paparella et al., 1975; Parving and Bak-Pedersen, 1978). Positive signs of a reduced difference limen for puretones, a sensory phenomenon, and negative signs for abnormal adaptation, a neural phenomenon, are consistent with cochlear pathology. Unfortunately, the site of lesion can spread toward more central structures in some instances. Teig (1968) demonstrated a higher incidence of pathological tone decay or auditory adaptation among subjects with inherited deafness whose hearing levels exceeded $50 \mathrm{~dB}$. Furthermore, histological studies performed on temporal bone tissues derived from cases with hereditary deafness revealed degenerative changes secondary to cochlear involvement, including atrophy of the spiral ganglion and central nuclei (Konigsmark, Mengel, and Berlin, 1971; Makishima and Snow, 1975; Proctor and Proctor, 1967). While most research delineates the cochlea as the primary site of lesion in cases of inherited, low frequency deafness, it becomes apparent that more central structures may become involved, particularly as the deafness advances.

The primary site of lesion for autosomal dominant low frequency sensorineural deafness is most often identified within the cochlea. Atrophy of the stria vascularis has been observed by Paparella et al. (1975), but the primary region of involvement is along the apical portion of the basilar 
membrane, the area most sensitive to low frequency stimuli (Konigsmark, Mengel, and Berlin, 1971; Vanderbilt Group, 1968). The Vanderbilt Group reported low frequency sensorineural deafness among laboratory animals with induced lesions to the cochlear apex. They concluded from their investigation of human subjects with low frequency sensorineural deafness, that the site of lesion originated in the apical portion of the cochlea.

As explained by Kinney (1950), the basilar membrane is tonotopically arranged with the highest frequencies located in the cochlear base, $3000 \mathrm{~Hz}$ estimated to lie midpoint, and $300 \mathrm{~Hz}$ about four-fifths of the way to the apex. The cochlear nerve was also found to be tonotopically organized (I1inuma, Shitara, Hoshino, and Kirikae, 1967). Nerve fibers arising from three areas of the basilar membrane which are sensitive to low, mid, and high frequency stimuli, are twisted in layers (Lundborg, 1955). Basal end responses are carried in the outermost layer of the nerve bundle, while mid cochlear responses are represented by neural fibers from the center layer and apical responses are transported along the innermost fibers. Ilinuma et al. provided evidence to support the concept that a low frequency hearing loss may be produced by partial sectioning of the cochlear nerve.

Differentiating genetic cochlear deafness from other pathologies of the inner ear on the basis of audiologic testing is oftentimes equivocal. For example, inherited, low frequency hearing loss may be incorrectly identified as 
Meniere's disease, because of the similarity in audiometric configurations. Meniere's disease, however, is often associated with a fluctuating hearing loss and concomitant vestibular dysfunction, while genetic low frequency deafness typically demonstrates relatively stable hearing thresholds and rarely involves vestibular functions (Konigsmark, Mengel, and Berlin, 1971; Parving, 1981).

The histopathological factors underlying dominant low frequency sensorineural deafness remain unclear. Several theories have been suggested, with (1) labyrinthine otosclerosis (Ilinuma et al., 1967; Parving, Johnsen, and Holm-Jensen, 1978), and (2) biochemical/bioelectrical alterations (Paparella et al., 1975; Proctor and Proctor, 1967) most often cited as probable sequella.

Labyrinthine otosclerosis. A disorder of the otic capsule, otosclerosis, frequently leads to stapes fixation and, subsequently, a conductive hearing loss (Cohn, 1981). As the disease progresses, however, degenerative changes observed within the cochlea, affecting the bony labyrinth, spiral ligament, stria vascularis, and organ of Corti, thereby contribute to a sensorineural component to the impairment (Schuknecht and Kirchner, 1974).

A purely sensorineural form of labyrinthine otosclerosis has been suggested by Ilinuma et al. (1967), and by the Vanderbilt Group (1968) as a possible cause for low frequency hearing loss. Although temporal bone tomography has revealed some types of low frequency hearing loss to be associated 
with Mondini-Alexander dysplasia, a malformation of both the bony and membranous labyrinths (Whetnall and Fry, 1964), normal tomograms were found in the majority of the subjects investigated by the Vanderbilt Group (1968). Localized in the cochlear apex, low frequency hearing loss may be attributable to malformations of only the membranous labyrinth, a condition referred to as Schreibe dysplasia.

A histologic description by Parving (1981) has indicated that otosclerotic changes in the cochlea may occur without stapedial involvement. However, Schuknecht and Kirchner (1974) doubt that otosclerosis severe enough to cause labyrinthine degeneration would not also fixate the stapes. Parving, Johnsen, and Holm-Jensen (1978) did not discount the possibility for such an occurrence, but were unable to confirm the presence of the disease process in their subjects with dominant low frequency sensorineural deafness.

Biochemical/bioelectrical alterations. A physiological change in the cochlear apex may occur as the result of alterations in the biochemical/bioelectrical consistency of the endolymph (Paparella et al., 1975; Proctor and Proctor, 1967). The stria vascularis, as described by Gacek (1971), is essential to the proper maintenance of the biochemical/bioelectrical levels of the endolymph. This structure is believed to be the source of the positive endolymphatic resting potential (Suga et al., 1976). A decrease in the level of this potential causes a reduction in the sensitivity of the cochlear response. If any alterations occur to the stria 
vascularis, it can subsequently alter the fragile environment of the endolymphatic system. Reported by Farrar (1978), degeneration may occur from vascular abnormalities which deprive the stria vascularis of a sufficient supply of oxygen. Triggered by genetic mutation, metabolic changes in the endolymphatic system could lead to enzymatic deficiencies and loss of cellular function. The presence of biochemical abnormalities has been observed in some types of inherited syndromes known to be associated with a sensorineural hearing loss. Such is the case with Pendred's syndrome, a disorder also frequently associated with goiter. As discussed by Bergstrom (1976), the goiter is caused by a defective enzyme which results in the production of an abnormal thyroid hormone. The hearing impairment may be due to the same enzymatic alteration and subsequent degeneration in the structure and/or function of the cochlea.

The attribution of low frequency sensorineural deafness to a generalized metabolic abnormality has yet to be substantiated by histologic evidence. Another difficulty with this theory is that, assuming no differential vulnerability, biochemical changes should affect the entire scala media, resulting in a more equally distributed hearing loss across all frequencies (Gacek, 1971). Experimentally, a low frequency sensorineural hearing loss can be produced with strial destruction localized to the cochlear apex, leaving the endolymphatic resting potential at the basal end of the cochlea unchanged, but this effect has not been produced by 
identifiable metabolic changes (Suga et al., 1976). The Vanderbilt Group (1968) indicated no evidence to suggest the presence of a metabolic abnormality in their subjects with dominant low frequency sensorineural deafness.

\section{Age of Onset}

Many genetic disorders do not manifest themselves during fetal development, but rather are first expressed in childhood or adulthood. Approximately one-third of hereditary deafness cases are present at birth, one-third develop during infancy or childhood, and about one-third begin in adulthood (Konigsmark, 1971). Among the later onset cases, the specific age at which time the disorder manifests itself varies widely. Everberg and Jensen (1976) observed degeneration as early as three years of age, while suga et al. (1976) reported cases of onset delayed until age sixty-five.

The age of onset for dominant low frequency sensorineural hearing loss has been reported by several investigators to occur within the first two decades of life. Cotton (1977) described one case where the disorder was recognized during infancy. A study of several different families affected with low frequency sensorineural deafness indicated ages of onset ranging from six to twelve years in different families (Konigsmark, Mengel, and Berlin, 1971). Other studies also reflect divergence in age of onset, depending upon the family investigated (Cotton, 1977; Ilinuma et al., 1967; Parving, 1981). 
Identification of the age of onset for inherited deafness is often difficult. Although individuals with a common pedigree may manifest similar deficits, the actual age at which the hearing loss becomes evident is not always uniform among all affected members. Suga et al. (1976) reported that onset for low frequency hereditary deafness ranged from early childhood up to the age of forty years within the same family. If hereditary hearing loss occurs later in life, it may be difficult to differentiate from presbycusis, or old age deafness (Paparella et al., 1975). Both problems demonstrate atrophy of the stria vascularis (Suga et al., 1976) and both begin years prior to the awareness of an impairment by the affected individual (Paparella et al.). It is likely that certain types of presbycusis occur as the result of genetically programmed cochlear alteration (Harris, 1963). Fortunately, most forms of presbycusis are relatively easy to differentiate from low frequency hereditary deafness, since the former predominantly affects higher frequencies.

In many children, it is impossible to accurately determine the age of onset for an inherited hearing loss. Whether the child's impairment was present at birth or occurred in infancy or early childhood, the disorder may go unrecognized until speech and language fail to develop normally. Depending upon the extent of the child's hearing loss, the younger the age of onset, the more severe the impairment to speech and language acquisition. Speech can be lost within a few weeks if a severe hearing loss adventitiously occurs by the 
age of two years, but normal speech may be retained for a year if the onset occurs in pre-adolescence (Whetnall and Fry, 1964). A child who is verbally delayed is likely to be suspected of an associated hearing loss and will usually be examined for this possibility. However, a child with a low frequency sensorineural loss will generally demonstrate very good speech and language skills and may go unidentified.

\section{Progression Rate}

There is a wide variation in the progression rate of inherited hearing losses. Most recessively transmitted deafness remains stable with no further decrease in hearing sensitivity from time of onset (Cotton, 1977; Teig, 1968). If a recessive hearing loss does progress, the progression rate is generally very rapid with profound deafness usually noted by early childhood (Paparella et al., 1975). A progressive sensorineural hearing loss with no associated abnormalities is usually dominantly transmitted (Farrar, 1978; Fraser, 1964), particularly if progression begins during adulthood (Cotton, 1977; Teig, 1968).

Among the dominant progressive types wherein low frequencies are affected first, several patterns for the rate of progression have been reported. Although an inherited low frequency sensorineural hearing loss of a nonprogressive nature has been described by Parving (1981), the majority of cases cited begin in childhood or in early adult life and slowly progress in severity. However, the rate of progression 
may accelerate during certain periods of an individual's lifetime, such that low frequencies are affected during the early years, followed by a rapid decrease in high frequencies during middle age and loss of sensitivity in the mid frequencies by the sixth decade (Konigsmark, Mengel, and Berlin, 1971). Parving and the Vanderbilt Group (1968) noted in their subjects with low frequency hearing loss that progression to higher frequencies began around the age of forty. The accelerated progression during later life may be attributable to presbycusic affects and may be difficult to delineate from the pre-existing genetic factors (Suga et al., 1976; Vanderbilt Group) .

Kinney (1950) reported his subjects demonstrated hearing threshold levels between 10 and $30 \mathrm{~dB}$ during the first and second decades, with a mild to moderate loss noted in middle age, and a moderate to severe impairment observed in the elderly. In the investigation by the Vanderbilt Group (1968), threshold levels of 30 to $40 \mathrm{~dB}$ were reported below $2000 \mathrm{~Hz}$, progressing to a moderately severe hearing loss involving both high and low frequencies in those subjects 50 years and older.

A hearing loss so severe as to demonstrate no response to any frequency at maximum intensity is usually of acquired origin rather than inherited (Fraser, 1964). A review of the literature by this author did not disclose any incidence of profound hereditary low frequency deafness. 
Laterality/Symmetry

A unilateral asymmetrical hearing loss is generally not inherited. In 122 subjects with unilateral deafness, Everberg (1960) estimated 25 to 30 percent were of hereditary origin. According to Konigsmark (1972), the majority of unilateral asymmetrical deafness cases found among families with suspected hereditary anomalies are actually due to nongenetic abnormalities. Dominant low frequency sensorineural losses are also largely bilateral and symmetrical with only 36 percent of the cases reported as unilateral (Parving and BakPedersen, 1978). For dominant low frequency sensorineural hearing loss occurring alone, an estimated 64 percent demonstrated bilateral symmetrical involvement (ibid.). Konigsmark and Suga et al. (1976) described similar findings.

\section{Summary}

Dominant low frequency sensorineural hearing loss with no associated abnormalities may be further delineated by its characteristic pattern of development: (1) the site of lesion is primarily localized to the cochlear apex, (2) the age of onset is usually within the first two decades of life, (3) the disorder progresses slowly usually affecting higher frequencies in middle age, stabilizing at a moderately severe level, and (4) the involvement is most often bilateral and symmetrical. 


\section{Monge Deafness}

In eighteenth century Costa Rica a group of individuals, many of whom were afflicted with genetic disorders, collectively established a small town called Taras. Among the residents of this village was the Monge family, one that carried a genetic mutation for a certain type of inherited deafness that has been transmitted to subsequent generations for over 200 years. At present, there are over 100 affected members of this family, all profoundly deaf by the age of thirty, and all with the potential of transmitting the disorder to 50 percent of their children (León, 1981).

Although the families affected are aware of the hereditary nature of their deafness, until recently no attempt has been made to clinically identify the specific genetic mutation involved. A pedigree for the Monge family, as illustrated in Figure 10, was begun in 1975 and reported by León, Sanchez, Vanegas, Villalobos, Torres, León, Howell, and Rodrigues (1981). The Monge pedigree, together with analysis of blood samples and karyotyping of family members, enabled these investigators to identify the mode of transmission as simple Mendelian autosomal dominant with complete penetrance and variable expressivity.

Monge deafness does not appear to be associated with other abnormalities, nor does tomography suggest any structural malformations of the bony labyrinth (León et al., 1981). Although no temporal bone studies have yet been accomplished, 


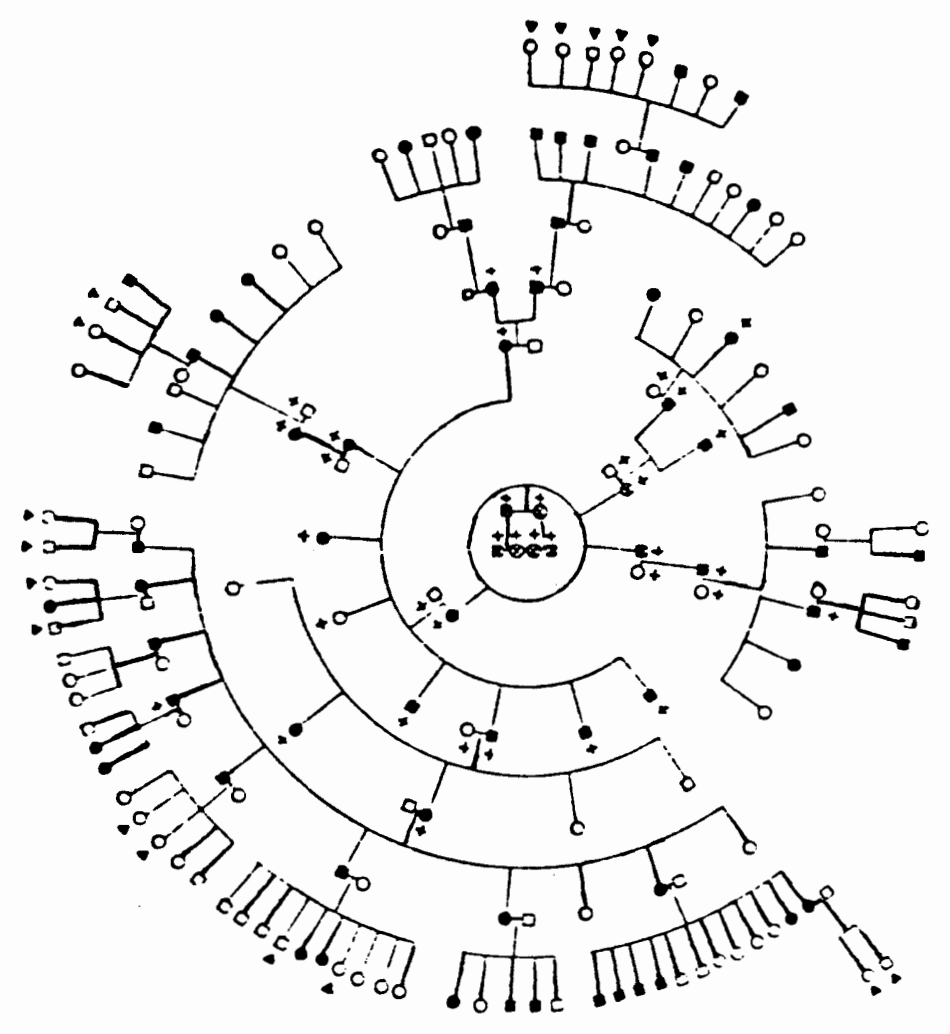

Figure 10. Pedigree of the Monge family. Hatched circles (females) and squares (males) represent individuals whose auditory status in unknown; triangles point to children who are under the presumed age of onset; solid squares or circles indicate deaf; and crosses designate deceased individuals (León et al., 1981).

the early audiometric findings indicate the apical portion of the cochlea as primary site of lesion.

A limited sample audiometric investigation by León et al. (1981), revealed the presence of a low frequency sensorineural hearing loss in the affected Monge members. As illustrated in Figure 11 , the disorder initially affects the low frequencies in early childhood, followed by slow progression 


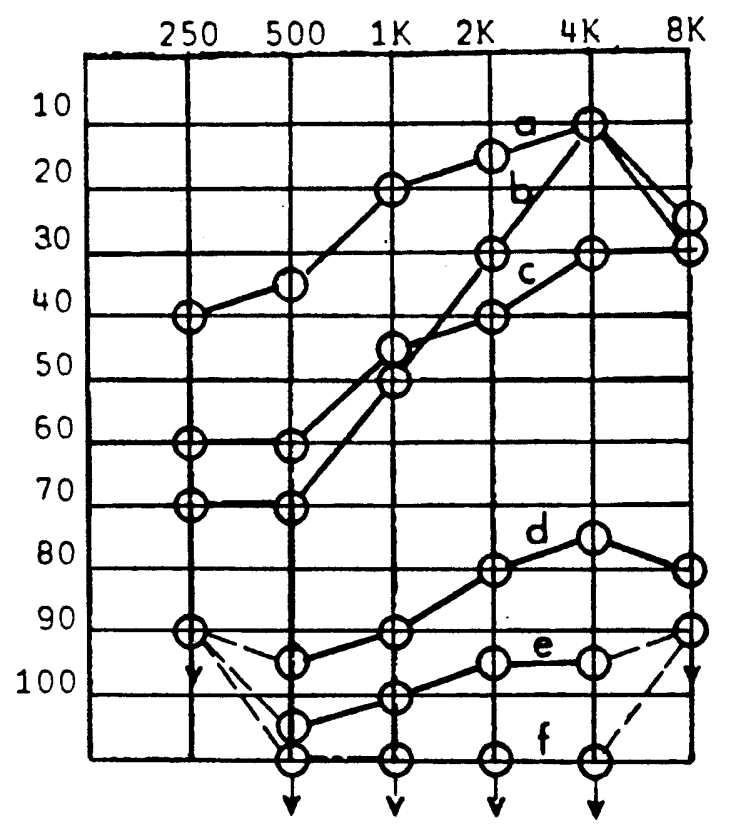

Right Ear

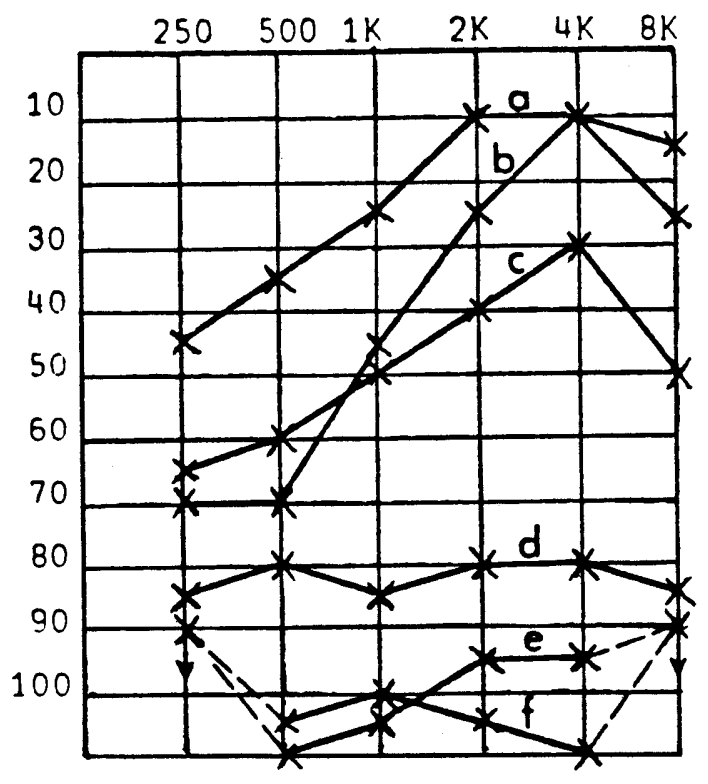

Left Ear

Figure 11. Representative puretone audiograms as a function of age for the Monge family. Ages: (a) 5 years, (b) 14 years, (c) 11 years, (d) 18 years, (e) 22 years, (f) 38 years (León et al., 1981).

across all frequencies by late adolescence or young adulthood. León et al. reported the hearing loss as bilateral and symmetrical with onset in children as young as five years of age. Although the minimum age of onset for Monge deafness is still uncertain, as seen in Figure 12, about one-half of the affected individuals report onset to occur within the first decade of life. During adolescence, the severity of the hearing loss increases to threshold levels of approximately $70 \mathrm{~dB}$ for lower frequencies. By early adulthood the affected members are profoundly deaf with hearing threshold levels frequently 


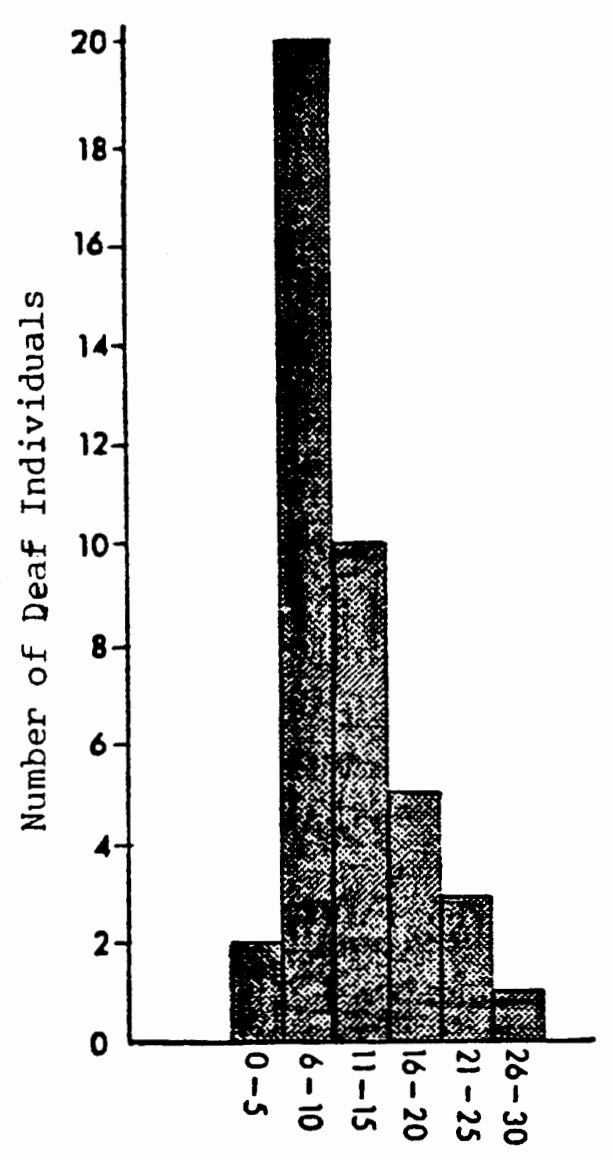

Figure 12. Reported age of onset for the Monge family (León et al., 1981).

observed in excess of $100 \mathrm{~dB}$ and involving the entire frequency spectrum. As reported by León et al. (1981) no episodes of vertigo were experienced by any affected member, but several adults reported periodic tinnitus.

In addition to the aforementioned puretone evidence gathered by León et al. (1981), further audiometric data and impedance test results were collected in 1979 (Maurer, 1981). Acoustic reflex testing confirmed the cochlear site of lesion in a limited sample of affected Monge members. The majority 
of cases demonstrated positive results for the Short Increment Sensitivity Index (SISI) test, while negative findings for tone decay were revealed.

Summary

Recent investigations by León et al. (1981) and Maurer (1981) have lead to the identification of a kinship in costa Rica, the Monge family, who are affected by a dominant genetic mutation for low frequency sensorineural hearing loss. A search of the literature failed to reveal any type of genetic deafness identical to the one in question, as characterized by early childhood onset, slow progression, and culminating in a profound bilateral hearing loss at all frequencies by age thirty. However, the audiological characteristics of this potentially unique form of hereditary deafness merit a more comprehensive investigation. Further study of the Monge family may yield new information on low frequency, inherited hearing loss and indeed may contribute new knowledge to the field of genetic deafness.

\section{Statement of Purpose}

The purpose of this study was to investigate certain audiological characteristics associated with hereditary deafness within an age differentiated sample of Monge family members.

The primary questions to be answered through auditory testing included: 
(1) What differential test data support specific site(s) of lesion?

(2) What hearing level changes occur as a function of chronological age among affected and unaffected members of the Monge family?

(3) What audiometric variations within the sample tested characterize this form of hereditary deafness? 


\section{CHAPTER III}

METHOD

The following methods and procedures were used to analyze the audiological characteristics of hereditary deafness specific to the Monge family in a sample of affected and unaffected members.

$\underline{\text { Subjects }}$

Fifty-four members of the Monge family were selected to participate as subjects for this study. They were drawn from communities near San Jose, Costa Rica, and were monetarily compensated for their voluntary participation. Subjects were chosen according to the following criteria: (1) genetic identification as members of the Monge family through case history information and blood test analysis performed by staff personnel from the Center of Investigation in Cellular and Molecular Biology, University of Costa Rica, (2) absence of conductive hearing loss as evidenced by otologic and audiometric examination, and (3) capability demonstrated for performing the required tasks.

of the fifty-four individuals who were initially selected to serve as subjects for this study, seven did not meet criteria. Two people were not genetic members of the Monge family, four individuals demonstrated conductive 
hearing losses, and one child did not demonstrate sufficient ability to perform the required tasks.

Following audiological assessment, the forty-seven remaining subjects were divided into three groups: (1) Experimental, (2) Control, and (3) Unknown. The Experimental Group consisted of twenty-five affected family members who exhibited Monge deafness and who demonstrated a low frequency sensorineural loss of hearing sensitivity $(\overline{\overline{ }} 20 \mathrm{~dB}$ at 250 and 500 $\mathrm{Hz}$ ). The ages of the Experimental Group ranged from 6 to 68 years, with a mean age of 31.6 years. Fourteen of the subjects were female and 11 were male. Twelve unaffected family members, those who did not exhibit Monge deafness, served as a control. The ages of the Control Group ranged from 7 to 44 years, with a mean age of 21.2 years. Eight of these subjects were female and 4 were male. Ten subjects could not be positively identified as either affected or unaffected members and were placed in a separate group of unknowns. Their test results were not included in the subsequent analysis of data for this study.

For purposes of expanding the sample population and examining the progressive nature of the disorder, audiometric test data previously obtained by León et al. (1981) and Maurer (1981) from affected Monge members were included as a second Experimental Group. Determination for inclusion in this group was based on confirmed genetic identification and audiometric test results consistent with sensorineural hearing loss. Experimental Group II consisted of twenty-seven 
individuals, with ages ranging from 4 to 53 years and a mean age of 24.3 years. Twelve of these subjects were female and fifteen were male.

Testing Environment

All testing for this study took place at the Centeno Guell Auditory Testing Facility in Guadelupe, Costa Rica. Audiologic testing was conducted in a sound chamber (Industrial Acoustics Corporation, Model 400-SER). Ambient noise levels measured periodically with a Quest sound level meter (Model 208) were within ANSI (1969) standards for bone conduction testing. Interior noise levels did not exceed $40 \mathrm{dBA}$. Tympanometry and acoustic reflexes were evaluated in a separate sound treated room.

\section{Instrumentation}

A clinical audiometer (Maico, Model MA-22) and a portable audiometer (Maico, Model MA-16) were used for puretone air and bone conduction testing at $250 \mathrm{~Hz}$ through $8000 \mathrm{~Hz}$. A standard clinical set of earphones (Telephonics, Model TDH-39) encased in foam rubber cushions (Acoustic Research, Model MX-4I/AR) delivered these air conducted stimuli. A standard clinical bone conduction oscillator (Radioear, Model B-خ2) presented all mastoid stimuli.

Speech stimuli were delivered through the Maico audiometer (Model MA-22). Live voice was presented through the standard speech channel and pre-recorded Spanish material was delivered to the audiometer by a cassette tape recorder 
(Superscope, Model CD-301A) through the tape input channel. The tape recording was calibrated to the audiometer VU meter by means of a $1000 \mathrm{~Hz}$ tone.

A Teledyne Impedance Bridge (Model TA-3D) was employed for all tympanometry and acoustic reflex testing. An adjustable headband held both an impedance measurement earprobe and a TDH-39 earphone mounted in an MX-4l/AR cushion.

\section{Calibration}

All conventional audiometric equipment was referenced to ANSI (1969) standards. Biological calibration checks were performed on subjects with normal hearing as a means of insuring continued calibration. The average of these scores were used as norms for both audiometers.

Prior to each period of testing, the impedance bridge was checked for calibration with the test cavity supplied by the manufacturers. Calibration of the bridge was maintained through periodic adjustment of the compliance, with probe tip inserted in the $2 \mathrm{cc}$ and $5 \mathrm{cc}$ couplers.

\section{Test Procedure}

As illustrated in Figure 13, prior to each subject's participation in this study, case histories and blood samples were obtained by staff personnel from the University of Costa Rica. Subjects were then given otoscopic examinations to determine the physical condition of their ear canals.

Before audiometric evaluation, each subject was informed of the test procedure by a spanish interpreter. Subjects 


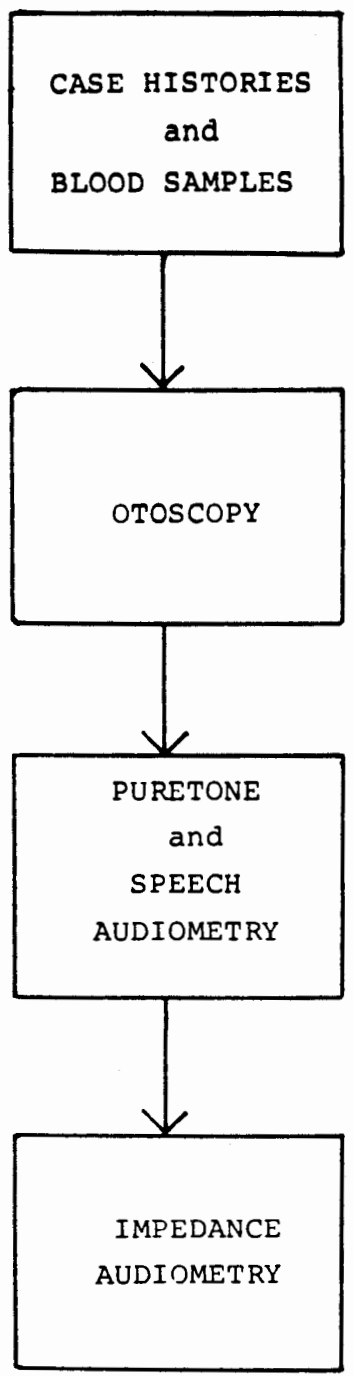

Figure 13. Block diagram of the test procedure utilized in this study.

were allowed to ask any questions concerning the test battery and were given the opportunity to practice the required tasks. Throughout the assessment, subjects were seated at a 90 degree angle from the examiner.

On a standard clinical audiometer, the modified HughsonWestlake technique (Carhart and Jerger, 1959) was used to 
obtain puretone air and bone conduction thresholds. Frequencies tested by air conduction included $250 \mathrm{~Hz}, 500 \mathrm{~Hz}$, $1000 \mathrm{~Hz}, 2000 \mathrm{~Hz}, 3000 \mathrm{~Hz}, 4000 \mathrm{~Hz}, 6000 \mathrm{~Hz}$, and $8000 \mathrm{~Hz}$. Frequencies tested by bone conduction included $250 \mathrm{~Hz}, 500 \mathrm{~Hz}$, $1000 \mathrm{~Hz}, 2000 \mathrm{~Hz}, 3000 \mathrm{~Hz}$, and $4000 \mathrm{~Hz}$.

Speech discrimination ability was determined at Most Comfortable Listening Level (MCL) or at maximum output of the audiometer (100 dBHL), as appropriate. Speech test material consisted of a pre-recorded cassette tape containing 50 mono- and bisyllabic Spanish words (Auditory Test Tape \#3, J.M. Tato, Buenos Aires, Argentina). Subject's verbal responses were monitored and recorded in writing by an interpreter.

For tympanometry measurements, an air-tight seal was established in the ear canal, then air pressure was varied from $-200 \mathrm{~mm} / \mathrm{H}_{2} \mathrm{O}$ to $+200 \mathrm{~mm} / \mathrm{H}_{2} \mathrm{O}$. The air pressure in the ear canal was then reduced to the point of maximum compliance of the tympanic membrane, and acoustic reflex thresholds were obtained. The frequencies tested contralaterally included $250 \mathrm{~Hz}, 500 \mathrm{~Hz}, 1000 \mathrm{~Hz}, 2000 \mathrm{~Hz}, 3000 \mathrm{~Hz}$, and $4000 \mathrm{~Hz}$. Ipsilateral reflexes were measured at $1000 \mathrm{~Hz}$ and $2000 \mathrm{~Hz}$. The presentation of test stimuli was adjusted in $5 \mathrm{~dB}$ SPL increments until the lowest level causing a $-.02 \mathrm{cc}$ deflection was observed on the digital display. Acoustic reflex decay testing was accomplished at $500 \mathrm{~Hz}, 1000 \mathrm{~Hz}$, and $2000 \mathrm{~Hz}$. 
Additional Testing

When appropriate, additional testing was administered to selected subjects. Ling's 5-sound test (Ling, 1978), involving the detection and/or discrimination of the phonemes $/ a /, / \mathrm{u} /, / \mathrm{i} /, / \mathrm{S} /$, and $/ \mathrm{s} /$ was given to 25 individuals. All five sounds appear frequently in the Spanish language and are highly familiar in everyday usage in spoken Spanish. Each phoneme was delivered three times in random order by monitored live voice to each ear at MCL. With adequate rehearsal, but no visual cues, subjects were asked to repeat each sound under earphones. To supplement previously collected data for site of lesion, the Rosenberg Tone Decay Test (Rosenberg, 1958) was administered to three subjects at $5 \mathrm{dBSL}$ for $500 \mathrm{~Hz}$ and $1000 \mathrm{~Hz}$. 


\section{CHAPTER IV}

\section{RESULTS}

\section{Genetic Laboratory Tests and Case}

\section{History Documentation}

During the present investigation, genetic laboratory analysis and case history documentation were obtained from members of the Monge family by staff personnel from the University of Costa Rica. Test findings indicated Monge deafness is genetically transmitted by a simple Mendelian autosomal dominant mutation with complete penetrance and no associated abnormalities.

As illustrated in the most recent documented Monge pedigree, Figure 14 (León, 1982), and as previously described in Chapter II, dominant transmission is characterized by a consistent pattern of affected individuals identified across several generations. Autosomal inheritance is suggested by the equal number of affected males to affected females. The sex of the carrier parent or affected offspring does not influence the dominantly inherited pattern. The genetic mutation is of complete penetrance, a characteristic common to autosomal dominant transmission. All identified Monge carriers exhibited a hearing loss to some degree, as well as having a similarly affected parent. 


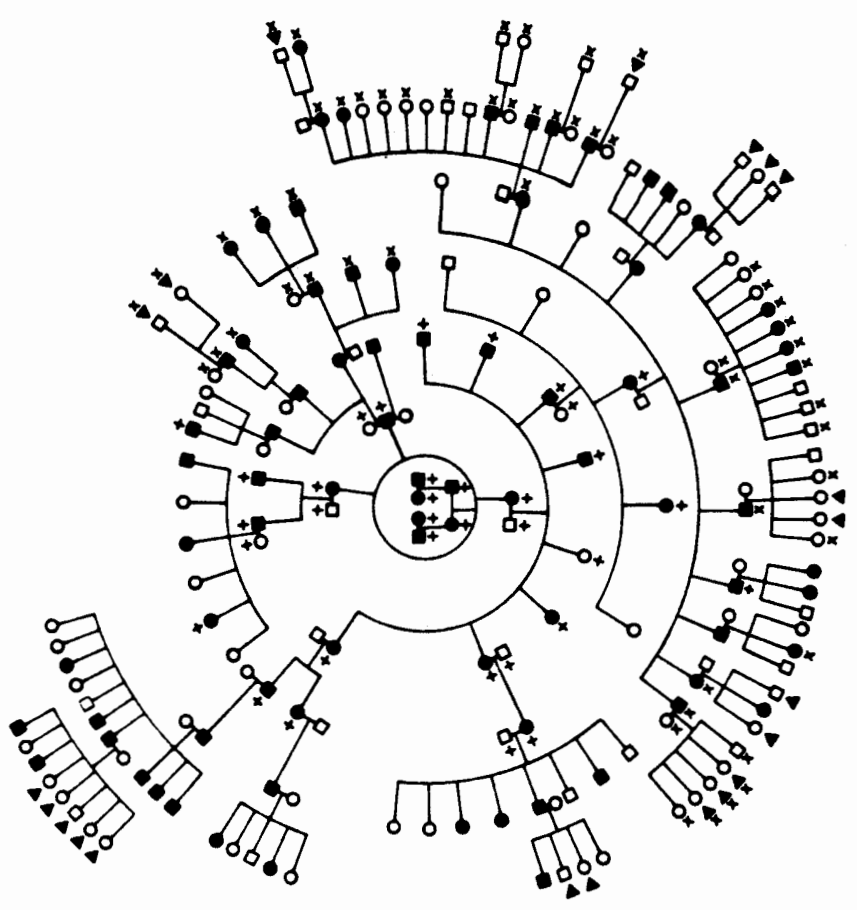

Figure 14. Current Monge family pedigree, indicating the individuals (X) for whom audiological data has been obtained. Triangles denote children under the age of onset; circles (females) and squares (males) with an asterisk representing individuals whose auditory status is unknown; solid squares or circles indicate deaf, and crosses designate deceased individuals (León, 1982).

\section{Audiological Characteristics}

Analysis of the audiological characteristics demonstrated by members of the Monge family revealed a recognizable profile for autosomal dominant low frequency sensorineural hearing loss. Although very similar to other types of inherited low frequency sensorineural impairment, Monge deafness is not identical to any hearing loss described in previously cited investigations.

Identification was determined in part by results 
obtained through the administration of several audiometric measurements including: (1) puretone air and bone conduction thresholds, (2) speech discrimination scores, (3) tone decay tests, (4) tympanometry, (5) acoustic reflex thresholds, (6) acoustic reflex decay tests, and (7) Ling's 5-sound test.

Audiological test findings were gathered from both the present investigation, as well as data collected in previous studies (León et al., 1981; Maurer, 1981). As seen in Table I, the sample population was divided into 3 groups: Control (unaffected), Experimental I (affected-present study), and Experimental II (affected-previous studies). The twelve members of the Control Group and twenty-five subjects from Experimental Group I satisfied inclusion criteria for the present investigation, as described in Chapter III. Data obtained on the twenty-seven individuals in Experimental Group II were included on the basis of genetic confirmation and the

TABLE I

POPULATION COMPARISONS BETWEEN CONTROL GROUP AND EXPERIMENTAL GROUPS I AND II

\begin{tabular}{lccccccc}
\hline & $\begin{array}{c}\text { Sample } \\
\text { Number } \\
(\mathrm{N})\end{array}$ & \multicolumn{2}{c}{ Sex } & & $\begin{array}{c}\text { Mean } \\
\text { Age } \\
\text { (years) }\end{array}$ & $\begin{array}{c}\text { Standard } \\
\text { Deviation } \\
\text { (SD) }\end{array}$ & $\begin{array}{c}\text { Age } \\
\text { Range } \\
\text { (years) }\end{array}$ \\
\cline { 2 - 7 } & 12 & 4 & 8 & 21.25 & 12.96 & $7-44$ \\
$\begin{array}{c}\text { CONTROL GROUP } \\
\text { EXPERIMENTAL } \\
\text { GROUP I } \\
\begin{array}{c}\text { EXPERIMENTAL } \\
\text { GROUP II }\end{array}\end{array}$ & 25 & 11 & 14 & 31.60 & 16.40 & $6-68$ \\
\hline
\end{tabular}


presence of an audiometrically measured sensorineural hearing loss.

Puretone air and bone conduction thresholds for the Control Group and Experimental Groups were measured at standard clinical frequencies in $5 \mathrm{dBHL}$ increments. For purposes of statistical analysis, those subjects who did not respond to intensity levels at maximum output of the audiometer (Appendix A), were assigned a decibel loss of 5 dBHL greater than the highest level generated at each test frequency, in accordance with Sank (1967).

Air conduction Hearing Threshold Levels (HTL) obtained from each group are summarized in Tables II (Control), III (Experimental I), and IV (Experimental II), with the mean HTL's, the standard deviation, and median presented for each frequency. As illustrated in Figure 15, a marked difference in the mean HTL's was observed when comparisons were made

\section{TABLE II}

PURETONE AIR CONDUCTION HEARING THRESHOLD

LEVELS FOR CONTROL GROUP

\begin{tabular}{l|cccccccc}
\hline \multicolumn{7}{c}{ Frequency } \\
\cline { 2 - 8 } & $250 \mathrm{~Hz}$ & $500 \mathrm{~Hz}$ & $1000 \mathrm{~Hz}$ & $2000 \mathrm{~Hz}$ & $3000 \mathrm{~Hz}$ & $4000 \mathrm{~Hz}$ & $6000 \mathrm{~Hz}$ & $8000 \mathrm{~Hz}$ \\
\cline { 2 - 8 } N (ears) & 24 & 24 & 24 & 24 & 15 & 23 & 21 & 24 \\
$\bar{X}$ HTL (dB) & 7.08 & 8.12 & 7.29 & 4.16 & 3.00 & 11.30 & 13.09 & 11.45 \\
Standard \\
$\begin{array}{l}\text { Deviation } \\
\text { Median }\end{array}$
\end{tabular}


TABLE III

PURETONE AIR CONDUCTION HEARING THRESHOLD LEVELS FOR EXPERIMENTAL GROUP I

\begin{tabular}{|c|c|c|c|c|c|c|c|c|}
\hline \multirow[b]{3}{*}{ N (ears) } & \multicolumn{8}{|c|}{ Frequency } \\
\hline & $250 \mathrm{~Hz}$ & $500 \mathrm{~Hz}$ & $1000 \mathrm{~Hz}$ & $2000 \mathrm{~Hz}$ & $3000 \mathrm{~Hz}$ & $4000 \mathrm{~Hz}$ & $6000 \mathrm{~Hz}$ & $8000 \mathrm{~Hz}$ \\
\hline & 48 & 48 & 48 & 48 & 44 & 48 & 47 & 47 \\
\hline$\overline{\mathrm{X}}$ HTL (dB) & 74.27 & 80.62 & 80.83 & 73.75 & 68.63 & 71.77 & 68.40 & 66.17 \\
\hline $\begin{array}{l}\text { Standard } \\
\text { Deviation }\end{array}$ & 24.96 & 28.31 & 31.92 & 34.71 & 38.28 & 38.77 & 33.57 & 37.24 \\
\hline Median & 87.5 & 92.5 & 92.5 & 92.5 & 87.5 & 92.5 & 95.0 & 90.0 \\
\hline
\end{tabular}

TABIE IV

PURETONE AIR CONDUCTION HEARING THRESHOLD LEVELS FOR EXPERIMENTAL GROUP II

\begin{tabular}{|c|c|c|c|c|c|c|c|c|}
\hline & \multicolumn{8}{|c|}{ Frequency } \\
\hline & $250 \mathrm{~Hz}$ & $500 \mathrm{~Hz}$ & $1000 \mathrm{~Hz}$ & $2000 \mathrm{~Hz}$ & $3000 \mathrm{~Hz}$ & $4000 \mathrm{~Hz}$ & $6000 \mathrm{~Hz}$ & $8000 \mathrm{~Hz}$ \\
\hline N (ears) & 49 & 52 & 51 & 50 & 30 & 46 & 26 & 50 \\
\hline$\overline{\mathbf{x}}$ нтL (dB) & 76.73 & 82.69 & 79.21 & 72.00 & 61.16 & 65.43 & 66.73 & 65.00 \\
\hline $\begin{array}{l}\text { Standard } \\
\text { Deviation }\end{array}$ & 18.52 & 23.97 & 27.26 & 31.02 & 35.20 & 40.50 & 37.14 & 33.82 \\
\hline Median & 80 & 77.5 & 85 & 80 & 77.5 & 77.5 & 95 & 85 \\
\hline
\end{tabular}




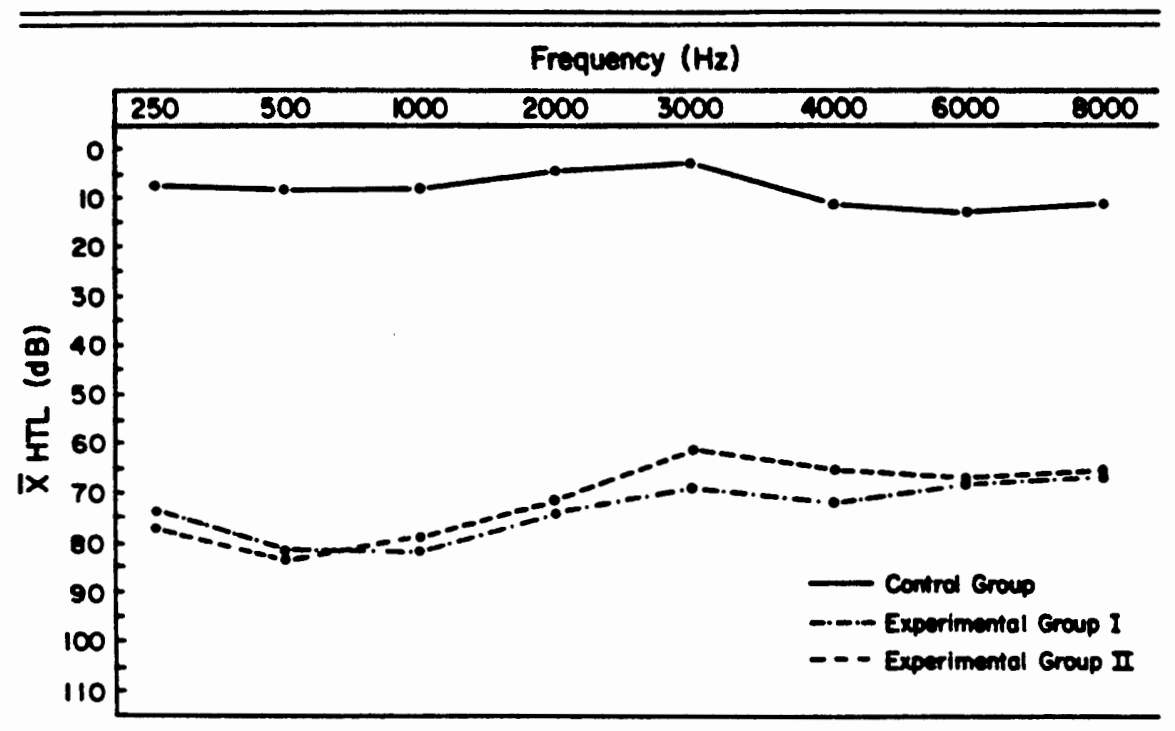

Figure 15. Puretone air conduction Hearing Threshold Levels for Control Group and Experimental Groups $I$ and II.

between the Control Group and the two Experimental Groups. Puretone air and bone conduction thresholds demonstrated by the Control Group were within normal limits for all test frequencies. Experimental Groups I and II reflected a severe loss in hearing threshold sensitivity across most of the frequency region.

To determine whether there was a significant difference in HTL's between Experimental Group I and Experimental Group II, a t-test for two independent means was calculated for each frequency in agreement with Bruning and Kintz (1968) (Appendix B). At the .01 level of confidence, no significant difference for the mean HTL's between Experimental Group I and Experimental Group II was demonstrated at any test 
frequency (Table V). The data for the two groups were then combined for all subsequent analysis.

\section{TABLE V}

$$
\begin{aligned}
& \text { t-TEST VALUES FOR MEAN HEARING THRESHOLD LEVEL } \\
& \text { DIFFERENCE BETWEEN EXPERIMENTAL } \\
& \text { GROUPS I AND II }
\end{aligned}
$$

\begin{tabular}{|c|c|c|c|c|c|c|c|c|}
\hline \multirow{4}{*}{$\begin{array}{c}\underline{t}^{\star} \\
\mathrm{df}\end{array}$} & \multicolumn{8}{|c|}{ Frequency } \\
\hline & $250 \mathrm{~Hz}$ & $500 \mathrm{~Hz}$ & $1000 \mathrm{~Hz}$ & $2000 \mathrm{~Hz}$ & $3000 \mathrm{~Hz}$ & $4000 \mathrm{~Hz}$ & $6000 \mathrm{~Hz}$ & $8000 \mathrm{~Hz}$ \\
\hline & .023 & .030 & -.001 & -.017 & -.081 & -.067 & -.055 & -.013 \\
\hline & 95 & 98 & 97 & 96 & 72 & 92 & 71 & 95 \\
\hline
\end{tabular}

In order to assess bilateral symmetry within the two Experimental Groups, mean HTL's, standard deviations, and median HTL's for the right ear were compared to those obtained for the left ear, as presented in Table VI. The audiometric configurations for right and left ears were remarkably similar (Figure 16), with the greatest difference found at $4000 \mathrm{~Hz}$, where the mean HTL of the left ear was $6 \mathrm{~dB}$ better than the right. A t-test in accordance with Bruning and Kintz (1968) was again derived at all test frequencies (Appendix B), demonstrating no significant difference between the mean HTL's for right and left ears (Table VII) at the .01 level of confidence. Further computations were therefore based on pooled data for right and left ears. The threshold test data for the Experimental Group 
TABLE VI

COMPARISON OF PURETONE AIR CONDUCTION HEARING

THRESHOLD LEVELS BETWEEN RIGHT AND LEFT

EARS FOR EXPERIMENTAL GROUP

\begin{tabular}{|c|c|c|c|c|c|c|c|c|}
\hline \multirow[b]{3}{*}{$\begin{array}{c}\text { RIGHT EAR } \\
N \text { (ears) }\end{array}$} & \multicolumn{8}{|c|}{ Prequency } \\
\hline & $250 \mathrm{~Hz}$ & $500 \mathrm{~Hz}$ & $1000 \mathrm{~Hz}$ & $2000 \mathrm{~Hz}$ & $3000 \mathrm{~Hz}$ & $4000 \mathrm{~Hz}$ & $6000 \mathrm{~Hz}$ & $8000 \mathrm{~Hz}$ \\
\hline & 47 & 49 & 49 & 49 & 38 & 45 & 36 & 49 \\
\hline $\bar{x}$ HTL (dB) & 75.63 & 82.34 & 79.69 & 73.87 & 65.52 & 71.55 & 69.72 & 65.51 \\
\hline $\begin{array}{l}\text { Standard } \\
\text { Deviation }\end{array}$ & 22.44 & 25.96 & 30.62 & 33.24 & 38.05 & 39.45 & 35.07 & 36.00 \\
\hline median & 87.5 & 90 & 90 & 85 & 77.5 & 85 & 90 & 90 \\
\hline $\begin{array}{l}\text { LEFT EAR } \\
\text { N (ears) }\end{array}$ & 50 & 51 & 50 & 19 & 36 & 49 & 37 & 18 \\
\hline$\overline{\mathbf{x}}$ HTL (dB) & 75.24 & 81.07 & 79.03 & 71.83 & 65.69 & 66.02 & 67.02 & 65.52 \\
\hline $\begin{array}{l}\text { Standard } \\
\text { Deviation }\end{array}$ & 21.40 & 26.34 & 28.46 & 32.49 & 36.39 & 39.85 & 35.71 & 35.10 \\
\hline modian & 80 & 80 & 85 & 80 & 77.5 & 80 & 95 & 87.5 \\
\hline
\end{tabular}

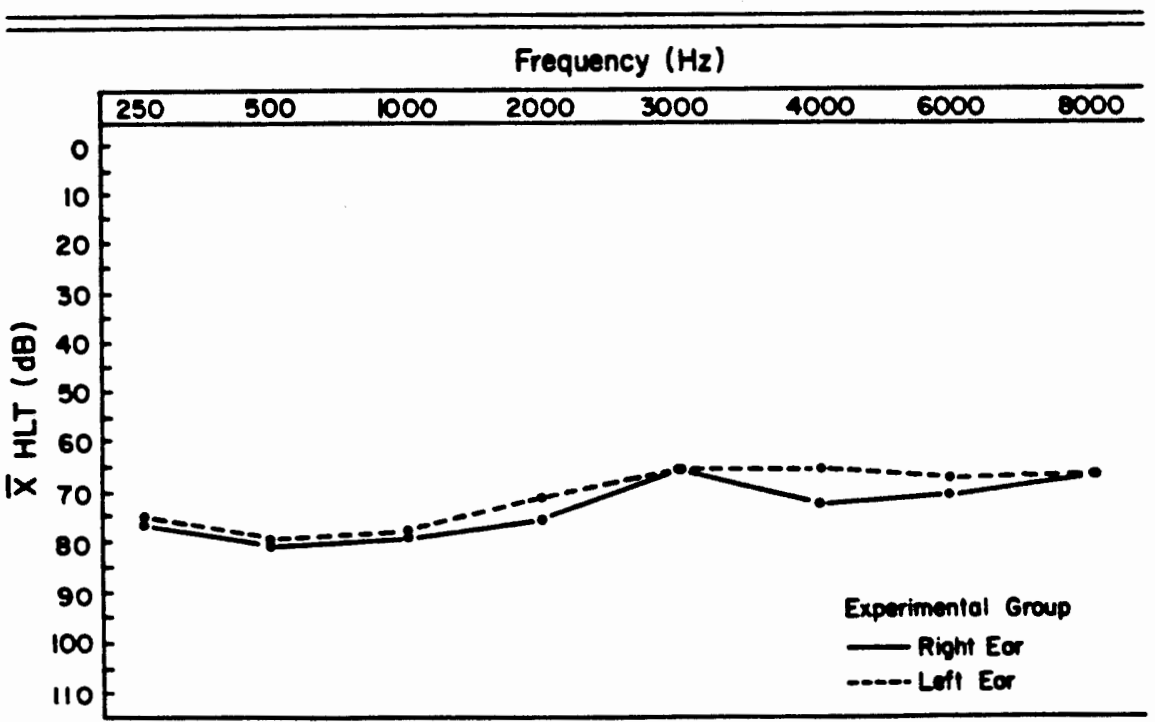

Figure 16. Comparison of puretone air conduction Hearing Threshold Levels between right and left ears for Experimental Group. 
TABLE VII

t-TEST VALUES FOR MEAN HEARING THRESHOLD LEVEL DIFFERENCE BETWEEN RIGHT AND LEFT EARS FOR EXPERIMENTAL GROUP

\begin{tabular}{|c|c|c|c|c|c|c|c|c|}
\hline & \multicolumn{8}{|c|}{ Frequency } \\
\hline & $250 \mathrm{~Hz}$ & $500 \mathrm{~Hz}$ & $1000 \mathrm{~Hz}$ & $2000 \mathrm{~Hz}$ & $3000 \mathrm{~Hz}$ & $4000 \mathrm{~Hz}$ & $6000 \mathrm{~Hz}$ & $8000 \mathrm{~Hz}$ \\
\hline$\underline{t}^{*}$ & .021 & .010 & .060 & -.023 & -.027 & .104 & -.019 & .021 \\
\hline$d f * *$ & 95 & 98 & 97 & 96 & 72 & 92 & 71 & 95 \\
\hline
\end{tabular}

was then divided by sex and calculated for the median and mean HTL's, as well as the standard deviations. Referring to Table VIII and Figure 17, it was revealed that the mean HTL's at all frequencies for males were approximately $18 \mathrm{~dB}$ poorer than for females. This discrepency may be attributed in part to the slightly younger average age of the female group as compared to the male group. However, standard deviations were considerable for both groups, and a t-test for two independent means (ibid.) (Appendix B) demonstrated no significant difference at the .01 level of confidence between sexes at any test frequency (Table IX). Male and female HTL data were then combined for all succeeding statistical analysis. Further investigation lead to the assessment of the relationship between chronological age and mean HTL's. With data arranged by age per decade, comparisons for the average HTL's, the standard deviations, and medians were made between 
TABLE VIII

COMPARISON OF PURETONE AIR CONDUCTION HEARING THRESHOLD LEVLES BETWEEN MALES AND FEMALES FOR EXPERIMENTAL GROUP

\begin{tabular}{|c|c|c|c|c|c|c|c|c|}
\hline \multirow[b]{3}{*}{ muss } & \multicolumn{8}{|c|}{ Prequency } \\
\hline & $250 \mathrm{~Hz}$ & $500 \mathrm{Mz}$ & $1000 \mathrm{~Hz}$ & $2000 \mathrm{~Hz}$ & $3000 \mathrm{~Hz}$ & $4000 \mathrm{~Hz}$ & $6000 \mathrm{~Hz}$ & $8000 \mathrm{~Hz}$ \\
\hline & & & & & & & & \\
\hline a (ears) & 49 & 50 & 49 & 50 & 37 & 46 & 36 & 49 \\
\hline $\bar{x}$ ATL (dB) & 81.83 & 08.00 & 87.44 & 10.70 & 77.29 & 79.67 & 79.02 & 75.61 \\
\hline $\begin{array}{l}\text { Standard } \\
\text { Deviation }\end{array}$ & 17.37 & 22.20 & 25.37 & 29.24 & 34.63 & 37.85 & 29.94 & 31.36 \\
\hline median & 90 & 92.5 & 95 & 92.5 & 85 & 97.5 & 95 & 95 \\
\hline FEMLES & & & & & & & & \\
\hline H (ears) & 48 & 50 & 50 & 48 & 37 & 48 & 37 & 48 \\
\hline $\bar{x}$ aTL (dB) & 69.06 & 74.40 & 71.90 & 64.68 & 54.32 & 58.12 & 56.89 & 55.20 \\
\hline $\begin{array}{l}\text { Standard } \\
\text { Deviation }\end{array}$ & 24.18 & 27.36 & 31.41 & 34.32 & 35.39 & 38.61 & 35.77 & 36.55 \\
\hline median & 77.5 & 77.5 & 77.5 & 77.5 & 57.5 & 57.5 & 45 & 42.5 \\
\hline
\end{tabular}

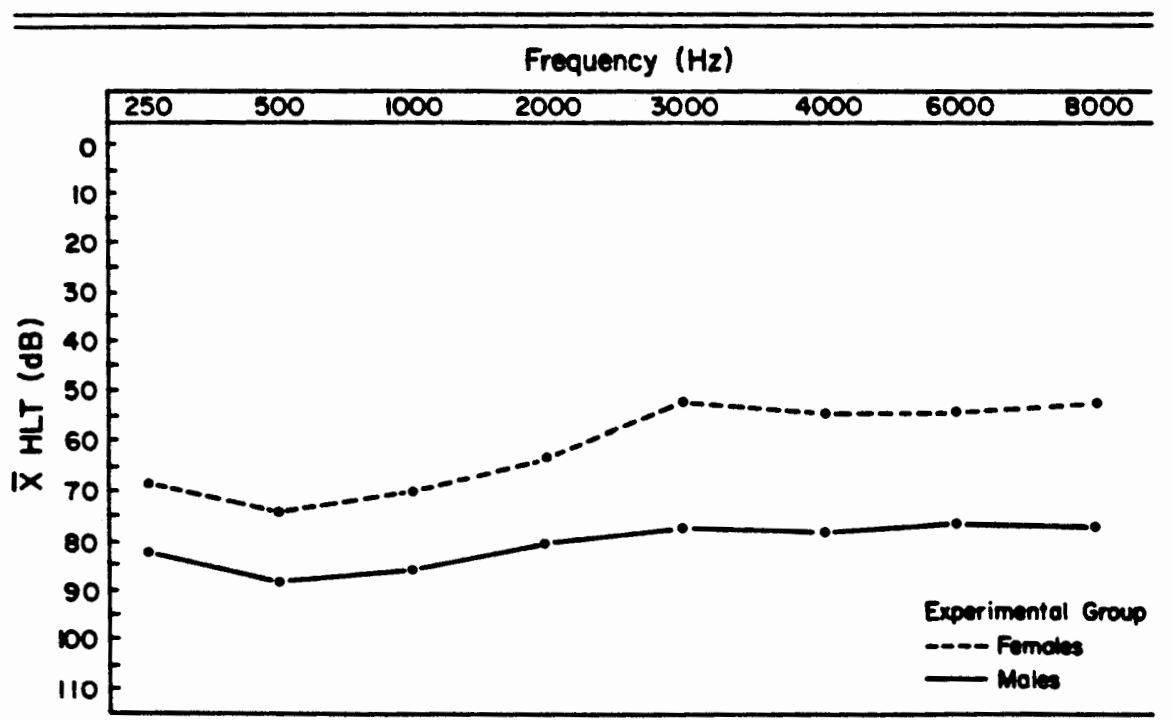

Figure 17. Comparison of puretone air conduction Hearing Threshold Levels between males and females for Experimental Group. 
TABLE IX

t-TEST VALUES FOR MEAN HEARING THRESHOLD LEVEL DIFFERENCE BETWEEN MALES AND FEMALES

FOR EXPERIMENTAL GROUP

\begin{tabular}{|c|c|c|c|c|c|c|c|c|}
\hline & & \multicolumn{7}{|c|}{ Frequency } \\
\hline & $250 \mathrm{~Hz}$ & $500 \mathrm{~Hz}$ & $1000 \mathrm{~Hz}$ & $2000 \mathrm{~Hz}$ & $3000 \mathrm{~Hz}$ & $4000 \mathrm{~Hz}$ & $6000 \mathrm{~Hz}$ & $8000 \mathrm{~Hz}$ \\
\hline$\underline{t}^{\star}$ & -.136 & -.098 & -.138 & -.183 & -.288 & -.245 & .267 & -.200 \\
\hline$d f \star \star$ & 95 & 98 & 97 & 96 & 72 & 92 & 71 & 95 \\
\hline
\end{tabular}

the Control Group (Table X) and the Experimental Group (Table XI). The Control Group as illustrated in Figure 18, demonstrated rather stable thresholds with no average HTL greater than $25 \mathrm{~dB}$ at any test frequency, regardless of age.

The Experimental Group (Figure 19) exhibited a positive relationship between age and HTL's in that, as age increased, HTL's similarly increased. Puretone air and bone conduction test results indicated that during the first and second decades of life, affected subjects sustained a mild to moderate sensorineural hearing loss through $1000 \mathrm{~Hz}(\overline{\mathrm{X}} \mathrm{APT}=47 \mathrm{dBHL})$, sloping upward to normal or near normal thresholds for higher frequencies. As seen in Figure 20, by the end of adolescence, the rate of progression, $6 \mathrm{dBHL} /$ decade, rapidly increased to $41 \mathrm{dBHL} /$ decade, with frequencies at $2000 \mathrm{~Hz}$ and above most affected in the change. By age 30 , thresholds were at severe levels across the entire frequency range $(\overline{\mathrm{X}} \mathrm{APT}=83 \mathrm{dBHL})$. 
TABLE X

PURETONE AIR CONDUCTION HEARING THRESHOLD LEVELS

AS A FUNCTION OF AGE FOR CONTROL GROUP

\begin{tabular}{|c|c|c|c|c|c|c|c|c|}
\hline \multirow[b]{3}{*}{$0-10$ Years } & \multicolumn{8}{|c|}{ Frequency } \\
\hline & $250 \mathrm{~Hz}$ & $500 \mathrm{~Hz}$ & $1000 \mathrm{~Hz}$ & $2000 \mathrm{~Hz}$ & $3000 \mathrm{~Hz}$ & $4000 \mathrm{~Hz}$ & $6000 \mathrm{~Hz}$ & $8000 \mathrm{~Hz}$ \\
\hline & & & & & & & & \\
\hline N (ears) & 8 & 8 & 8 & 8 & 5 & 7 & 8 & 8 \\
\hline $\bar{X}$ HTL $(d B)$ & 6.87 & 10.00 & 8.12 & 3.12 & 3.00 & 10.71 & 13.12 & 10.62 \\
\hline $\begin{array}{l}\text { Standard } \\
\text { Deviation }\end{array}$ & 2.58 & 7.55 & 7.52 & 2.58 & 4.47 & 4.49 & 13.07 & 10.50 \\
\hline Median & 7.5 & 12.5 & 10.0 & 5.0 & 0 & 10.0 & 12.5 & 10.0 \\
\hline $11-20$ Years & & & & & & & & \\
\hline $\mathrm{N}$ (ears) & 4 & 4 & 4 & 4 & 4 & 4 & 4 & 4 \\
\hline $\bar{X}$ HTL (dB) & 5.00 & 7.50 & 6.25 & 0 & 0 & 1.25 & 16.25 & 5.00 \\
\hline $\begin{array}{l}\text { Standard } \\
\text { Deviation }\end{array}$ & 5.77 & 2.88 & 6.29 & 0 & 0 & 2.50 & 6.29 & 5.77 \\
\hline Median & 5.0 & 7.5 & 10.0 & 0 & 0 & 2.5 & 20.0 & 5.0 \\
\hline 21-30 Years & & & & & & & & \\
\hline$N$ (ears) & 6 & 6 & 6 & 6 & 6 & 6 & 6 & 6 \\
\hline$\overline{\mathrm{x}}$ нTL (dB) & 7.50 & 6.66 & 5.00 & 5.83 & 5.00 & 10.83 & 10.00 & 5.00 \\
\hline $\begin{array}{l}\text { Standard } \\
\text { Deviation }\end{array}$ & 9.35 & 9.30 & 4.47 & 5.84 & 6.32 & 10.68 & 8.94 & 8.36 \\
\hline Median & 7.5 & 15.0 & 7.5 & 7.5 & 2.5 & 7.5 & 7.5 & 5.0 \\
\hline $31+$ Years & & & & & & & & \\
\hline N (ears) & 6 & 6 & 6 & 6 & 0 & 6 & 3 & 6 \\
\hline$\overline{\mathrm{x}}$ HTL (dB) & 8.33 & 7.50 & 9.16 & 6.66 & & 19.16 & 15.00 & 23.33 \\
\hline $\begin{array}{l}\text { Standard } \\
\text { Deviation }\end{array}$ & 5.16 & 5.24 & 7.35 & 5.16 & & 7.35 & 13.22 & 10.32 \\
\hline Median & 12.5 & 7.5 & 12.5 & 7.5 & & 17.5 & 10.0 & 25.0 \\
\hline
\end{tabular}

For the next 10 years, the rate of progression slowed to approximately $17 \mathrm{dBHL} /$ decade, resulting in a flat profound hearing loss $(\overline{\mathrm{X}} \mathrm{APT}=100 \mathrm{dBHL})$ by age 40 .

The Average Puretone Thresholds (APT) presented in Table XII further exemplify the progressive nature of the disorder, declining from a mild hearing loss during ahildhood to a profound loss of hearing sensitivity beyond the age of 
TABLE XI

PURETONE AIR CONDUCTION HEARING THRESHOLD LEVELS AS A FUNCTION OF AGE FOR EXPERIMENTAL GROUP

\begin{tabular}{|c|c|c|c|c|c|c|c|c|}
\hline \multirow[b]{3}{*}{$0-10$ Years } & \multicolumn{8}{|c|}{ Frequency } \\
\hline & $250 \mathrm{~Hz}$ & $500 \mathrm{~Hz}$ & $1000 \mathrm{~Hz}$ & $2000 \mathrm{~Hz}$ & $3000 \mathrm{~Hz}$ & $4000 \mathrm{~Hz}$ & $6000 \mathrm{~Hz}$ & $8000 \mathrm{~Hz}$ \\
\hline & & & & & & & & \\
\hline N (ears) & 11 & 12 & 12 & 11 & 9 & 11 & 7 & 12 \\
\hline$\overline{\mathrm{X}}$ HTL (dB) & 52.72 & 51.25 & 40.83 & 29.54 & 22.77 & 20.00 & 21.42 & 25.83 \\
\hline $\begin{array}{l}\text { Standard } \\
\text { Deviation }\end{array}$ & 24.42 & 26.63 & 29.98 & 24.84 & 21.37 & 15.81 & 15.99 & 12.58 \\
\hline Median & 60 & 62.5 & 52.5 & 40 & 35 & 20 & 20 & 27.5 \\
\hline \multicolumn{9}{|l|}{$11-20$ Years } \\
\hline N (ears) & 24 & 24 & 23 & 23 & 20 & 22 & 16 & 23 \\
\hline$\overline{\mathrm{x}} \mathrm{HTL}$ ( $\mathrm{AB})$ & 58.53 & 60.41 & 55.65 & 39.13 & 27.00 & 24.77 & 20.62 & 24.56 \\
\hline $\begin{array}{l}\text { Standard } \\
\text { Deviation }\end{array}$ & 21.49 & 22.59 & 23.65 & 21.72 & 21.66 & 19.90 & 12.76 & 22.35 \\
\hline Median & 60 & 65 & 55 & 35 & 25 & 20 & 20 & 15 \\
\hline \multicolumn{9}{|l|}{$21-30$ Years } \\
\hline N (ears) & 19 & 20 & 20 & 20 & 15 & 18 & 16 & 19 \\
\hline$\overline{\mathrm{X}}$ HTL (dB) & 75.52 & 83.00 & 84.25 & 82.50 & 81.00 & 75.83 & 80.93 & 76.84 \\
\hline $\begin{array}{l}\text { Standard } \\
\text { Deviation }\end{array}$ & 15.17 & 16.00 & 17.86 & 20.74 & 13.91 & 29.66 & 20.01 & 26.83 \\
\hline Median & 80 & 80 & 85 & 87.5 & 80 & 80 & 92.5 & 90 \\
\hline \multicolumn{9}{|l|}{$31-40$ Years } \\
\hline N (ears) & 23 & 24 & 24 & 24 & 14 & 23 & 16 & 21 \\
\hline$\overline{\mathrm{x}}$ H'L (dB) & 90.86 & 100.20 & 99.58 & 96.66 & 97.85 & 101.52 & 94.37 & 88.57 \\
\hline $\begin{array}{l}\text { Standard } \\
\text { Deviation }\end{array}$ & 6.68 & 10.15 & 11.50 & 9.28 & 11.55 & 9.58 & 2.50 & 20.86 \\
\hline Median & 95 & 100 & 100 & 95 & 100 & 100 & 95 & 95 \\
\hline \multicolumn{9}{|l|}{$41+$ Years } \\
\hline N (ears) & 20 & 20 & 20 & 20 & 16 & 20 & 18 & 20 \\
\hline$\overline{\mathrm{X}}$ нTL (dB) & 90.75 & 99.50 & 101.75 & 97.25 & 95.31 & 99.50 & 92.50 & 94.50 \\
\hline $\begin{array}{l}\text { Standard } \\
\text { Deviation }\end{array}$ & 6.12 & 10.50 & 12.27 & 11.86 & 17.07 & 15.29 & 6.00 & 1.53 \\
\hline Median & 95 & 100 & 105 & 95 & 107.5 & 100 & 95 & 95 \\
\hline
\end{tabular}




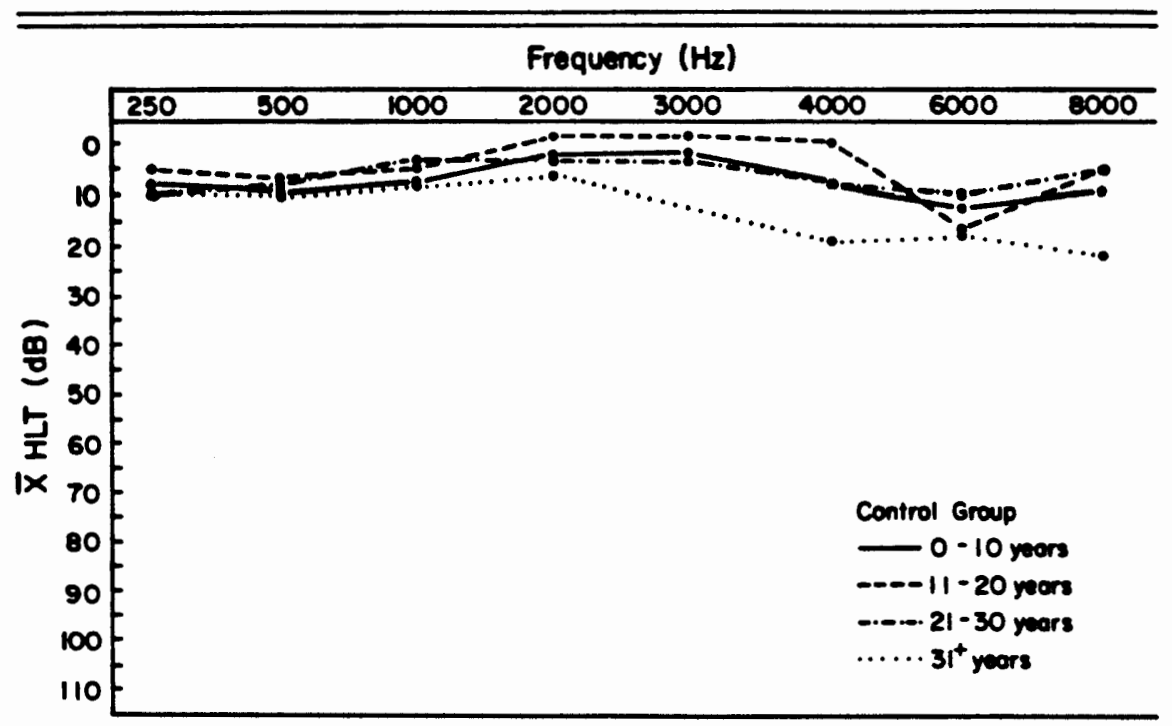

Figure 18. Puretone air conduction Hearing Threshold Levels as a function of age for Control Group.

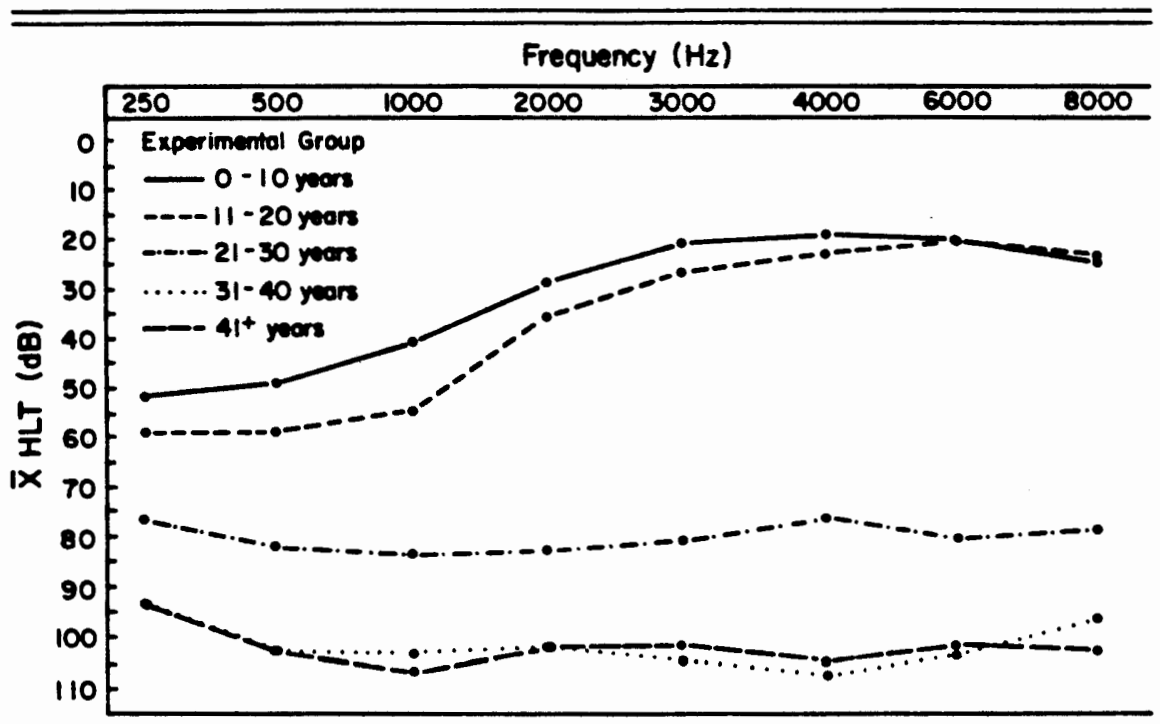

Figure 19. Puretone air conduction Hearing Threshold Levels as a function of age for Experimental Group. 


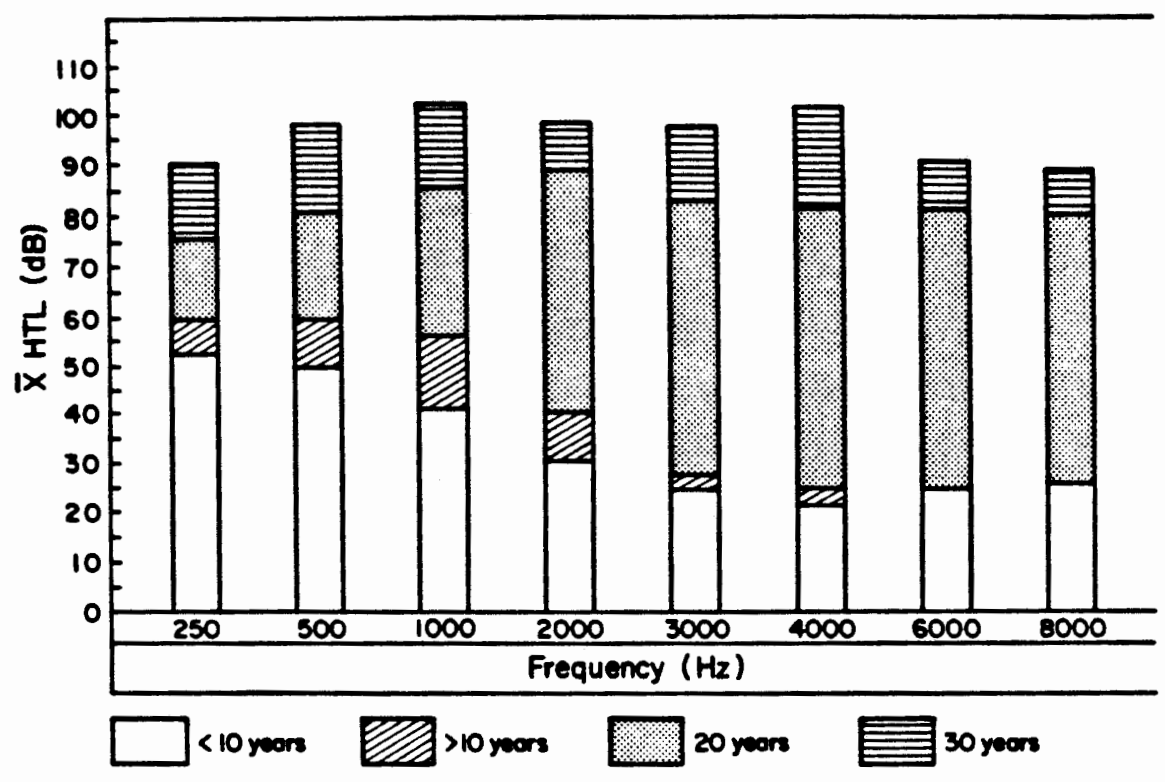

Figure 20. The amount of decibel loss for each frequency as a function of age for Experimental Group. Note: Subjects 10 years and younger, demonstrate greatest hearing loss for $250 \mathrm{~Hz}$ and $500 \mathrm{~Hz}$, while those 20 to 30 years old, show evidence of rapid progression of loss culminating in profound deafness after age 30 .

\section{TABLE XII}

MEAN AVERAGE PURETONE THRESHOLDS AS A FUNCTION OF AGE FOR EXPERIMENTAL GROUP

\begin{tabular}{ccc} 
Age (years) & Sample (ears) & APT (dBHL) \\
\hline $0-10$ & 12 & 41 \\
$11-20$ & 24 & 52 \\
$21-30$ & 20 & 83 \\
$31-40$ & 24 & 99 \\
$41+$ & 20 & 100
\end{tabular}


30. When the APT was delineated by sex, both males and females demonstrated similar thresholds for each age group, as depicted in the histogram in Figure 21.

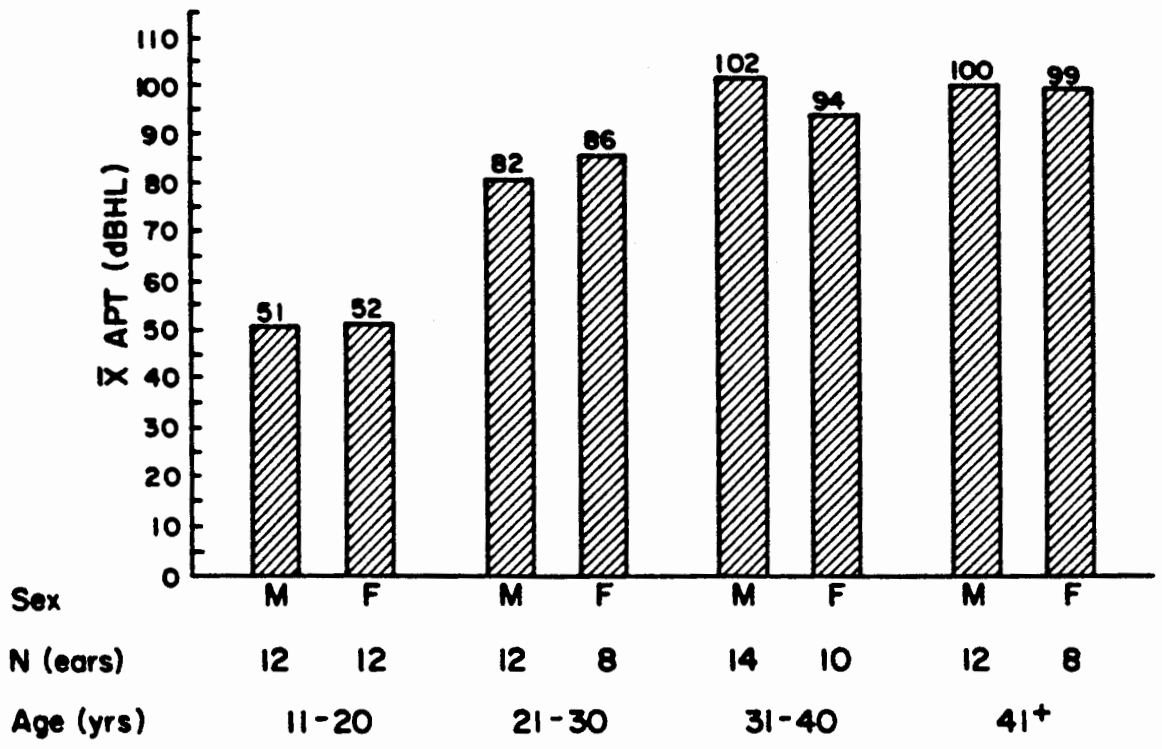

Figure 21. Comparison of Average Puretone Thresholds as a function of age between males and females for the Experimental Group.

To determine the strength of association between the subject's chronological age and HTL, a Pearson Product-Moment Correlation equation was calculated on a Honeywell Level 66 GCos computer, utilizing the sPSS Batch system by Nie, Hull, Jenkins, Steinbrenner, and Bent (1975) and updated by Hull and Nie (1981). The Pearson $r$ and $r^{2}$ values for each frequency are presented in Table XIII. In accordance with silverman's 1977 classification, the strength of the relationship between age and HTL's is considered moderately linear for most frequencies, except at $250 \mathrm{~Hz}$ and $500 \mathrm{~Hz}$, where weak 


\section{TABLE XIII}

PEARSON $r$ AND $r^{2}$ VALUES FOR THE DEGREE

OF ASSOCIATION BETWEEN AGE AND

HEARING THRESHOLD LEVELS

FOR EXPERIMENTAL GROUP

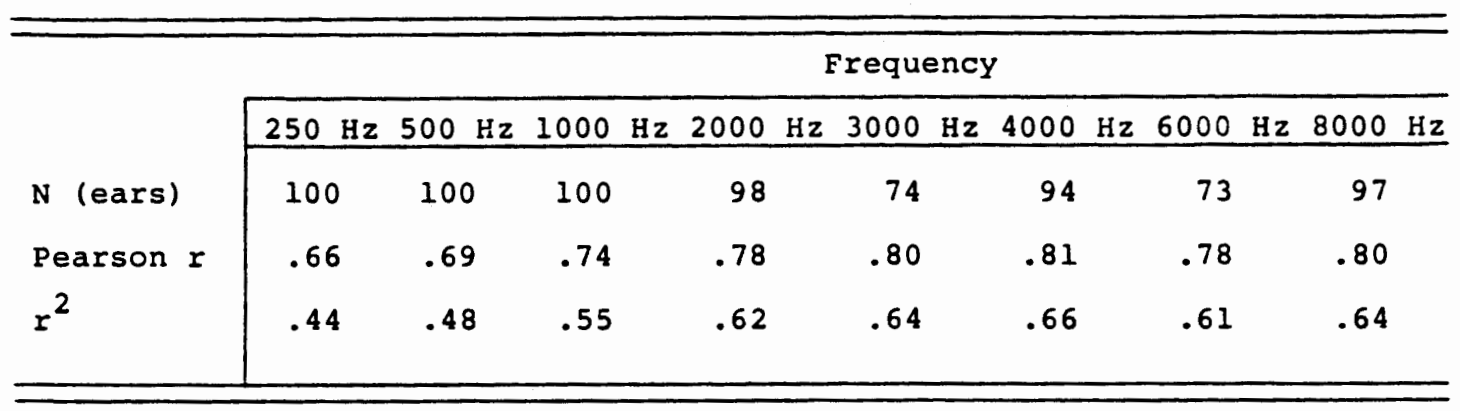

linearity was indicated when derived by $r^{2}$. This is primarily associated with the fact that younger age children demonstrate the greatest variance in HTI's at these lower frequencies.

To examine firther the variation found in thresholds for subjects below the age of 25 , audiometric test data were grouped into 7 different family branches. As illustrated in Figure 22, with age and sex held constant, mean puretone thresholds were found to vary markedly from one family to another, but as age increased, branches became more homogeneous in the sense that older family members demonstrated similar audiometric patterns (Figure 23). Comparison of HTL's between siblings from the same family branch revealed similar puretone configurations, as illustrated by Figure 24 .

Averaged speech discrimination scores were compared to the mean APT, as presented in Table XIV. An inverse 


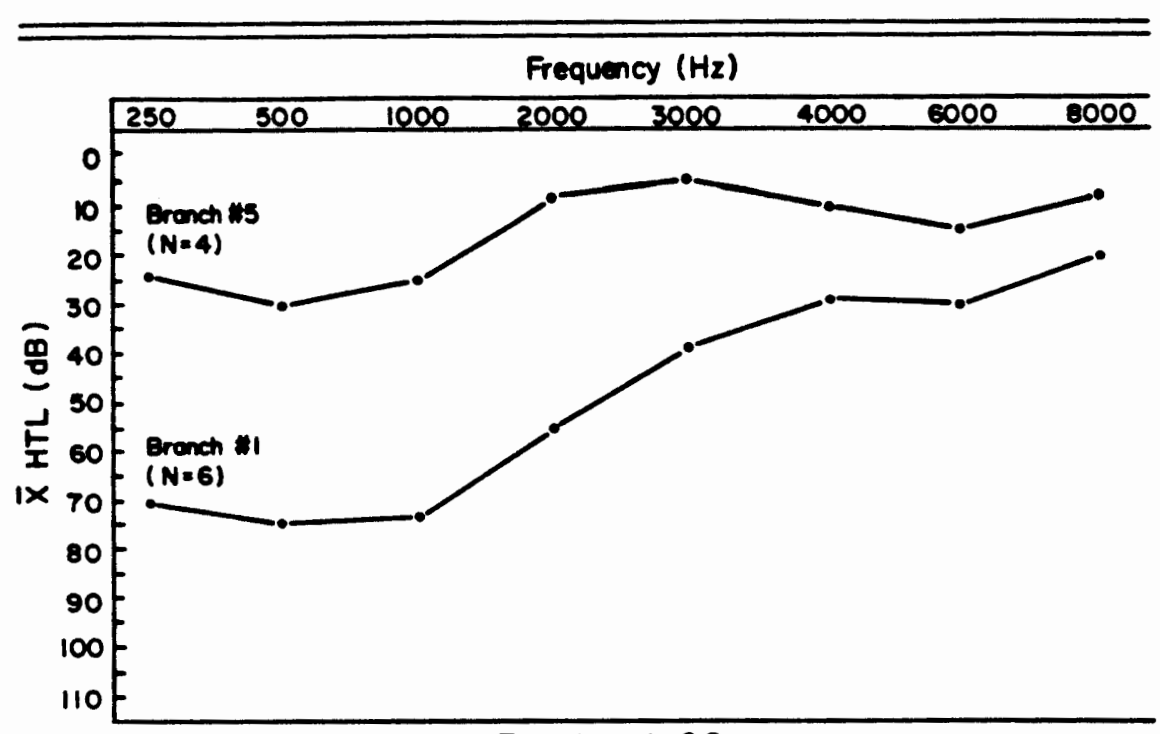

a. Female $11-20$ years

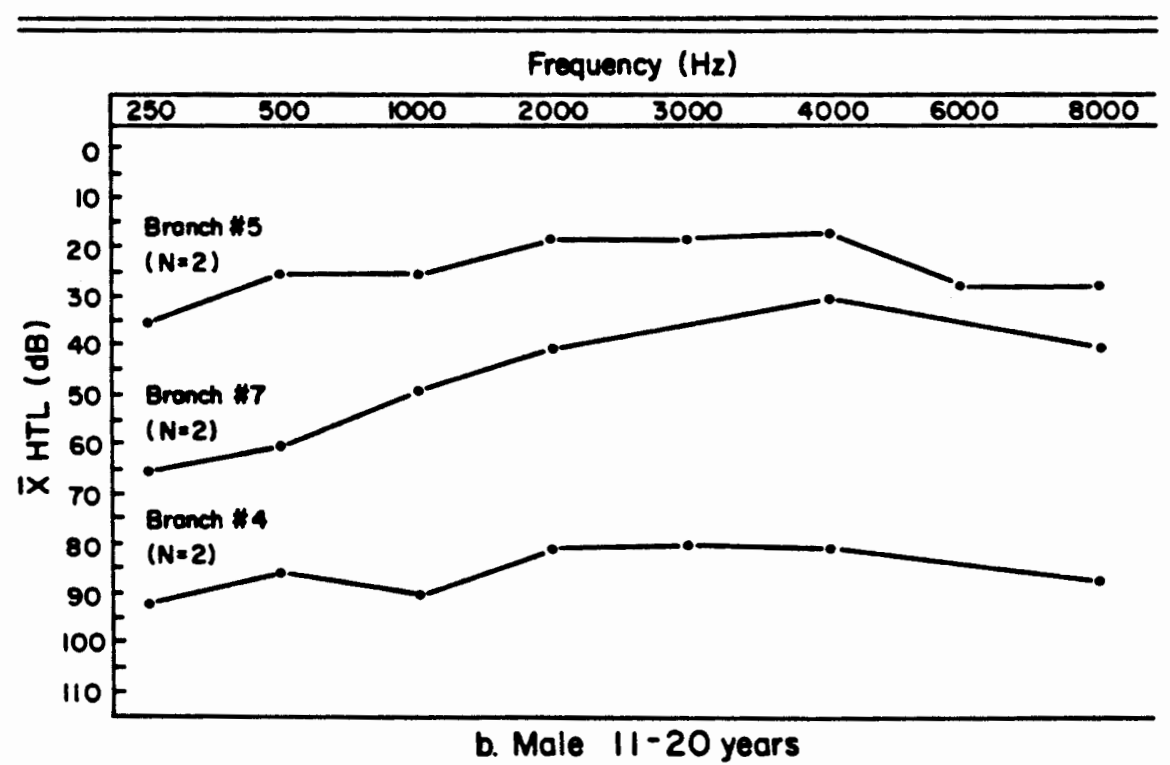

Figure 22. Comparison of puretone air conduction Hearing Threshold Levels for different family branches.

relationship was demonstrated between the two measures, with speech discrimination ability expectedly decreasing as the APT increased. Speech discrimination scores decreased approximately 12 percent/decade through age 30; however, as the 


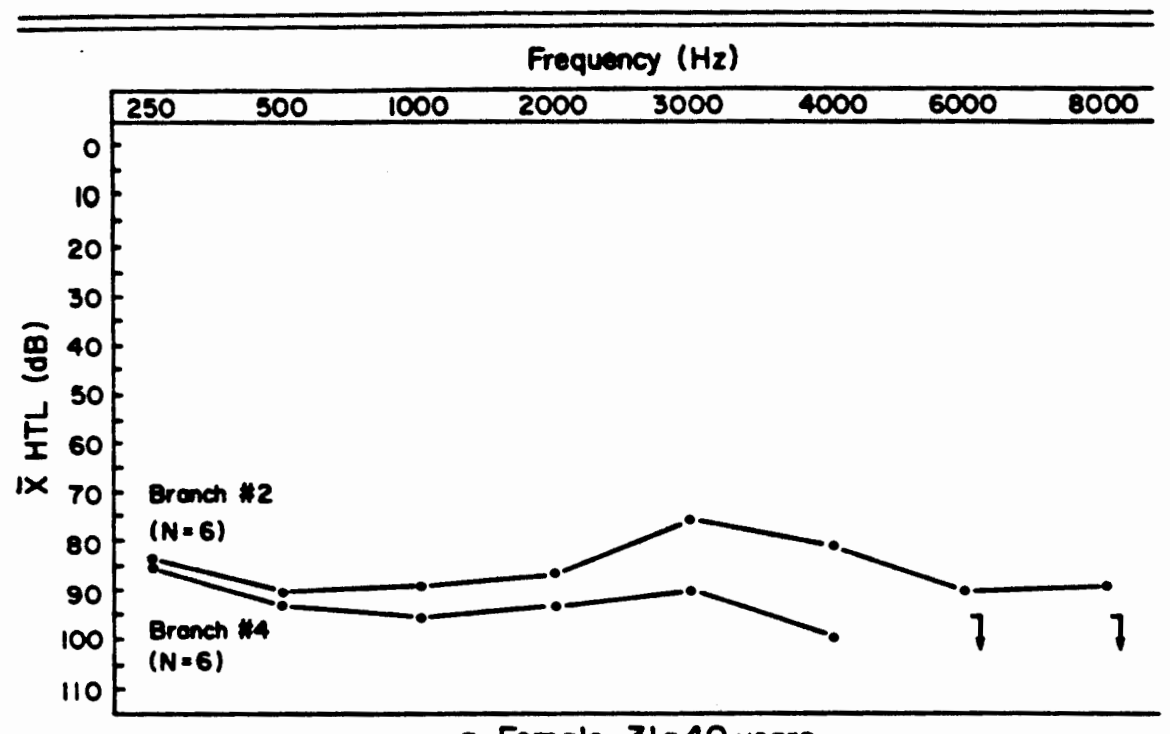

a. Female $31-40$ years

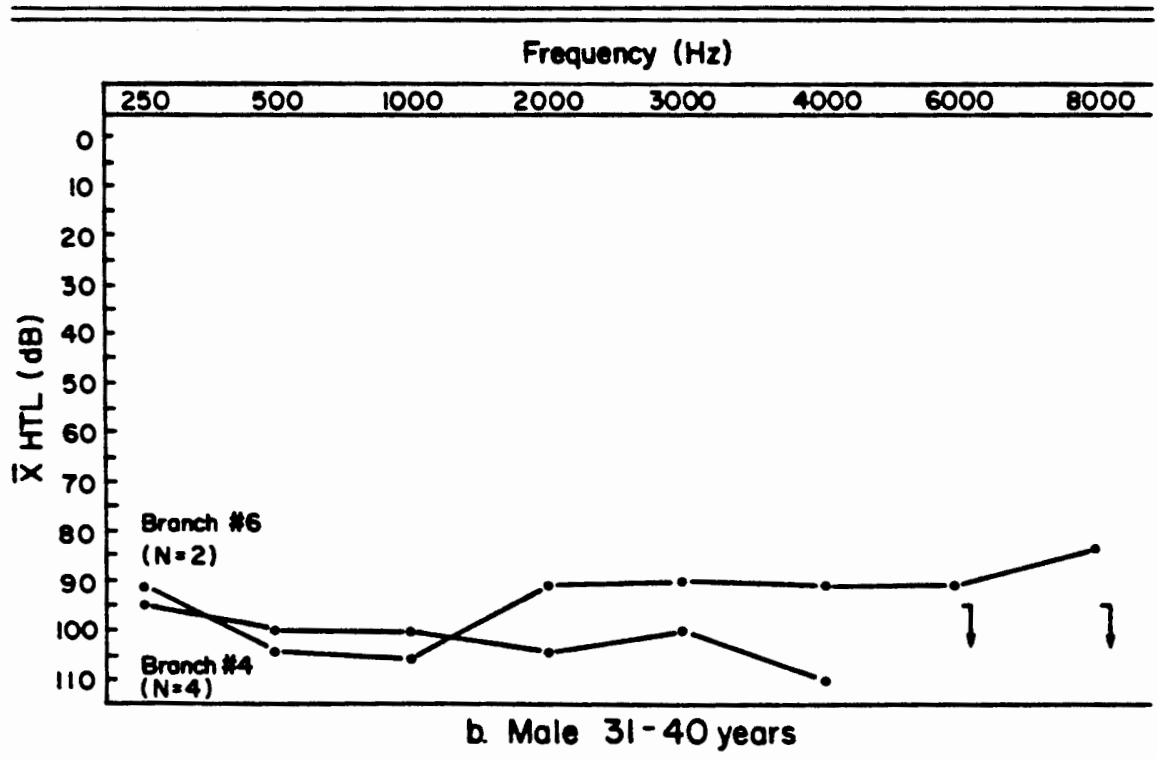

Figure 23. Comparison of puretone air conduction Hearing Threshold Levels in older subjects from different family branches.

APT progressed from severe to profound levels in subjects 31 years and older, speech discrimination ability dropped more rapidly, culminating in an average score of only 10 percent for older family members. 


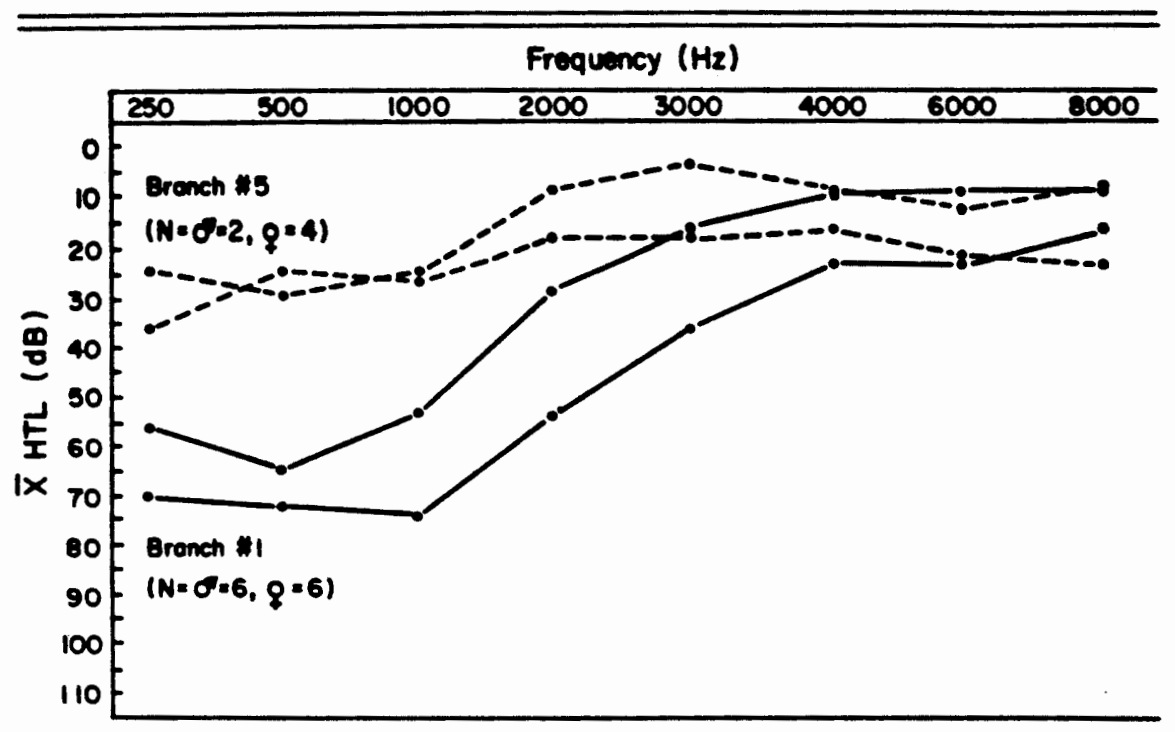

Figure 24. Comparison of puretone air conduction Hearing Threshold Levels in siblings from different family branches.

TABLE XIV

COMPARISON OF MEAN SPEECH DISCRIMINATION SCORE TO THE AVERAGE PURETONE THRESHOLD AS A FUNCTION OF AGE FOR EXPERIMENTAL GROUP

\begin{tabular}{crcr}
$\begin{array}{c}\text { Age } \\
\text { (years) }\end{array}$ & $\begin{array}{c}\text { Sample } \\
\text { (ears) }\end{array}$ & $\begin{array}{c}\text { Speech } \\
\text { Discrimination }\end{array}$ & $\begin{array}{c}\text { Average } \\
\text { Puretone } \\
\text { Threshold }\end{array}$ \\
\hline $0-10$ & 2 & $82 \%$ & $7 \mathrm{dBHL}$ \\
$11-20$ & 10 & 708 & $48 \mathrm{dBHL}$ \\
$21-30$ & 4 & $58 \%$ & $72 \mathrm{dBHL}$ \\
$31+$ & 6 & $10 \%$ & $90 \mathrm{dBHL}$
\end{tabular}

Presented at Most Comfortable Listening Level (MCL), the Ling 5-sound test was administered to 18 ears. The percentage correct for each phoneme, $/ a /, / u /, / i /, / S /$ and $/ s /$, 
was calculated for each chronological age decade with comparisons made between these scores and the mean APT (Table XV). The single child within the 0-10 year age group demonstrated no difficulty in echoically responding to the five sounds. However, within the next age decade, 11-20 years, error responses occurred in four of the five sounds with the most significant depreciation in the / $\mathrm{u} /$ phoneme, where an average performance score of only 78 percent was achieved. Individuals within the third age group, 21-30 years, demonstrated markedly reduced scores on the Ling 5-sound test for the $/ \mathrm{u} /$, /i/ and /s/ phonemes. Finally, within the profoundly deaf age group, 31 years and older, performance scores were extremely poor on the $/ a /$ and $/ u /$ sounds, moderately depressed on the /i/ sound, and remarkably within normal limits on the /S/ and /s/ phonemes.

\section{TABLE XV}

COMPARISON OF AVERAGED PERCENTAGE CORRECT OF LING'S 5-SOUND TEST TO THE MEAN AVERAGE PURETONE

THRESHOLD AS A FUNCTION OF AGE FOR EXPERIMENTAL GROUP

\begin{tabular}{cccccccc}
\hline \hline $\begin{array}{c}\text { Age } \\
\text { (years) }\end{array}$ & $\begin{array}{c}\text { Sample } \\
\text { (ears) }\end{array}$ & $\underline{a}$ & $\underline{u}$ & $\underline{\mathbf{i}}$ & $\underline{\mathbf{S}}$ & $\underline{\mathbf{s}}$ & $\underline{\text { APT }}$ \\
$0-10$ & 1 & 1008 & 1008 & 1008 & 1008 & 1008 & $7 \mathrm{dBHL}$ \\
$11-20$ & 9 & 1008 & 788 & 898 & 968 & 938 & $50 \mathrm{dBHL}$ \\
$21-30$ & 5 & 878 & 738 & 678 & 1008 & 738 & $76 \mathrm{dBHL}$ \\
$31+$ & 3 & 338 & 568 & 678 & 1008 & 1008 & $90 \mathrm{dBHL}$ \\
\hline
\end{tabular}


In addition to puretone air and bone conduction threshold measurements, further delineation for site of lesion was accomplished through a selected differential test battery. Consistent with the puretone air and bone conducted HTL's, tympanometry demonstrated Type A tympanograms, suggesting normal acoustic transmission through the middle ear, and contra-indicating conductive pathology.

The Rosenberg Tone Decay test and acoustic reflex decay measurements revealed no instances of abnormal auditory adaptation or significant reflex decay. These findings contra-indicated retrocochlear involvement.

The acoustic reflex thresholds were measured for both the Control and Experimental Groups. Summarized in Table XVI and XVII, the mean sensation Levels (SL) were derived for each frequency and grouped by decade. As seen in Table XVIII, the mean SL's for the Experimental Group were approximately $11 \mathrm{~dB}$ greater than for the control Group, with most rapid increase occurring in post-adolescence. In the Control Group, no acoustic reflex was observed at less than 60 dBSL above the puretone air conducted threshold for any test frequency. However, in the Experimental Group, 63 percent of all acoustic reflexes were present at less than $60 \mathrm{dBSL}$ above the puretone air conducted threshold, consistent with a reduced difference limen for intensity, a strong indicator for cochlear site of pathology. Unexpectedly, the mean SL's for the acous tic reflexes in the control Group occurred at pathologically elevated thresholds, averaging $98 \mathrm{~dB}$, as compared to Jerger, 
TABLE XVI

COMPARISON OF MEAN ACOUSTIC REFLEX SENSATION LEVELS AND PURETONE AIR CONDUCTION HEARING THRESHOLD LEVELS AS A FUNCTION OF AGE FOR CONTROL GROUP

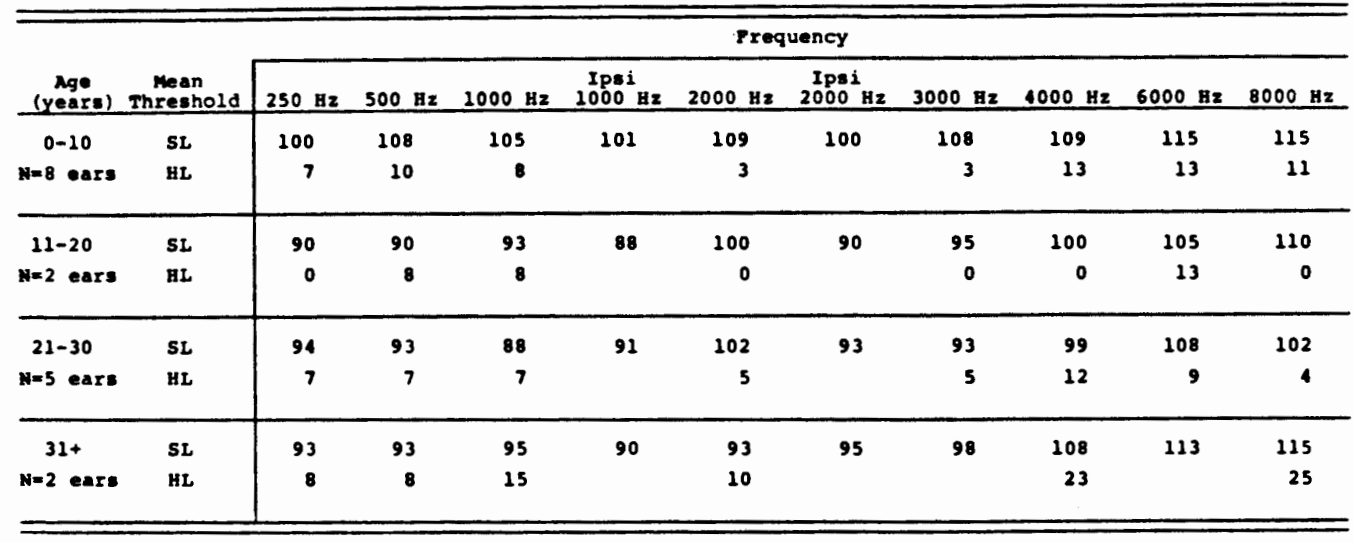

\section{TABLE XVII}

COMPARISON OF MEAN ACOUSTIC REFLEX SENSATION LEVELS AND PURETONE AIR CONDUCTION HEARING THRESHOLD LEVELS AS A FUNCTION OF AGE FOR EXPERIMENTAL GROUP

\begin{tabular}{|c|c|c|c|c|c|c|c|c|c|c|c|}
\hline \multirow[b]{2}{*}{$\begin{array}{c}\text { Age } \\
\text { (years) } \\
\end{array}$} & \multirow[b]{2}{*}{$\begin{array}{l}\text { Mean } \\
\text { Threshold }\end{array}$} & \multicolumn{10}{|c|}{ Frequency } \\
\hline & & $250 \mathrm{~Hz}$ & $500 \mathrm{~Hz}$ & $1000 \mathrm{~Hz}$ & $\begin{array}{c}\text { Ipsi } \\
1000 \mathrm{~Hz}\end{array}$ & $2000 \mathrm{~Hz}$ & $\begin{array}{c}I p s 1 \\
2000 \mathrm{~Hz}\end{array}$ & $3000 \mathrm{~Hz}$ & $1000 \mathrm{~Hz}$ & $6000 \mathrm{~Hz}$ & $8000 \mathrm{~Hz}$ \\
\hline $0-10$ & SL & 105 & 114 & 114 & 103 & 111 & 103 & 114 & 114 & 115 & 115 \\
\hline$N=4$ ear: & HL & 50 & 46 & 35 & & 29 & & 24 & 19 & 20 & 35 \\
\hline $11-20$ & sL & 105 & 112 & 107 & 109 & 114 & 108 & 106 & 112 & 110 & 114 \\
\hline$N=16$ ears & BL & 69 & 63 & 59 & & 37 & & 35 & 33 & 35 & 31 \\
\hline $21-30$ & sL & 205 & 114 & 115 & 112 & 114 & 112 & 113 & 113 & 115 & 115 \\
\hline$N=15$ car: & HI & 77 & 83 & 87 & & 82 & & 82 & 96 & 79 & 77 \\
\hline $31+$ & si & 105 & 114 & 115 & 112 & 115 & 112 & 115 & 115 & 115 & 115 \\
\hline N=8 ear: & HL & 95 & 103 & 106 & & 101 & & 102 & 103 & 94 & 93 \\
\hline
\end{tabular}


TABLE XVIII

COMPARISON OF MEAN ACOUSTIC REFLEX SENSATION LEVELS, AVERAGING ALL FREQUENCIES, AS A FUNCTION OF AGE FOR CONTROL GROUP AND EXPERIMENTAL GROUP

\begin{tabular}{ccc}
\hline $\begin{array}{c}\text { Age } \\
\text { years) }\end{array}$ & $\begin{array}{c}\text { Control } \\
\text { Group }\end{array}$ & $\begin{array}{c}\text { dBSL } \\
\text { Experimental } \\
\text { Group }\end{array}$ \\
\hline $0-10$ & 109 & 111 \\
$11-20$ & 98 & 110 \\
$21-30$ & 97 & 113 \\
$31+$ & 100 & 113 \\
\hline
\end{tabular}

Jerger, and Mauldin's 1972 data showing the average reflex SL's for normal listeners as $85 \mathrm{~dB}$.

\section{Discussion}

Monge deafness is genetically transmitted by a simple Mendelian autosomal dominant mutation with complete penetrance and no associated abnormalities. Through case histories, blood analysis and karyotyping, results obtained during the present investigation by staff personnel from the University of Costa Rica were in agreement with findings previously reported by León et al. (1981) .

The audiological test results obtained from members of the Monge family of Costa Rica indicate a slow, progressive low frequency sensorineural hearing loss. These findings confirm more limited data previously reported by León et al. 
(1981) and Maurer (1981), and, with some notable exceptions, are consistent with similar types of inherited deafness described by other investigators in Chapter II.

The hearing loss exhibited by affected Monge members is bilateral and symmetrical with onset first noted during early childhood after the usual acquisition of speech and language. The actual age at which the hearing impairment becomes evident is not uniform among all affected members. The HTL's in younger subjects vary markedly among different family branches and even between siblings within the same family. This observation is consistent with variable expressivity, characteristic of autosomal dominant transmission.

Across the spectrum of test frequencies, males exhibited somewhat poorer HTL's than females. The difference was not statistically significant, and may be attributed to the wide variation in HTL's observed in both sexes, a variance that was most evident in the younger age groups. This finding tends to contra-indicate a possible difference in vulnerability toward expressivity between sexes.

Variations in the progressive nature of the hearing loss was observed. Both the rate at which progression occurred and the frequency region most affected was dependent upon chronological age. The cochlear involvement progresses slowly, affecting lower frequencies until late adolescence or early adulthood, then accelerates most rapidly in the 21-30 year old group with greater loss of high frequency hair cells. Beyond age thirty the rate of progression slows, with all 
frequencies similarly affected.

Apparently unique to the Monge family is the degree of severity exhibited by affected members and the early age at which these depressed threshold levels are reached. By age thirty, Monge family members demonstrated a profound flat hearing loss. In studies reviewed in Chapter II, no autosomal dominant low frequency sensorineural hearing loss was described which progressed beyond a severe impairment (85 dB APT), nor was there any previous evidence where severity was achieved before age forty.

However, Monge deafness is consistent with other types of inherited low frequency hearing loss in that it is sensorineural in nature with initial involvement localized to the cochlear apex, the area most sensitive to low frequency stimuli. This was demonstrated in subjects below the age of twenty whose test data revealed depressed HTL's at $250 \mathrm{~Hz}$ and $500 \mathrm{~Hz}$ but projected near normal hearing sensitivities for higher frequencies.

Cochlear degeneration, from apex to base, was further demonstrated by the affected subjects' reversed responses to Ling's 5-sound test. Consistent with Berlin (1981), individuals with a significant low frequency hearing loss but relatively normal thresholds for higher frequencies generally demonstrate greater difficulty identifying the vowel phonemes $/ a /, / u /$ and /i/ when compared to recognition of /S/ and /s/.

As discussed in Chapter II, reversed responses would be expected for subjects who sustain a hearing deficit as that 
described above. However, the phonemes $/ S /$ and $/ s /$ were most frequently identified within all age groups, apparently irrespective of HTL's. In agreement with Giolas (1982), even subjects who demonstrate severe to profound flat audiometric configurations continue to recognize the $/ S /$ and /s/ with great accuracy, despite the absence of visual cues.

A possible explanation as to why these two voiceless sounds continue to be readily identified while vowels are not, among such hearing loss cases, may be associated with the different frequency spectra produced by the two different classes of phonemes. As reported by Sanders (1971), vowels require the first and second formants for accurate identification, but consonants necessitate recognition of higher frequency harmonics. Both the $/ S /$ and $/ s /$ sounds are relatively broadband in frequency response with poorly defined formant regions. However, since Ling's 5-sound test was administered at a suprathreshold level, subjects with severe or profound HTL's were provided with sufficient intensity to enable fragmented feature detection of consonants, but not for vowel phonemes. The reason for this is that as stimulus intensity is increased, additional phonemic information is gained by an increase in the number of harmonics located in the higher frequency region. Vowels would require a greater intensity spread in order to achieve detection by profoundly deaf subjects than consonants, whose broadband spectra that reach into the higher frequencies require less energy to gain additional phonemic information. 
In view of the progression rate for Monge deafness, learning factors may also play a role in subjects greater accuracy for identifying the $/ S /$ and /s/ sounds. Since low frequency HTL's deteriorate before high frequency thresholds, a child acquiring speech and language receives less acoustic information for a shorter period of time in establishing criteria for feature detection of vowels than for consonants. As the hearing loss progresses in severity, the individual must rely on increasingly less information to differentiate phonemes. Therefore, those sounds with a better established learning foundation for detection will be more readily identified.

Results obtained during acoustic reflex testing yielded an unexpected finding from the control Group. These subjects demonstrated averaged reflex Sensation Levels (SL) of $98 \mathrm{~dB}$, slightly above the $85 \mathrm{~dB}$ average reported for normal listeners by Jerger, Jerger, and Mauldin (1972). As previously described in Chapter II, both Anderson and Wedenberg (1968) and Barr (1973) reported a high incidence of elevated acoustic reflex SL's in normal hearing carrier parents, but these authors did not address the presence of such findings in normal hearing family members who supposedly did not carry genetic mutations. It may be speculated that the elevated reflexes observed in the Control Group of the present investigation were due to a subtle manifestation of the genetic mutation in question; however, further research is required before any definitive statement can be made with confidence. 


\section{CHAPTER V}

\section{SUMMARY AND IMPLICATIONS}

The purpose of this investigation was to determine specific audiological characteristics associated with hereditary deafness as demonstrated by Monge family members of Costa Rica. A review of the literature failed to reveal any type of genetic deafness identical to the one in question. Results were obtained through an audiological test battery administered to 25 affected and 12 unaffected Monge family members. Previously collected data for an additional 27 affected members were included in the present study.

As a result of the data gathered in this investigation and that collected by previous investigators, as well as concurrent genetic information obtained by staff personnel from the University of Costa Rica, it was concluded that:

(1) Monge deafness is genetically transmitted by a simple Mendelian autosomal dominant mutation with complete penetrance and no associated abnormalities.

(2) The initial site of lesion appears to be the apical portion of the cochlea.

(3) Significant onset occurs during early childhood following normal speech and language acquisition.

(4) The rate at which the hearing loss progresses 
and the frequency regions affected are contingent upon the subject's chronological age.

(a) Younger members of the Monge family demonstrate predominantly low frequency sensorineural hearing losses that progress slowly through adolescence.

(b) Subjects 20 to 30 years old experience a rapid deterioration of hearing sensitivity, ultimately progressing from a moderate low frequency impairment to profound deafness.

(c) Monge members beyond age 30, demonstrate little significant difference in audiometric characteristics, regardless of age.

(5) The age of onset and progression rate through the first two decades varies with the affected member's family branch.

(6) The hearing loss exhibited by affected Monge members is bilateral and symmetrical, with no significant difference between males and females or between right and left ears.

(7) Speech discrimination testing yielded normal results during the first decade of life with performance scores rapidly deteriorating to $0 \%$ among aging, profoundly deaf members.

(8) Irrespective of age and the extent of the hearing loss, Monge members identified voiceless consoants with greater accuracy than vowels. 
(9) Averaged acoustic reflex thresholds for the Control Group were elicited at generally elevated Sensation Levels (SL).

\section{Recommendations for Future Research}

\section{Identification Measures}

(1) A larger data sample could provide more definitive information regarding the audiological characteristics observed among different family branches and as a function of age.

(2) By expanding the sample of Monge members below the age of 10 years, a more definitive determination of age of onset may be accomplished.

(3) A longitudinal study of the audiological characteristics for those subjects who yet remain unidentified as either affected or unaffected may assist in earlier prediction of the problem in future newborns.

(4) A larger data sample could provide a more definitive answer as to whether acoustic reflex thresholds in unaffected Monge members are significantly elevated when compared to normal hearing non-family members.

(5) To further delineate site of lesion, vestibular function could be assessed through electronystagmography testing.

(6) Histopathological examination of temporal bone 
samples could contribute additional information to site of lesion and degenerative processes.

\section{Rehabilitation Measures}

(1) The development of a genetic counseling program made available to Monge family members could contribute to their better understanding of the potential impairment.

(2) The development and implementation of a rehabilitive program including assessment and remediation for speech and language, amplification, and speechreading may help to maximize Monge members' communicative skills.

(3) Academic and vocational environments could be modified in order to minimize communication difficulties experienced by affected members. 
REFERENCES

AMERICAN NATIONAL STANDARDS INSTITUTE. Specification for audiometers. S3.6-1969. New York: American National Standards Institute, 1970.

ANDERSON, H., \& WEDENBERG, E. Audiometric identification of normal hearing carriers of genes for deafness. Acta Oto-Laryngologica (Stockholm), 1968, 65, 535-554.

BARR, B. Aspects of the aetiology of deafness. In W. Taylor (Ed.), Disorders of Auditory Function. London: Academic press, 1973, 17-29.

BERGSTROM L. Congenital deafness. In J.L. Northern (Ed.), Hearing Disorders. Boston: Little, Brown and Company, 1976, 17I-177.

BERGSTROM, L. Medical problems and their management. In R.J. Raeser \& M.P. Downs (Eds.), Auditory Disorders in School Children. New York: Thieme-Stratton, Inc., 1981, 102-119.

BERLIN, C. Personal correspondence. July 11, 1981.

BROWN, $K$. The genetics of childhood deafness. In F. McConnell \& P. Ward (Eds.), Deafness in Childhood. Nashville, TN: Vanderbilt University Press, 1967, 177-202.

BRUNING, J. \& KINTZ, B.L. Computational Handbook of Statistics. Glenview, IL: Scott, Foresman and Company, 1968.

CARHART, R., \& JERGER, J. Preferred method for clinical determination of pure tone thresholds. Journal of Speech and Hearing Disorders, 1959, 24, 330-34.

COHN, A. Etiology and pathology of disorders affecting hearing. In F. Martin (Ed.), Medical Audiology. Englewood Cliffs, NJ: Prentice-Hal1, Inc., 1981, 123-144.

COTTON, R. Progressive hearing 1oss. In B. Jaffe (Ed.), Hearing Loss in Children. Baltimore: University Park Press, 1977, 482-489.

EVERBERG, G. Further studies on hereditary unilateral deafness. Acta Oto-Laryngologica (Stockholm), 1960, 51, 615-635. 
EVERBERG, G. \& JENSEN, J. Labyrinthine malformations: genetical and radiological aspects. Acta Oto-Laryngologica, $1976,82,238-241$.

FARRAR, D.A. Dominant hereditary nerve deafness. Journal of Laryngology and Otology, 1978, 92, 243-246.

FRASER, G.R. Review article: profound childhood deafness. Journal of Medical Genetics, 1964, 1, 118-151.

FRASER, G.R. The causes of profound deafness in childhood. In G. Wolstenholme and J. Knight (Eds.), Sensorineural Hearing Loss. London: J. \& A. Churchill, 1970, 5-40.

GACEK, R. The pathology of hereditary sensorineural hearing 10ss. Annals of Otology, Rhinology and Laryngology, $1971,80,289-298$.

GIOLAS, T. Hearing - Handicapped Adults. In F. Martin (Ed.), Remediation of Communication Disorders Series. Englewood Cliffs, NJ: Prentice-Hall, Inc., 1982.

GRAVENDEEL, D., PLOMP, R. \& ENG, M. Perceptive bass deafness. Acta Oto-Laryngologica, 1960, 51, 548-560.

HARRIS, J. Research frontiers in audiology. In J. Jerger (Ed.), Modern Developments in Audiology. New York: Academic Press, 1963, 409-432.

HEREDITARY DEAFNESS PUBLIC SERVICE PROGRAMS. What Every Person Should Know About Hereditary and Deafness. Washington, DC: Gallaudet College, 1975 .

HOLMES, L. Medical genetics. In B. Jaffe (Ed.), Hearing Loss in Children. Baltimore: University Park Press, 1977, 253-265.

HULL, C.H. \& NIE, N. SPSS Update: New Procedures and Facilities for Releases 7,8 and 9 . New York: McGraw-Hill, 1981 .

ILINUMA, T., SHITARA, T., HOSHINO, T. \& KIRIKAE, I. Sensorineural hearing loss for low tones. Archives of Otolaryngology, $1967,86,110-116$.

JERGER, J., JERGER, S. \& MAULDIN, L. Studies in impedance audiometry: normal and sensorineural ears. Archives of Otolaryngology, 1972, 96, 513-523.

JERGER, S., JERGER, J., MAULDIN, L. \& SEGAL, P. Studies in impedance audiometry: children less than six years old. Archives of Otolaryngology, 1974, 99, 1-9. 
JONES, P.A. Causative factors and prevention of childhood deafness. Volta Review, 1976, 78, 268-275.

KINNEY, C., Pathology of hereditary deafness. Annals of otology, Rhinology and Laryngology, $1950, \overline{59,1117}-1122$.

KIRIKAE, I., SHITARA, T. \& SATO, T. Classification and differential diagnosis of deafness. International Audiology, $1966,5,71-73$.

KONIGSMARK, B.W. Hereditary deafness in man. New England Journal of Medicine, 1969, 281, 713-720.

KONIGSMARK, B.W. Hereditary congenital severe deafness syndromes. Annals of Otology, Rhinology and Laryngology, $1971,80,269-288$.

KONIGSMARK, B.W. Genetic hearing loss with no associated abnormalities: a review. Journal of Speech and Hearing Disorders, $1972,37,89-99$.

KONIGSMARK, B.W., MENGEL, M. \& BERLIN, C.I. Familial low frequency hearing 1oss. Laryngoscope, 1971, 81, 759771 .

LEÓN, P.E. Lecture. Portland State University, Portland, Oregon, March 10, 1981.

LEÓN, P.E. Personal correspondence. May 27, 1982.

LEÓN, P.E. BONILLA, J.A., SANCHEZ, J.R., VANEGAS, R., VILLALOBOS, M., TORRES, L., LEOON, F., HOWELL, A.L. \& RODRIGUES, J.A. Low frequency hereditary deafness in man with childhood onset. American Journal of Human Genetics, 1981, 33, 209-214.

LIM, D. Histology of the developing inner ear: normal anatomy and developmental anomalies. In B. Jaffe (Ed.), Hearing Loss in Children. Baltimore: University Park Press, 1977, 27-50.

IINDEMAN, R. Congenital sensorineural deafness. In A. Graham (Ed.), Sensorineural Hearing Processes and Disorders. Boston: Little, Brown and Company, 1967, 451-463.

LINDSAY, J. Profound childhood deafness: inner ear pathology. Annals of Otology, Rhinology and Laryngology, supp. 5, 1973, 82, 7-121.

LING, D. Auditory coding and recording: an analysis of auditory training procedures for hearing-impaired children. In M. Ross and T. Giolas (Eds.), Auditory Management of Hearing-Impaired Children. Baltimore: University Park Press, 1978, 181-218. 
LUNDBORG, T. Nerve deafness for low tones. Acta Oto-Laryngologica, 1955, 45, 215-225.

MAKISHIMA, K. \& SNOW, J. Pathologic features of the inner ear in congenital deafness. Archives of Otolaryngology, 1975, 101, 600-604.

MAURER, J.F. Interview. Portland State University, Portland, Oregon, July 16, 1981.

NANCE, $W$. The principles and practice of genetic counseling. Annals of Otology, Rhinology and Laryngology, 1971, 80, $246-254$.

NIE, N., HULL, C.H., JENKINS, J.G., STEINBRENNER, K. \& BENT, D. Statistical Package for the Social Sciences. New York: McGraw-Hill, 1975 .

NOBER, E.H. Pseudoauditory bone-conduction thresholds. Journal of Speech and Hearing Disorders, 1964, 29, 469-476.

NORTHERN, J.L. \& DOWNS, M.P. Hearing in Children. Baltimore: The Williams \& Wilkins Company, 1978 .

OSTERHAMMEL, D. \& OSTERHAMMEL, P. Age and sex variations for the normal stapedial reflex thresholds and tympanometric compliance values. Scandinavian Audiology, 1979, 8, $459-472$.

PAPARELLA, M. , HANSON, D., RAO, K. \& ULVESTAD, R. Genetic sensorineural deafness in adults. Annals of Otology, Rhinology and Laryngology, 1975, 84, 459-472.

PARVING, A. Low frequency sensorineural hearing loss: diagnostic problems and new aspects. Hearing Aid Journal, 1981, sept., 11-26.

PARVING, A. \& BAK-PEDERSEN, K. Clinical findings and diagnostic problems in sensorineural low frequency hearing loss. Acta Oto-Laryngologica, 1978, 85, 184-190.

PARVING, A., JOHNSEN, N.J. \& HOLM-JENSEN, S. Dominantly inherited low-frequency hearing loss. Audiology, 1978, $17,165-172$.

PROCTOR, C. \& PROCTOR, B. Understanding hereditary nerve deafness. Archives of Otolaryngology, 1967, 85, 45-62.

REPORT OF THE CONFERENCE COMMITTEE ON NOMENCLATURE. American Annals of the Deaf, $1938,83,1-3$. 
RICCARDI, V.M. A geneticist's approach to deafness. Volta Review, 1979, 8, 9-14.

ROSENBERG, P.E. Rapid clinical measurement of tone decay. Paper presented at the American Speech and Hearing Association convention, New York, November, 1958.

RUBEN, R. \& ROZYCKI, D. Clinical aspects of genetic deafness. Annals of Otology, Rhinology and Laryngology, $1971,8 \overline{0,255-263 .}$

SANDERS, D.A. Aural Rehabilitation. Englewood Cliffs, NJ: Prentice-Hall, Inc., 1971.

SANK, D. Genetic aspects of early total deafness. In J. Rainer, K. Altshuler and F. Kallmann (Eds.), Family and Mental Health Problems in a Deaf Population. Springfield, IL: Charles C. Thomas, 1969, 28-81.

SCHUKNECHT, H.F. Pathology of sensorineural deafness of genetic origin. In F. McConnell and P.H. Ward (Eds.), Deafness in Childhood. Nashville, TN: Vanderbilt University Press, 1967, 69-90.

SCHUKNECHT, H.F. \& KIRCHNER, J. Cochlear otosclerosis: fact or fantasy? Laryngoscope, 1974, 84, 766-782.

SILVERMAN, F. Research Design in Speech Pathology and Audiology. Englewood Cliffs, NJ: Prentice-Hall, Inc., 1977 .

SUGA, F., NAUNTON, R.F., MAITLAND, S.K. \& HEDBERG, K.E. Hereditary progressive sensorineural deafness. Journal of Laryngology and Otology, 1976, 90, 667-685.

TAYLOR, I.G., BRASIER, V.J., HINE, W.D., MORRIS, T. \& POWELL, C.I. Some aspects of the audiology of familial hearing loss. In W. Taylor (Ed.), Disorders of Auditory Function. London: Academic Press, 1973, 71-83.

TAYLOR, I.G., HINE, W.D., BRASIER, V.J., CHIVERALLS, K. \& MORRIS, T. A study of the causes of hearing loss in a population of deaf children with special reference to genetic factors. Journal of Laryngology and Otology, $1975,89,899-914$.

TEIG, E. Hereditary progressive perceptive deafness in a family of 72 patients. Acta Oto-Laryngologica, 1968, $65,365-372$.

THORNTON, A.R. \& ABBAS, P.J. LOw frequency hearing loss: perception of filtered speech, psychophysical tuning curves and masking. Journal of the Acoustic Society of America, $1980,67,63 \overline{8-643}$. 
VANDERBILT UNIVERSITY HEREDITARY DEAFNESS STUDY GROUP (ALLEN, J., HONRUBIA, V., MCCONNELL, F., MCLEOUD, A., NANCE, W., PUNCH, J., STREAM, R., SWEENEY, A., WARD, P., WEBB, W. \& WOLCOTT, S., Dominantly inherited low frequency hearing loss. Archives of Otolaryngology, 1968, 88, $242-250$.

WHETNALL, E. \& FRY, D. The Deaf Child. London: William Heinemann Medical Books Limited, 1964.

WILBER, L. Acoustic reflex measurement: procedures, interpretations and variables. In A. Feldman and L. Wilber (Eds.), Acoustic Impedance and Admittance: The Measurement of Middle Ear Function. Baltimore: The Williams \& Wilkins Company, 1976, 197-216.

WRIGHT, M. The Pathology of Deafness. Manchester, England: Manchester University Press, 1971. 


\section{APPENDIX A}

THE MAXIMUM INTENSITY LEVELS GENERATED AT EACH FREQUENCY FOR THE MAICO, MODEL MA-22 AND MODEL MA-16 FOR BOTH PURETONE AIR AND BONE CONDUCTION

\begin{tabular}{|c|c|c|c|c|c|c|c|c|c|}
\hline \multirow[b]{2}{*}{ dBHL } & \multicolumn{9}{|c|}{ Frequency } \\
\hline & $250 \mathrm{~Hz}$ & $500 \mathrm{~Hz}$ & $1000 \mathrm{~Hz}$ & $2000 \mathrm{~Hz}$ & $3000 \mathrm{~Hz}$ & $1000 \mathrm{H}$ & $00 \mathrm{H}$ & 000 & $\mathrm{~Hz}$ \\
\hline $\begin{array}{l}\text { Air } \\
\text { Conduction }\end{array}$ & 90 & 110 & 110 & 110 & 110 & 110 & 90 & 9 & 0 \\
\hline $\begin{array}{l}\text { Bone } \\
\text { Conduction }\end{array}$ & 45 & 70 & 70 & 70 & 70 & 70 & & & \\
\hline
\end{tabular}

APPENDIX B

t-TEST EQUATION FOR TWO INDEPENDENT MEANS IN ACCORDANCE WITH BRUNING AND KINTZ, 1968

$$
\underline{t}=\frac{\bar{x}_{1}-\bar{x}_{2}}{\sqrt{\frac{\sum x_{1}^{2}-\frac{\left(\sum x_{1}\right)^{2}}{N_{1}}+\sum x_{2}^{2}-\frac{\left(\sum x_{2}\right)^{2}}{N_{2}}}{\left(N_{1}+N_{2}\right)-2}\left(\frac{1}{N_{1}}+\frac{1}{N_{2}}\right)}}
$$

